NBSIR 85-3034

\title{
FRACTURE MECHANICS
}

CHARACTERIZATION OF CRACK

ARREST AND REINITIATION INTWO

UNCONVENTIONAL SPECIMENS

T. Teramoto

D.T. Read

R.B. King

FILE COPY

DO NOT REMOVE

National Bureau of Standards

U.S. Department of Commerce

Boulder, Colorado 80303

June 1986 


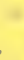




\title{
FRACTURE MECHANICS
}

\section{CHARACTERIZATION OF CRACK ARREST AND REINITIATION IN TWO UNCONVENTIONAL SPECIMENS}

\author{
T. Teramoto† \\ D.T. Read \\ R.B. King ††
}

Fracture and Deformation Division

Institute for Materials Science and Engineering

National Bureau of Standards

Boulder, Colorado 80303

June 1986

Sponsored by

Office of Naval Research

Arlington, Virginia 22217

and

David Taylor Naval Ship Research and Development Center

Annapolis, Maryland 21402

†Present address: Institute of Engineering Mechanics, University of Tsukuba, Sakura, Ibaraki 305, Japan ††Present address: IBM Research Division, San Jose, CA 95193

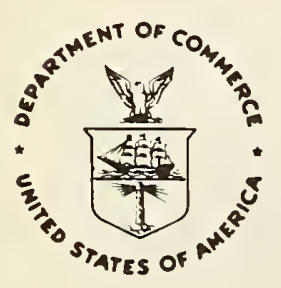

U.S. DEPARTMENT OF COMMERCE, Malcolm Baldrige, Secretary 

I. FRACTURE MECHANICS PARAMETERS IN CRACK ARREST SPECIMENS

1. Introduction $\ldots \ldots \ldots \ldots \ldots \ldots \ldots \ldots \ldots \ldots \ldots \ldots \ldots \ldots \ldots$

1.1 Purpose of Crack Arrest Testing.................. 1

1.2 Need to Understand Dynamics of the Boundary............ 3

1.3 Need for a Method for Calculation of the

Fracture Mechanics Parameter.................... 4

2. Previous Fracture Mechanics Analyses of Crack Arrest........ 5

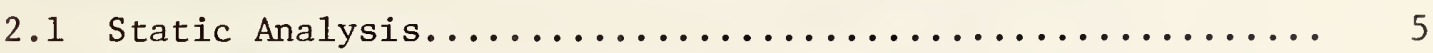

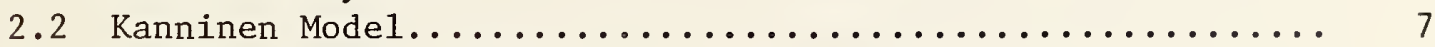

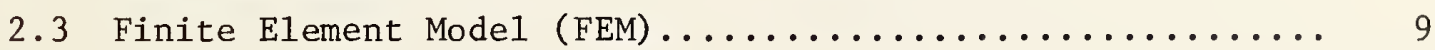

3. Mass-Spring Model of Crack Arrest Specimen.............. 10

3.1 A Crack Arrest System Under Fixed-Grip Conditions........ 12

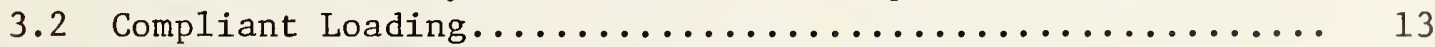

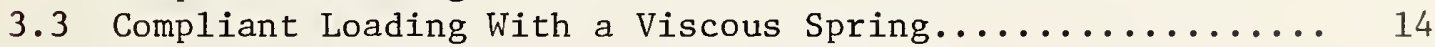

3.4 Compliant Loading of a Yielding Specimen............. 15

4. Extraction of the Fracture Mechanics Parameter............ 17

4.1 Stress Intensity Factor $\mathrm{K}$ From the MS Model........... 17

4.2 Stress Intensity Factor K From the Kanninen DCB Model..... 18

4.3 Stress Intensity Factor $\mathrm{K}$ From the FEM Mode1............ 19

4.4 Elastic-P1astic Crack-Driving Force J From the MS Mode1... 19

5. Comparison of the Models........................ 21

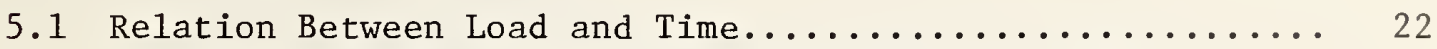

5.2 Relation Between Load-Point Displacement and Time....... 23

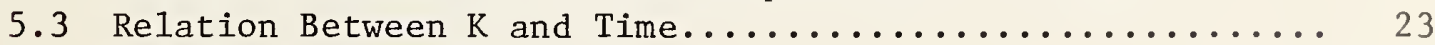

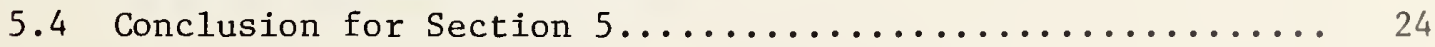

6. Comparison of the MS Mode1 With Experimental Data......... 24

6.1 Relation Between Load, Load-Point Displacement, and Time... 24

6.2 Relation Between $\mathrm{J}$ and Time..................... 26

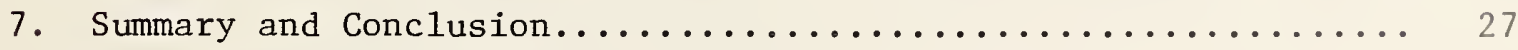

7.1 Validity of the MS Model for General Features of

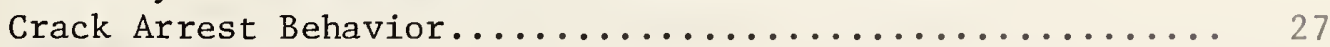

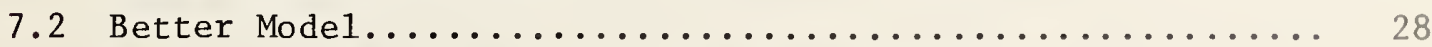

7.3 Method of Comparison With Experimental Data........... 29

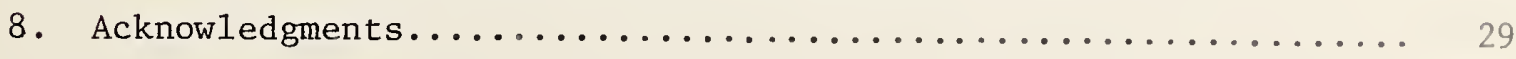

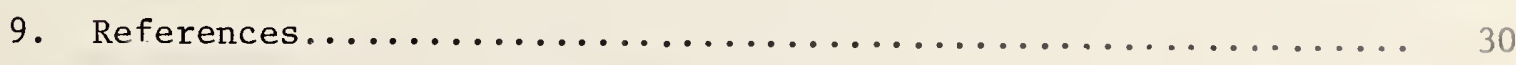

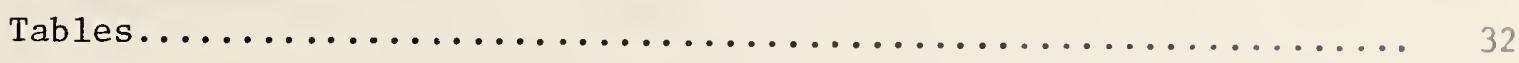

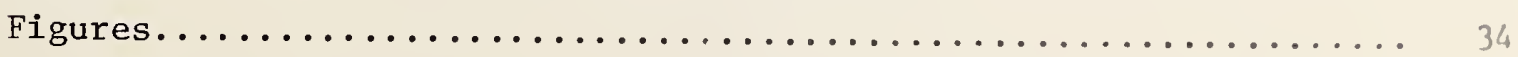


II. CRACK ARREST EXPERIMENTS AND ANALYSIS WITH RISING K FIELD

1. Introduction................................... 65

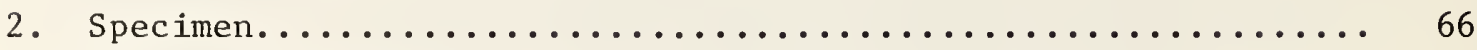

3. Analytical Methods........................... 67

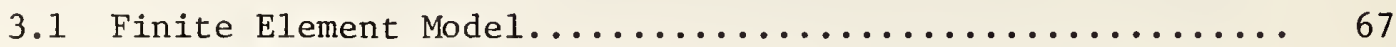

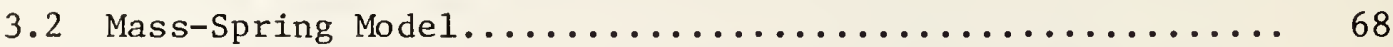

4. Material and Techniques.......................... 70

5. $\operatorname{Results\ldots \ldots \ldots \ldots \ldots \ldots \ldots \ldots \ldots \ldots \ldots \ldots \ldots \ldots \ldots \ldots \ldots \ldots \ldots \ldots } 71$

6. Discussion........................................ 74

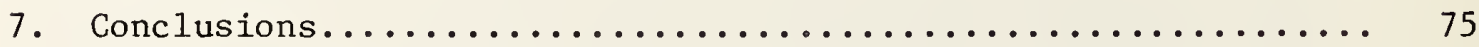

8. Acknowledgments............................ 76

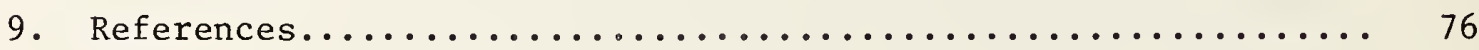

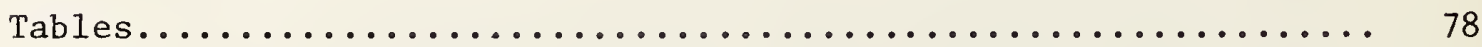

Figures.......................................... 81 


\section{FRACTURE MECHANICS PARAMETERS IN CRACK ARREST SPECIMENS}

T. Teramoto, D.T. Read, and R.B. King

Fracture and Deformation Division

National Bureau of Standards

Boulder, Colorado 80303

A simple elastic-plastic-fracture-mechanics-based model of crack propagation, arrest, re-initiation, and propagation is described. This model requires much less computing resources than dynamic, elastic-plastic finite element calculations, and allows estimates of applied J-integral, load, and crack mouth opening displacement during initial rapid crack propagation, re-initiation and repropagation. A comparison of this new model to other available models and to experimental results indicates that it can successfully reproduce the essential features of the behavior of specimens containing propagating cracks.

Key words: crack arrest; dynamic fracture; stress intensity factor; J-integral; mass-spring; double-cantilever-beam model; finite element model.

\section{Introduction}

\section{1 Purpose of Crack Arrest Testing}

Failure of large welded steel structures, such as ships, can occur if a crack, once initiated, severs large sections of the structure. Such failures have actually occurred. To prevent such failures, crack arrester plates are often included in ships. Such plates are required to have sufficient toughness that running cracks that enter them will be unable to propagate, and will thus be prevented from fatally damaging the ship.

Fracture mechanics principles can be applied to the selection of materials for structural crack arrester plates if the crack arrest toughness of candidate materials and the driving force for dynamic crack propagation can be compared. Exact determination of these parameters requires dynamic fracture mechanics 
analyses of both crack arrest test specimens and crack arrester plates in structures. Such analyses are unavailable at present. Crack arrest and reinitiation are elastic-plastic phenomena, and reinitiation can involve ductile tearing as well as plastic deformation near the crack tip. Clearly, exact analyses of the crack arrest-reinitiation event will be unavailable for some time. However, analysis using simplified models has provided significant progress to date, notably linear elastic calculations of dynamic stress intensity factors. At present, 'no dynamic elastic-plastic calculations, however simplified, are avai1able.

Tests of the crack arrest toughness of steels have been designed using available understanding of the crack arrest process. Many large scale crack propagation-arrest tests of brittle materials have been conducted, especially the test described, for example, by Feely et al. [1] (Esso test) in the United States and double-tension tests [2] in Japan. The fundamental concept used for analysis of these tests was that a static fracture mechanics approach could be applied, even though the crack propagation involved complicated dynamic effects. This simple approach is strictly correct as long as reflected stress waves from specimen boundaries do not affect the running crack tip [3]. However, longer running cracks are apt to be affected by the boundary conditions.

Battelle Memorial Institute developed a small specimen crack arrest test, the Double Cantilever Beam (DCB) specimen, and performed a complete dynamic elastic analysis using a simple beam model several years ago [4]. It was concluded that dynamic fracture toughness is a function of the crack velocity and that minimum fracture toughness should be used in structural design. That work shed some light on dynamic fracture mechanics analysis, although new problems were discovered. 


\subsection{Need to Understand Dynamics of the Boundary}

Recent experimental studies have indicated that for structural safety the preceeding arrest concept is not necessarily sufficient because the arrested crack may be reinitiated in the arrester when load is applied to the uncracked ligament remaining after initial, momentary arrest. The stress redistribution or reloading cannot take place until the running crack tip encounters the crack arrester, because crack velocity is, in general, very high (500-1500 m/s). The whole massive structure deforms gradually, because of inertia, reloading the ligament and applying a large crack-driving force. If this crack-driving force exceeds the reinitiation toughness, the structure can be further damaged by additional, possibly unstable, crack extension.

Previous analyses have not considered this reinitiation phase, because conventional testing procedures do not maintain the initially applied load both during crack propagation and after initial crack arrest. Therefore, the specimen has been regarded as being under fixed-grip conditions before crack arrest, because of inertia.

King et a1. [5] have developed a crack arrest-reinitiation test. Their specimen configuration is similar to the DCB specimen developed at Battelle. But their specimen consists mostly of ductile material, with a brittle crack propagation path produced by electron-beam welding. This relatively brittle weld in a ductile base plate simulates a low-toughness plate adjacent to a crack arrester in a structure. The load is applied through a number of disk springs, to prevent load drop resulting from the large compliance change during crack extension. This spring displaces the specimen grip, producing a large load on the uncracked ligament; thus, reinitiation of an arrested crack can easily take place. 
1.3 Need for a Method for Calculation of the Fracture Mechanics Parameter

The complete fracture event in steel, which consists of crack initiation, propagation, arrest and reinitiation, has both macroscopic and microscopic aspects. It is impossible with the use of any model to analyze such complicated behavior completely. However, it is possible to study fracture characteristics to an extent, using simple models that extract key features of the fracture behavior. The crack arrest-reinitiation behavior is largely divided into two phases. Linear Elastic Fracture Mechanics (LEFM) analysis is applicable before crack arrest because the yield point of the material is elevated by the high strain rate at the fast-running crack tip; post-test examination of this part of the fracture surface usually suggests a macroscopically brittle failure mode. On the other hand, Elastic-Plastic Fracture Mechanics (EPFM) analysis is applicable after crack arrest because the uncracked ligament can yield. The dynamic stress intensity $K_{D}$, calculated by LEFM, is pertinent as a fracture mechanics parameter before arrest. Dynamic crack propagation in a finite body has been analyzed in terms of $K_{D}$ using the Finite Element Method (FEM) [6], Finite Difference Method (FDM) [7], and so on.

These are, in fact, calculations of the behavior of models of fracture mechanics specimens. The models are fairly elaborate, but they are linearelastic and two-dimensional.

The linear-elastic fracture mechanics parameter $K_{D}$ is not appropriate for characterization of dynamic elastic-plastic crack tip behavior after crack arrest. Because parameters such as the J-integral, Crack Opening Displacement (COD) or Crack Opening Angle (COA) are found to be useful even for unstable fractures with large plastic deformation under quasistatic loading, these parameters are considered to be promising for the dynamic case, because the strain near the crack tip after arrest, in general, changes much more slowly than during crack propagation. These parameters could be calculated using 
dynamic elastic-plastic finite element analyses of two-dimensional models, which are currently under development. The computing resources required for such analyses are significant; furthermore, given such an analysis, one would like a way to check it. Simplified models, requiring only small computing resources, offer insight into the crack arrest-reinitiation process and a means of checking more exact models.

This study proposes a simple model involving masses and springs (MS mode1) to analyze crack arrest-reinitiation tests. Both elastic and elastic-plastic dynamic behavior are treated. The MS model was verified by comparing the time dependencies of loads, load point displacements and elastic stress intensity factors calculated using the MS model with those calculated using the Kanninen double-cantilever-beam model and a finite element model. The values obtained are approximately the same for all models; this agreement provides encouragement to pursue the MS model further. Elastic-plastic behavior after crack arrest was modeled for two specimens of the one type and dynamic J-integral values were calculated.

In this paper, dynamic $J$, the elastic-plastic crack driving force, will be obtained as the fracture mechanics parameter during the crack arrest test; we will discuss how the J-integral is calculated in several models and what the J-integral obtained means.

2. Previous Fracture Mechanics Analyses of Crack Arrest

\subsection{Static Analysis}

Dynamic crack arrest has commonly been regarded as quasistatic in conventional dynamic fracture experiments, although Kanninen [8] has proposed an analytical solution in which a crack runs at constant velocity in infinite material with small-scale yielding. To date, crack arrest phenomena can be 
treated only by static analysis. Crack arrest toughness, $K_{a}$, a stress intensity, has often been obtained by the Esso test or double-tension test with a temperature gradient. In these test specimens, the running crack is arrested when the toughness at the crack tip exceeds the crack-driving force. It was concluded that static analysis could be used to estimate crack arrest toughness because dynamic effects on the crack tip were rather small just before crack arrest. Crosley et a1. [9] also insist on the validity of static analysis for crack arrest tests using the tapered DCB specimen. But other experimental investigations using very wide specimens have revealed that the simple approach based on the arrest toughness concept is invalid for the case of long arrested cracks [10].

Freund [3] analyzed a running crack in a semi-infinite body and found a simple relation between dynamic stress intensity $K_{D}$ and static stress intensity $K_{S}$ as follows:

$$
K_{D}=\left(1-\dot{a} / C_{R}\right)^{\frac{1}{2}} K_{S}
$$

where $C_{R}$ is Rayleigh wave velocity and $\dot{a}$ is crack velocity. On the basis of Freund's concept, $K_{D}$ equals $K_{S}$ at crack arrest $(\dot{a}=0)$. If the crack runs a short distance compared with specimen size and is arrested before the reflected stress wave significantly affects the running crack tip, the effect of dynamic aspects, such as kinetic energy, stress wave propagation and so on may be neglected. Kanazawa et a1. [11] carried out a series of dynamic fracture experiments using a double-tension test with varied distance between two loading points, where significant wave interaction occurred. Static analysis was found to become insufficient as the crack ran farther because boundary conditions affected the crack tip. 


\subsection{Kanninen Model}

The DCB specimen used as a crack arrest specimen can be modeled by a simple beam configuration. Kanninen [12] attempted to model the DCB specimen as an Euler-Bernoulli beam with extensional springs along the uncracked ligament, as shown in Fig. 1. The governing equation of the beam deflection of this model is as follows:

$$
\left(d^{4} w / d x^{4}\right)+4 \lambda^{4} H(x) w=0
$$

where $H(x)=1$ for $x \geqq 0$

$$
=0 \text { for } x<0 \text {, }
$$

and $\lambda^{4}=3 \mathrm{k} / \mathrm{EBh}^{3}, \mathrm{a}=$ crack length, $\mathrm{b}=$ remaining ligament, $\mathrm{h}=$ specimen halfheight, $B=$ specimen thickness, $k=$ spring stiffness $(=2 E B / h), w=1$ ateral deflection of the beam and $E=$ Young's modulus. Equation (1) was solved using Laplace transformation, and the compliance was expressed as

$$
\delta / P=\phi / E B
$$

where $P=$ load, $\delta=$ load point displacement, and

$\Phi=\left(2 / \lambda^{3} h^{3}\right)\left\{2 \lambda^{3} a^{3}+\left(6 \lambda^{2} a^{2}[\sinh (\lambda b) \cosh (\lambda b)+\sin (\lambda b) \cos (\lambda b)]+6 \lambda a[\sinh 2(\lambda b)\right.\right.$

$\left.\left.+\sin ^{2}(\lambda b)\right]+3[\sinh (\lambda b) \cosh (\lambda b)-\sin (\lambda b) \cos (\lambda b)]\right) /\left[\sinh ^{2}(\lambda b)-\right.$ $\left.\left.\sin ^{2}(\lambda b)\right]\right\}$.

Stress intensity is given as

$$
\begin{aligned}
K= & \left(2 \sqrt{3 P} / \lambda B h^{3} / 2\right)\left\{\lambda a\left[\sinh ^{2}(\lambda b)+\sin ^{2} \lambda b\right]+\sinh (\lambda b) \cosh (\lambda b)-\sin \lambda b \cos \lambda b\right\} \\
& /\left[\sinh ^{2}(\lambda b)-\sin ^{2} \lambda b\right] .
\end{aligned}
$$


Next, Kanninen et al. [13] proposed the Timoshenko beam model with a generalized foundation, where not only extensional but rotational inertia is included, as shown in Fig. 2. The following equation of motion was introduced under fixed-grip conditions:

$\rho A \frac{\partial^{2} w}{\partial t^{2}}=\frac{\partial}{\partial x}\left[\kappa G A\left(\frac{\partial w}{\partial x}-\zeta\right)\right]-H^{*} k_{e} w$

$\rho I \frac{\partial^{2} \zeta}{\partial t^{2}}=\frac{\partial}{\partial x}\left(E I \frac{\partial \zeta}{\partial x}\right)+\kappa G A\left(\frac{\partial w}{\partial x}-\zeta\right) H^{*} k_{r} \zeta$

where $w$ is average lateral deflection; $\zeta$, average rotational angle; $A$, cross section area; I, moment of inertia; $\rho$, density; $G$, shear modulus. Extensional $\left(k_{e}\right)$ and rotational $\left(k_{r}\right)$ spring stiffness are given as

$$
\begin{aligned}
& k_{e}=2 E B / h \\
& k_{r}=\kappa G A / 2,
\end{aligned},
$$

where $\mathrm{k}=\frac{10(1+v)}{12+11 v}$, and $v=$ Poisson's ratio.

$H^{*}$ is a modified step function as used in eq. (1). The equation of motion can be explicitly solved using the Finite Difference Method. Crack extension is simulated by the elimination of springs, one by one, at the crack tip position at the specified time. If the uncracked ligament is larger than half of specimen height, compliance and stress intensity of this model are simply expressed as follows:

$$
\begin{aligned}
& \frac{\delta}{\mathrm{P}}=\frac{4 \mathrm{a}^{3}}{\mathrm{EBh}^{3}}\left[1+\frac{3 \sqrt{5}}{4}\left(\frac{\mathrm{h}}{\mathrm{a}}\right)+\frac{3}{2}\left(\frac{\mathrm{h}}{\mathrm{a}}\right)^{2}+\frac{3 \sqrt{ } 5}{16}\left(\frac{\mathrm{h}}{\mathrm{a}}\right)^{3}\right] \\
& K_{D}=\frac{(2 \sqrt{3}) \mathrm{Pa}}{B h^{3 / 2}}\left[1+\frac{\sqrt{5}}{2}\left(\frac{h}{\mathrm{a}}\right)+\frac{1}{2}\left(\frac{\mathrm{h}}{\mathrm{a}}\right)^{2}\right]^{\frac{1}{2}} .
\end{aligned}
$$


Numerical and experimental investigation revealed that the recovery of kinetic energy contributes to driving the running crack farther and that dynamic fracture toughness can be defined as a function of crack velocity, as follows:

$\frac{K_{D}}{K_{C}}=1+A_{1}\left(\frac{\dot{a}}{C_{0}}\right)+A_{2}\left(\frac{\dot{a}}{C_{0}}\right)^{2}$

where $K_{C}$ is static crack initiation toughness, $C_{0}$ is the bar wave velocity, and $A_{1}$ and $A_{2}$ are material constants.

\subsection{Finite Element Model (FEM)}

Many numerical studies have used Finite Element Models (FEM) to investigate dynamic crack propagation and arrest phenomena [6, 14-17]. These models include conventional triangular elements $[6,14]$, rectangular elements [15], and singular and isoparametric elements [16]. Any FEM model divides the specimen into many elements. Afterwards, the equations of motion of the individual elements are synthesized into an equation of motion of the whole specimen as follows:

$[M]\{\ddot{u}\}+[C]\{\dot{u}\}+[K]\{u\}=\{f\}$

where $[M],[C]$ and $[K]$ are mass, damping and stiffness matrices, respectively; $\{i \dot{u}\},\{\dot{u}\}$, and $\{u\}$ are the acceleration, velocity and displacement vectors of model points, respectively; and $\{f\}$ is the force vector applied to nodes. There are many ways to solve such an equation of motion numerically; care must be used in selecting the relationship between the time step and least element size [14]. Equation (8) will be found later to correspond with the equation of motion of a simple model, which consists of a mass and a spring. 
In the usual FEM, crack extension is simulated by the gradual release of the reaction force of the node corresponding to the crack tip and by the vanishing of that force by the time the crack arrives at the next node. This numerical technique was proved to be valid by comparison with an improved analytical solution by Malluck and King [6]. It is thought that the energy of the whole specimen can be dissipated near the crack tip by using this technique. On the other hand, a singular element near the crack tip can move along with the propagating crack tip in the improved analytical solution.

FEM is a useful technique to analyze any arbitrary specimen configuration accurately; it can enable modeling of the two-dimensional propagation of the stress wave that radiates from the crack tip. However, it requires excessive computer time to use the FEM model even if the specimen is assumed linear elastic.

\section{Mass-Spring Model of Crack Arrest Specimen}

This study describes a simple model for dynamic analysis even under largescale yielding conditions; the dynamic fracture behavior can be characterized using the J-integral calculated from this simple model. The model is applied to a specific DCB specimen; however, it is believed that this model can be applied equally well to other specimen geometries. The crack arrestreinitiation test specimen treated here, the configuration of which is similar to the OCB specimen, was developed by King et al. [5]. Figure 3a shows the loading system of this specimen schematically. The load was applied through the external massive spring. The MS model substitutes the simple mass and spring system, shown in Fig. 3b, for the actual specimen and loading devices. $\mathrm{K}_{\mathrm{ex}}$ is the stiffness of the external loading spring and in this model $\mathrm{K}_{\mathrm{s}}$ is the stiffness of the specimen, which depends on crack length as given below, from eq. (2): 


$$
\kappa_{S}=E B / 2 \Phi .
$$

$M_{\text {ex }}$ is the mass of both the loading spring and the associated apparatus; $u$ is regarded as total displacement of the loading point. It is very easy to write and solve the equation of motion for such a simple model, and it is assumed that total energy, displacement and load can govern the motion of this system. The drawback is that the actual specimen and load train have many normal modes of oscillation because the active mass and compliance are distributed throughout the specimen and load train. The simple model of Fig. 3 b radically simplifies the actual mass and compliance distribution, and has only one normal mode of oscillation.

Net Section Yielding (NSY), that is, complete yielding of the uncracked ligament, is easily realized in the spring-loaded DCB specimen, because the reloading facilitates increase of the applied stress and application of a large moment along the short uncracked ligament. Two simple assumptions may be adopted in this mass-spring model to express NSY and large deformation of the specimen: limit load corresponding with NSY; and damping factor, which models the elevation of the yielding point due to strain rate. One may question whether this simplified model is adequate to reproduce the actual complicated behavior that can be observed during dynamic elastic-plastic fracture. However, it will be possible to characterize dynamic elastic-plastic fracture behavior to some extent if load or load-point displacement, obtained numerically, can fit those obtained by experiment. In addition, the specimen is divided into two parts to get dynamic $J$ using a static analogy. A spring with the same compliance as the specimen and a limit load with a damping factor are substituted for the deformed specimen. The former yields elastic displacement of the specimen while the latter yields plastic displacement. $J$ is obtained using 
these two displacements and limit load, which occurs after the applied load on the specimen spring exceeds the limit load.

Details are given below for fixed grip, compliant loading, compliant loading with viscosity in the spring, and compliant, viscous spring loading of a yielding specimen.

\subsection{A Crack Arrest System Under Fixed-Grip Conditions}

Assume that a DCB specimen is fractured under fixed-grip conditions, which are approximately satisfied during crack propagation for the DCB specimen under wedge loading. It has been verified at Battelle Institute that the crack runs at nearly constant speed during propagation [4].

For the MS model, a fixed-grip condition is achieved by fixing the displacement of the mass in Fig. 3b. The relation between crack length and time, or crack velocity, was input to the numerical calculation. This case is static because the mass never moves. The load $P$ applied to the specimen is given as

$$
P=k_{s} \cdot u \text {. }
$$

In this model, $\kappa_{S}$ is the spring constant of the specimen, and it decreases with increasing crack size, that is, with time. $k_{s}$ is taken to be the static stiffness of an identical specimen with crack length equal to the instantaneous dynamic crack length.

Figure 4 shows the load change with time for three different constant crack velocities, which encompass the experimentally observed crack velocity [5]. Initial applied load and crack propagation distance are common to the three cases. The load is found to drop quickly with the crack velocity because of the large compliance change occurring during crack propagation. 


\section{2 Compliant Loading}

In this section, consider that the load is applied to the specimen through the loading spring and that the crack runs $135 \mathrm{~mm}$ at $714 \mathrm{~m} / \mathrm{s}$. The effect of mass and spring on the fracture behavior of the specimen are investigated. The equation of motion for the system shown in Fig. $3 b$ is:

$$
M_{e x} \ddot{u}+\left(\kappa_{e x}+\kappa_{s}\right) u=\kappa_{e x} u_{A},
$$

where $u_{A}$ is the initially applied displacement at the loading end. As the specimen stiffness changes during crack propagation, the following integral equation ranging from time $t$ to $t+\Delta t$ should hold, using D'Alembert's principle:

$$
\int_{t}^{t+\Delta t}\left\{\left[M_{e x} \ddot{i}(\tau)+\left[k_{e x}+k_{s}(\tau)\right] u(\tau)\right]-k_{e x} u_{A}\right\} d \tau=0
$$

where $\Delta t$ is the time increment. Therefore, eq. (11) is replaced by

$$
M_{e x} \Delta \ddot{u}+\left(k_{e x}+\kappa_{s}\right) \Delta u+\Delta K_{s} u=0
$$

where $\Delta \ddot{u}, \Delta u, \Delta K_{s}$ are the increments of acceleration, displacement and spring stiffness from $t$ to $t+\Delta t$. This incremental equation of motion is explicitly solved by Newmark's $\beta$ method. The time increment is carefully chosen to be less than one period of the natural frequency of this system as follows:

$$
\Delta t \leqq\left[M_{e x} /\left(\kappa_{e x}+\kappa_{s}\right)\right]^{\frac{1}{2}}
$$


Therefore, $\Delta t$ is set to $1 \mu s$. The change of load and displacement with $M_{\text {ex }}$ are shown in Figs. 5 and 6 . The load $P$ is given by eq. (10). Crack arrest is imposed at about 190 Hs, and the load drop during crack propagation is independent of mass. As the force balance that exists before crack initiation changes during crack propagation in Fig. 3b, the force difference is inertial force:

$$
M_{e x} \ddot{u}=F_{1}-F_{2}
$$

where $F_{1}$ is the force applied to the external loading spring and $F_{2}$ is the force applied to the specimen. If $M_{e x}$ is large enough that acceleration ij is regarded as negligible, the fixed-grip condition is achieved during crack propagation. This fact is supported by the variation of displacement with mass shown in Fig. 6. The load is found to recover quickly after the external loading spring begins to work, but the period depends on the mass. The displacement increases quickly after crack arrest and has the same period as the load.

The changes of load and displacement with various stiffnesses of the external loading spring are shown in Figs. 7 and 8 , respectively. Similarly, there is no effect of the load or the displacement among three cases during crack propagation. It is concluded from Figs. 5-8 that the external spring stiffness affects the load and displacement much less than the mass.

\subsection{Compliant Loading With a Viscous Spring}

The damping term, or viscosity, is introduced in the external spring as shown in Fig. 9, to account for the following friction effects in the actual experiment: the friction of the loading grip; the friction in the external spring, which consists of several disk washers; and the friction between loading grip and spring apparatus. The equation of motion is given as 


$$
M_{e x} \ddot{u}+C_{e x} \dot{u}+\left(k_{e x}+k_{s}\right) u=\kappa_{e x} u_{A}
$$

where $C_{e x}$ is the viscosity coefficient of the high spring. The incremental equation of motion, analogous to eq. 13 , is also used instead of eq. (14) during crack propagation. The changes of the load and the displacement are shown in Figs. 10 and 11, respectively, for arbitrarily chosen viscosity coefficients. The initial condition in the calculation is the same as used in the last section. While the change of the load and the displacement are the same with and without the viscosity effect during crack propagation, the recovery of the load and the displacement are found to be delayed after arrest when viscosity is included. The result with a small viscosity coefficient approaches the linear elastic case. It is noted that the period of the system is unchanged in spite of the introduction of viscosity, because the range of viscosity is such that the system is lightly damped.

\subsection{Compliant Loading of a Yielding Specimen}

The simple model is extended to simulate NSY behavior after crack arrest. As shown in Fig. 12, it is assumed that the load applied to the uncracked ligament remains at the limit load after the load on the specimen reaches limit

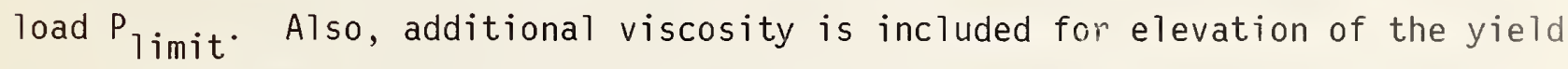
point due to strain rate and internal friction of the specimen. Another mass, $M_{s}$, yields the plastic displacement of the specimen. Here a value of $M_{s}=$ $27 \mathrm{~kg}$ was used; this was the mass of the specimen alone. $P_{\text {limit }}$ is given as

$$
P_{1 \text { imit }}=\sigma_{f}\left\{-(2 W-b)+\left[(2 W-b)^{2}+b^{2}\right]^{\frac{1}{2}}\right\} B
$$

where $W$ is specimen width, $b$ is remaining ligament, and $\sigma_{f}$ is the flow stress of the specimen material. The load is evaluated as follows: 


$$
P=k_{s}\left(u-u_{p}\right)-M_{s} \ddot{u}_{p}
$$

Here $u_{p}$ is the plastic part of the displacement. This system remains elastic as long as the load $P$ does not exceed $P_{1 i m i t}$. The equations of motion governing this system are

$$
M_{e x} \ddot{u}+C_{e x} \dot{u}+\left(K_{e x}+K_{S}\right) u=K_{e x} u_{A} \text {, for } P<P_{1 \text { imit }}
$$

and

$$
\begin{aligned}
& M_{e x} \ddot{u}+c_{e x} \dot{u}+\left(k_{e x}+\kappa_{s}\right) u=\kappa_{e x} u_{A}+\kappa_{s} u_{p} \\
& M_{s} \ddot{u}_{p}+c_{s} \dot{u}_{p}+k_{s} u_{p}=\kappa_{s} u-P_{1 \text { imit }} \text {, for } P \geqq P_{1 \text { imit }}
\end{aligned}
$$

where $C_{S}$ is the viscous coefficient in the specimen. The effect of changes in the viscosity coefficient on load and displacement is shown in Figs. 13 and 14. Flow stress $\sigma_{f}$ is assumed to be $551 \mathrm{MPa}$. These plots present very different features after crack arrest, depending on the viscosity. When the viscosity is rather small, the load does not increase so much, and both total and plastic displacements increase remarkably with time. These phenomena are considered to be applicable to an approximately elastic-plastic rate-insensitive material. When the viscosity is too large, the load and total displacement oscillate strongly. As their behaviors seem close to elastic, they can be applied to rate sensitive material. The moderate viscosity yields a smooth increase of the displacements and a gradual decrease of the recovered load. Both the load and the displacements are expected to be saturated at certain values at long times. 


\section{Extraction of the Fracture Mechanics Parameters}

Since this MS model simulates the crack arrest-reinitiation test, it is necessary to extract the appropriate fracture mechanics parameters corresponding with each aspect and to investigate their validity. To facilitate specific comparison of the models, the extraction of fracture mechanics parameters from Kanninen's DCB model and the FEM model are also reviewed. Then a method for calculating the elastic-plastic crack driving force in terms of the J-integral from the MS model is introduced.

\section{1 Stress Intensity Factor $K$ from the MS Model}

$K$ is obtained using the MS model in Fig. 3b. The potential and kinetic energy $\pi$ of this system is given as

$$
\pi=\frac{1}{2} M_{e x} \dot{u}^{2}+\frac{1}{2} K_{s} u^{2}+\frac{1}{2} K_{e x}\left(u_{A}-u\right)^{2} .
$$

The total energy release rate is obtained by differentiating eq. (18) with crack length a, as follows:

$$
-\frac{\partial \pi}{\partial a}=-\frac{\partial \pi}{\partial t} \frac{1}{\dot{a}}=-\frac{u^{2}}{2} \frac{\partial \kappa_{s}}{\partial a}-\left[M_{e x} \dot{u}+\left(\kappa_{s}+\kappa_{e x}\right) u-\kappa_{e x} u_{A}\right] \frac{\dot{u}}{\dot{a}} .
$$

The term in square brackets vanishes because it corresponds with the equation of motion as given in eq. (11). Then, the energy release rate is

$$
-\frac{\partial \pi}{\partial a}=-\frac{u^{2}}{2} \quad \frac{\partial \kappa_{s}}{\partial a}
$$

Equations (9) and (10) are substituted into the above equation, and eq. (20) becomes

$$
-\frac{\partial \pi}{\partial a}=\frac{p^{2}}{E B} \frac{\partial \phi}{\partial a} .
$$


Using the relation between stress intensity $K$ and potential energy release rate, $K$ is expressed as

$$
K=\frac{P}{B}\left(\frac{\partial \phi}{\partial a}\right)^{\frac{1}{2}},
$$

where $\phi$ is defined in eq. (3). This $K$ results in eq. (4) mentioned previously.

\subsection{Stress Intensity Factor K From the Kanninen DCB Model}

In the Kanninen model (Section 2.2), the crack propagation is simulated by releasing the springs corresponding with the moving crack tip, which is located discretely along the uncracked ligament. Strain energy from extending and bending is stored in each spring. Total strain energy $U$ and total kinetic energy $\mathrm{T}$ are given:

$$
\dot{U}=\int\left[E I\left(\frac{\partial \zeta}{\partial x}\right)^{2}+k G A\left(\frac{\partial w}{\partial x}-\zeta\right)^{2}+H^{*}\left(k_{e} w^{2}+k_{r} \zeta^{2}\right) d x\right]
$$

and $\quad T=\int \rho A\left(\frac{\partial w}{\partial t}\right)^{2}+\rho I\left(\frac{\partial \zeta}{\partial t}\right)^{2} d x$.

If the fixed-grip condition is assumed in this specimen, total energy $\pi$ is obtained as

$$
\pi=U+T \text {. }
$$

The energy release rate is obtained by substituting eq. (22) into eq. (23):

$$
-\frac{\partial \pi}{\partial a}=\left[\frac{1}{B}\left(k_{e} w^{2}+k_{r} \xi^{2}\right)\right]_{x=a} .
$$

The above expression is exactly equal to the energy stored in the spring located at the crack tip. This spring energy is dissipated with crack extension. Accordingly, $K$ is expressed as 


$$
K=\left[\frac{E}{B}\left(k_{e} w^{2}+k_{r} \zeta^{2}\right)\right]^{\frac{1}{2}} \quad x=a .
$$

\section{3 Stress Intensity Factor $K$ from the FEM Model}

$K$ is obtained in this study using a conventional FEM model with triangular elements. Crack propagation is simulated as follows: the reaction force of the node that corresponds with the crack tip is decreased gradually with crack extension and vanishes when the crack reaches the next node (in Fig. 15). Malluck proved [6] that the numerical result was independent of the details of releasing the spring force. Energy is eliminated gradually from the system by this technique because the nodal force does work. The dissipated energy $D$ is

$$
D=\int_{0}^{v_{0}} f d v \text {, }
$$

where $v_{0}$ is the crack opening displacement of the node closest behind the crack tip when the crack reaches the next node. $k$ is given as

$$
K=\left[E \int_{0}^{v_{0}} \frac{f d v}{B \Delta a}\right]^{\frac{1}{2}},
$$

where $\Delta a$ is space step, which should be as small as possible. Furthermore, the difference among element sizes should be minimized because differences can cause unexpected stress waves.

\section{4 Elastic-Plastic Crack-Driving Force J From the MS Mode1}

The MS model, in which plasticity is incorporated, was employed in Section

2.4 to analyze elastic-plastic fracture behavior after the specimen load exceeded the limit load. $J$ is divided into elastic ( $\mathrm{J}_{\mathrm{e}}$ ) and plastic parts $\left(J_{p}\right)$ as follows:

$$
J=J_{e}+J_{p} .
$$


$\mathrm{J}_{\mathrm{p}}$ is associated with $\operatorname{COD}\left(\delta_{\mathrm{p}}\right)$ through the Dugdale Model

$$
J_{p}=\sigma_{f} \delta_{p}
$$

When it is assumed that only plastic load-point displacement can contribute to $\delta_{p}$ and that the DCB specimen hinges around the neutral point of the stress along the uncracked ligament, $\delta_{p}$ becomes

$$
\delta_{p}=\left\{1+(-2 W+2 b) /\left[(2 W-b)^{2}+b^{2}\right]^{\frac{1}{2}}\right\} u_{p} .
$$

Elastic load-point displacement $u_{e}$ is given as

$$
u_{e}=u-u_{p}
$$

$\mathrm{J}_{\mathrm{e}}$ is obtained by using $\mathrm{K}$ :

$$
J_{e}=K^{2} / E .
$$

Because $K$ is proportional to $u_{e}$,

$$
J_{e} \propto u_{e}^{2} .
$$

Consequently the resulting $\mathrm{J}$-integral, denoted $\mathrm{J}_{1}$ is

$$
J_{1}=\left(K^{2} / E\right)+\sigma_{f} \delta_{p} .
$$


Note that eq. (31) often gives unreasonably large values, because the load at the specimen exceeds the limit load. Assume that the load applied to the elastic spring of the specimen is spurious; that is, the viscous load is spurious and only the limit load contributes to plastic fracture. Then, $J_{e}$ must be

$$
J_{e} \leqq K_{N S Y}^{2} / E
$$

Therefore, another $\mathrm{J}$ is given as

$$
J_{2}=\left(K_{N S Y}^{2} / E\right)+\sigma_{f} \delta_{p}
$$

It is very difficult to obtain true $\mathrm{J}$ using this simple model, and it is questionable whether $\mathrm{J}_{1}$ or $\mathrm{J}_{2}$ is valid.

Figure 16 shows the change of $\mathrm{J}$ with time for the three viscosity coefficients mentioned above. A large difference is seen between $\mathrm{J}_{1}$ and $\mathrm{J}_{2}$ after NSY. It seems that these values approach each other with time. This means that the system becomes stable gradually. To study this question, it will be necessary to collect detailed experimental data for a comparison with numerical results.

\section{Comparison of the Models}

In this section, dependencies of load, load-point displacement and stress intensity factor $K$ for the three models considered are compared. Load and load-point displacement are compared because they are considered valuable indicators of the performance of any crack arrest model, and they can be compared with experimental results. If a model cannot produce reasonable behavior for calculated load and load-point displacement, its ability to calculate fracture mechanics parameters correctly must be seriously questioned. Stress intensity 
factors $K$ from the three models are presented as further evidence of the ability of the MS model to calculate fracture mechanics parameters during dynamic crack propagation. The static comparison, listed in Table 1 , gives examples of the degree of agreement to be expected between different models. Note that as b becomes equal to or less than $a$, the agreement deteriorates. The values for Kanninen eq. (6) apply for the static MS model because this equation was incorporated into the static MS model.

\subsection{Relation Between Load and Time}

The results from each model are compared before crack arrest under fixedgrip conditions and under compliant loading. Crack initiation, velocity, and arrest are imposed. The comparison is confined within the elastic limit. Time increment $\Delta t$ and space step $\Delta x$ are carefully chosen to avoid numerical divergence as follows: $\Delta t=0.5 \mu \mathrm{s}$ and $\Delta x=5 \mathrm{~mm}$ for the Kanninen model; $\Delta t=$ $0.5 \mu \mathrm{s}$ for the FEM model. The mesh is shown in Fig. 17. The Kanninen and FEM models are explicitly solved employing the finite difference method and Newmark's $\beta$ method $\left(\beta=\frac{1}{4}\right)$, respectively. The change of the load with time is shown in Fig. 18 where the crack ran for $135 \mathrm{~mm}$ at two speeds, and was arrested under fixed-grip conditions. The load calculated by the MS model drops smoothly because this model includes only the lowest normal mode. On the other hand, the other models present complicated oscillations because higher order modes are superposed and each element of the specimen oscillates with 1 or 2 degrees of freedom. In the Kanniren and FEM models, the load begins to drop at about 160 us after crack initiation, while in the MS model the load drops immediately after crack initiation and $160 \mu \mathrm{s}$ is the amount of time for the radiated stress wave from the initial crack tip to propagate to the loading point. The trend of load change in the MS model, however, is regarded as agreeing well with the 
more elaborate models. It is concluded that the lowest normal mode is dominant in this specimen, and is modeled accurately by the MS model.

Next, Fig. 19 shows the change of load that is applied in the mass-spring system. Also shown is the Kanninen model that has twice the mass and external spring stiffness because half of the specimen is treated in this model. Although the Kanninen model expresses rather large oscillations after crack arrest, its trend agrees well with that of the MS model. Thus the validity of the MS model was supported by comparing it with the Kanninen model for the load change.

\subsection{Relation Between Load-Point Displacement and Time}

Figure 20 shows the change of total load-point displacement with time in the mass-spring system, where the crack ran for $135 \mathrm{~mm}$ and was arrested there. Both the MS and the Kanninen models express a smooth increase without complicated oscillations as in load change. Excellent agreement is achieved in the change of total load-point displacement. This suggests that an accurate prediction of the displacement may be possible for comparison with experimental results.

\subsection{Relation Between $K$ and Time}

The comparison of the fracture mechanics parameter is now made for three different models. The change of $K$ is shown in Fig. 21 , under the same fixedgrip conditions as in Sec. 5.1. Excellent agreement is observed between the Kanninen and the FEM models throughout the time of interest. Although there are small differences between the MS model and the other two models just after crack initiation, the trend of the MS model agrees well with the others. Figure 22 shows the change of $K$ with time in the mass-spring system, as in Sec. 5.2. No significant differences are found between the MS and the Kanninen models 
even after crack arrest. The conclusion is that MS model is as useful for analysis of dynamic elastic fracture behavior as are the other two models.

\subsection{Conclusion for Section 5}

The fracture behavior of the specimen was found to be expressed satisfactorily with the use of the MS model if the specimen was linear elastic. That is, the fracture parameter $\mathrm{K}$, which was extracted from the MS model, was consistent with that of the other models. This suggests that such a simple model is valid from the viewpoint of fracture mechanics as expressing only the lowest normal mode and that the fracture parameter can be estimated from this model within engineering allowance.

\section{Comparison of the MS Model With Experimental Data}

6.1 Relation Between Load, Load-Point Displacement, and Time

In this section, the MS model is applied to analyze the crack

arrest-reinitiation test conducted at NBS [5]. The material tested is HY 80 , which shows approximately elastic-perfectly-plastic mechanical behavior with a yield stress of $551 \mathrm{MPa}$. Young's modulus and Poisson's ratio are assumed to be $200 \mathrm{GPa}$ and 0.3 , respectively. The specimen configuration and load system are schematically shown in Fig. 3a. The load was applied to the specimen through the external load spring. The recorded data were the load, by load ce11; loadpoint displacement, by clip-on gauge; and crack velocity, by tripwires. The fracture surface showed a brittle failure mode before the crack arrest and ductile failure accompanied by tearing after crack arrest.

This MS model is applied to two test specimens, where all data were completely obtained: HY80-4 and HY80-6. Momentary crack arrest was deduced from crack velocity or strain near the crack tip, both recorded in these two tests. 
Table 2 shows experimental conditions and results. The mass and stiffness of the external spring are given, but this model requires two viscous coefficients. These are chosen by trial and error so that the numerical results of the MS model fit the experimental records. The limit load is given from eq. (15):

$$
P_{\text {Timit }}=181.7 \mathrm{kN} \text {. }
$$

The relation between load and time is shown in Fig. 23 for HY80-6. The experimental load record shows large oscillations at high frequency. It is believed that the load calculated by the MS model with two different viscosity coefficients indicates the average variation of experimental load. The trend, that is, the recovery of the load after crack arrest, seems to agree well with the experimental one, although the load calculated from the MS model drops more quickly just after crack initiation than does the experimental load, because of stress wave propagation.

Figure 24 shows the change of load-point displacement with time for HY80-6. The experimental displacement tends to approach the numerical result, using $C_{\text {ex }}=87.6 \mathrm{kN} \cdot \mathrm{s} / \mathrm{m}$ and $C_{\mathrm{s}}=63.1 \mathrm{kN} \cdot \mathrm{s} / \mathrm{m}$. Dotted 1ines indicate the displacement when the specimen is assumed to be linear elastic. This is correct before about $4 \mathrm{~ms}$, but deviates greatly from experimental displacements afterwards. This deviation indicates that elastic analysis is unsatisfactory for the actual test specimen.

Figures 25 and 26 show the change of the load and the load-point displacement with time, respectively, for HY80-4. The displacement from the MS model is slightly smaller overall than the experimental displacement because the actual viscous coefficient of the external spring is smaller for HY80-4 than for HY80-6. 
It is important to know the fracture parameter during crack propagation. The change of $K$ with time is shown in Fig. 27 by the MS and the Kanninen models for HY80-4 and HY80-6. Both results seem to be generally satisfactory. The stress intensities at crack arrest are

$$
\begin{aligned}
& \mathrm{K}_{\mathrm{a}}=51.4 \mathrm{MPa} / \mathrm{m} \text { for } \mathrm{HY} 80-4, \\
& \mathrm{~K}_{\mathrm{a}}=62.2 \mathrm{MPa} / \mathrm{m} \text { for HY80-6. }
\end{aligned}
$$

These stress intensities must be less than crack arrest toughness because crack arrest certainly occurred at $190 \mathrm{~mm}$.

\subsection{Relation Between $\mathrm{J}$ and Time}

There is no method available to evaluate $\mathrm{J}$ directly in dynamic elasticplastic fracture experiments, although $\mathrm{J}$ can be obtained using load vs. load line displacement curves in the static case.

Here we describe a method for evaluating $J$ based on the load point displacement obtained by experiment. If the load point displacement $\Delta$ does not exceed $\Delta_{N S Y}$, then

$$
J=K^{2} / E
$$

where $K$ is calculated using eq. (4). $\Delta_{N S Y}$ is the displacement evaluated at limit load $P_{\text {limit, }}$ and is obtained using eq. (2):

$$
\Delta_{\mathrm{NSY}}=3.4 \mathrm{~mm}
$$


When $\Delta$ is larger than $\Delta_{N S Y}, J$ is divided into the elastic component $J_{e}$ and the plastic component $J_{p}$. They are expressed as in Sec. 4.3. K KSY is easily obtained by eq. (4):

$$
\mathrm{K}_{\mathrm{NSY}}=260 \mathrm{MPa} \sqrt{\mathrm{a}}
$$

Consequently, experimental $\mathrm{J}$ is obtained with the use of eq. (30) as

$$
J=\left(K_{N S Y}^{2} / E\right)+\sigma_{f}\left\{1+(-2 W+2 b) /\left[(2 W-b)^{2}+b^{2}\right]^{\frac{1}{2}}\right\}\left(\Delta-\Delta_{N S Y}\right) .
$$

Figs. 28 and 29 show the relation between $j$ and time for HY80-6 and HY80-4, respectively. The solid line $\left(J_{1}\right)$ and dotted line $\left(J_{2}\right)$ begin to deviate after NSY. The experimental $\mathrm{J}$ is close to $\mathrm{J}_{1}$ for HY80-4 and is between $\mathrm{J}_{1}$ and $\mathrm{J}_{2}$ for HY80-6. While $\Delta$ corresponds with u of the MS model, $\Delta-\Delta_{\text {NSY }}$ should be equal to $u_{p}$. It seems, however, that the increase of $u_{p}$ is slower than that of $\Delta-\Delta_{\text {NSY }}$. The relative merits of these two sets of assumptions about $J$ are difficult to assess because of different definitions of plastic displacement and because of different methods to obtain $J$. It is likely, however, that $J$ calculated by either method does not deviate excessively from the actual $\mathrm{J}$.

\section{Summary and Conclusion}

7.1 Validity of the MS Model for General Features of Crack Arrest Behavior First, the MS model compared well with the Kanninen and the FEM models within elastic limits under several conditions. Comparisons of calculated values of the fracture parameter $K$ showed the validity of the analysis of elastic crack propagation and arrest using the MS model. Next, the introduction of viscosity made it possible to treat plasticity effects. Especially. experimental load and load-point displacement were simulated successfully by 
the MS model using viscosity and limit load. The methods were found attractive for assessing $\mathrm{J}$ by simple assumptions, although the input parameters are not known well enough to rigorously characterize dynamic elastic-plastic fracture. It is satisfactory that the MS model could extract the essence of the complicated features.

\subsection{Better Model}

A very simple model was proposed based on the crack arrest-reinitiation test specimen developed at NBS. This model is a useful tool to analyze both elastic and elastic-plastic fracture dynamically. The other models, such as the Kanninen or the elastic FEM model, are not appropriate for the analysis of dynamic elastic-plastic fracture. Elastic-plastic dynamic FEM models require substantial computational effort. A simple model should be established to extract the characteristics of fracture. However, it is noted that an excessively simplified model often results in the neglect of microscopic features of the material. Comparison is always necessary with experimental results and with other models.

Strictly speaking, the above simple model is valid only before reinitiation, because limit load, viscosity in the specimen and the stiffness of the specimen must vary after the crack reinitiates. It will be necessary to measure the reinitiation time and the crack velocity after reinitiation and to change the above parameters for a more complete estimate.

A similar equation of motion could be introduced for different specimens or different loading systems by modifying the MS model, although the stiffness of the cracked specimen must be known. The establishment of effective mass or stiffness can make it possible to estimate the dynamic fracture behavior for an actual structure such as a ship section. 
Care must be taken with the introduction of plasticity in the model. Viscosity and limit load concepts facilitated modeling for plasticity in the MS model, because NSY occurred after crack arrest. A similar model could be formulated for specimens with a large plastic zone before NSY. For example, a spring constant that varies with displacement after arrest, as in Fig. 30 , could be used.

\subsection{Method of Comparison with Experimental Data}

It is important to choose carefully which numerical parameters should be compared with experiment. Dynamic measurements are often difficult to analyze. The load tends to show a different value at each location because of stress wave propagation. In addition, the superposed high frequency of the specimen makes it hard to properly estimate the fracture load.

On the other hand, the displacement does not oscillate as much as the load or strain, although it is also hard to measure. Small spurious fluctuations should be neglected because they are not essential and because the simple model often fails to reproduce them. It is believed that comparison with displacement is most reliable.

\section{Acknowledgments}

Financial support from the Office of Naval Research (for the first author) and the Naval Sea Systems Command, 05R25, (for the co-authors), is grateful1y acknowledged. Technical assistance from D. P. Vigliotti and J. D. McColskey is deeply appreciated. 
9. References

[1] Feely, F. J., Jr., Northup, M. S., Kleppe, S. R., and Gensamer, M., "Studies on the Brittle Failure of Tankage Steel Plates," Welding J., 34, 1955, pp. 596-s-607-s.

[2] Kihara, H., Kanzawa, T., Ikeda, K., Okabe, H., Nakajima, T., and Yajima, H., "Study on Welded Type Crack Arrester," IIW Doc. No. X-618-17, 1971.

[3] Freund, L. B., "Dynamic Crack Propagation," The Mechanics of Fracture, ed. F. Erdogan, ASME AMD, Vol. 19, ASME, 1975, pp. 105-134.

[4] Hahn, G. T., Hoagland, R. G., Rosenfield, A. R. and Senjoha, R., "Rapid Crack Propagation in a High Strength Steel," Metal. Trans., 5, 1974, pp. 475-482.

[5] King, R. B., Teramoto, T. and Read, D. T., "Material Selection Criteria for Crack Arrester Strakes in Naval Vessels Second Interim Progress Report," NBSIR 84-3012, National Bureau of Standards, 1984.

[6] Malluck, J. F. and King, W. W., "Fast Fracture Simulated by Conventional Finite Elements: A Comparison of Two Energy-Release Rate Algorithms," ASTM STP 711, 1980 , pp. 38-53.

[7] Shmuely, M., "Effect of Poisson's Ratio on Crack Propagation and Arrest in the Double-Cantilever-Beam Specimen," ASTM STP 627, 1977, pp. 135-141.

[8] Kanninen, M. F., "An Estimate of the Limiting Speed of a Propagating Ductile Crack," J. Mech. Phys. Solids, 16, 1968, pp. 215-228.

[9] Crosley, P. B. and Ripling, E. J., "Characteristics of a Run-Arrest Segment of Crack Extension," ASTM STP 627, 1977, pp. 203-227.

[10] Kanazawa, T., Machida, S. and Teramoto, T., "Preliminary Approach to Experimental and Numerical Study on Fast Crack Propagation and Crack Arrest," ASTM STP 627, 1977, pp. 39-58.

[11] Kanazawa, T., Machida, S., Teramoto, T., and Yoshinari, H., "Study on Fast Fracture and Crack Arrest," Exp. Mech., 21, 1981, pp. 78-88.

[12] Kanninen, M. F., "An Augmented Double-Cantilever-Beam Model for Studying Crack Propagation and Arrest," Int. J. Fracture, 9(1), 1977, pp. 83-92.

[13] Kanninen, M. F., Popelar, C. and Gehlen, P. C., "Dynamic Analysis of Crack Propagation and Arrest in the Double-cantilever-Beam Specimen," ASTM STP 627, 1977, p. 18.

[14] Keegstra, P. N. R., "A Transient Finite Element Crack Propagation Mode 1 for Nuclear Pressure Vessel Steels," J. Inst. Nuc. Eng., 17(4), 1976, pp. 89-96. 
[15] Mal1, S., Kobayashi, A. S., and Urabe, Y., "Dynamic Photoelastic and Dynamic Finite Element Analysis of Polycarbonate Dynamic Tear Test Specimens," ASTM STP 677, 1979, pp. 498-510.

[16] Nishioka, T., Stonesifer, R. B., and Atluri, S. N., "An Evaluation of Several Moving SIngularity Finite Elements Models for Fast Fracture Analysis," Eng. Fract. Mech., 15(1), 1981, pp. 205-218.

[17] Kanazawa, T., Kobayashi, A. S., Machida, S., and Urabe, Y., "Fracture Dynamic Analysis of Crack Arrest Test Specimens," Proc. Ist Inst. Conf. of Numerical Methods in Fracture Mechanics, 1978, pp. 709-720. 
Table 1. Comparison of Models

\begin{tabular}{|c|c|c|c|c|c|c|c|}
\hline \multirow[b]{2}{*}{$\stackrel{a^{*}}{(\mathrm{~mm})}$} & \multirow[b]{2}{*}{$\underset{(\mathrm{mm})}{b^{*}}$} & \multicolumn{3}{|c|}{ Stress intensity (MPa $\sqrt{\mathrm{m}})$} & \multicolumn{3}{|c|}{ Compliance $(\mathrm{m} / \mathrm{N})$} \\
\hline & & FEM & $\begin{array}{c}\text { Kanninen } \\
\text { eq. (7) }\end{array}$ & $\begin{array}{l}\text { Kanninen } \\
\text { eq. (4) }\end{array}$ & FEM & $\begin{array}{l}\text { Kanninen } \\
\text { eq. (6) }\end{array}$ & $\begin{array}{c}\text { Kanninen } \\
\text { eq. (2) }\end{array}$ \\
\hline 50 & 255 & 140.6 & 143.0 & 144.4 & $1.797 \times 10^{-9}$ & $1.707 \times 10^{-9}$ & $1.603 \times 10^{-9}$ \\
\hline 100 & 205 & 200.8 & 183.2 & 210.7 & $3.845 \times 10^{-9}$ & $3.558 \times 10^{-9}$ & $3.727 \times 10^{-9}$ \\
\hline 150 & 155 & 293.3 & 229.1 & 342.0 & $8.031 \times 10^{-9}$ & $6.501 \times 10^{-9}$ & $8.693 \times 10^{-9}$ \\
\hline 200 & 105 & 513.4 & 273.5 & 727.7 & $1.892 \times 10^{-8}$ & $1.083 \times 10^{-8}$ & $2.630 \times 10^{-8}$ \\
\hline
\end{tabular}

* $\quad P=0.431 \mathrm{MN}$.

** $\quad K$ is calculated with the conversion $J=K^{2} / E$, where the $J$-integral is obtained using the isoparametric FEM model. 
Table 2. Testing Conditions and Experimental Results

\begin{tabular}{lccccc}
\hline Specimen & $\begin{array}{c}\text { Stiffness of } \\
\text { spring } \\
(\mathrm{MN} / \mathrm{m})\end{array}$ & $\begin{array}{c}\text { External } \\
\text { mass } \\
(\mathrm{kg})\end{array}$ & $\begin{array}{c}\text { Initial load } \\
\mathrm{P}_{\text {in }} \\
(\mathrm{MN})\end{array}$ & $\begin{array}{c}\text { Initial stress } \\
\text { intensity } \\
\mathrm{K}_{\text {in }}(\mathrm{MPa} / \mathrm{m})\end{array}$ & $\begin{array}{c}\text { Mean crack } \\
\text { velocity } \\
\mathrm{a}_{\text {mean }}(\mathrm{m} / \mathrm{s})\end{array}$ \\
\hline HY80-4 & 13.6 & 120 & 0.431 & 147 & 750 \\
HY80-6 & 9.1 & 136 & 0.372 & 134 & 365 \\
\hline
\end{tabular}



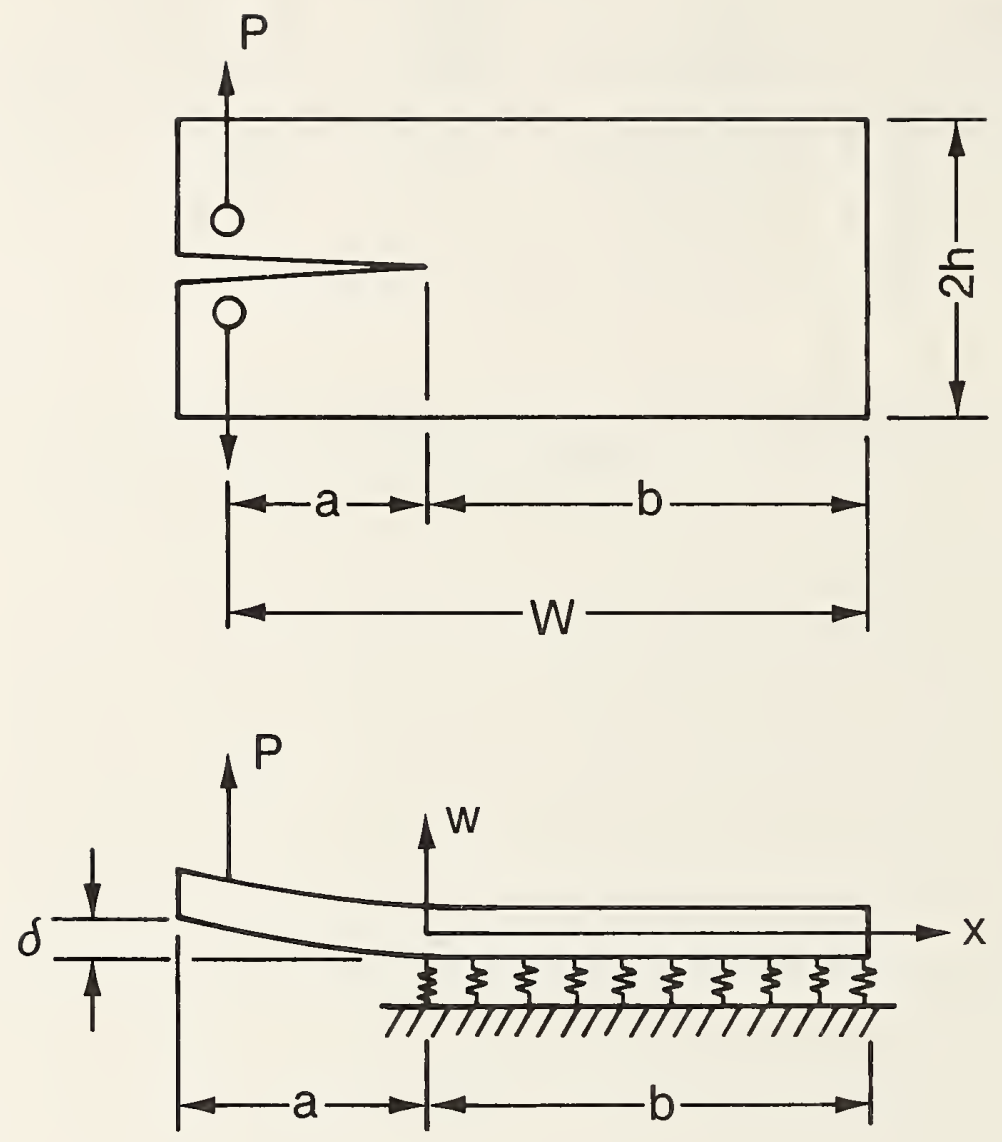

Figure 1. Specimen configuration and Euler-Bernoulli bearn model with a winkler foundation. 


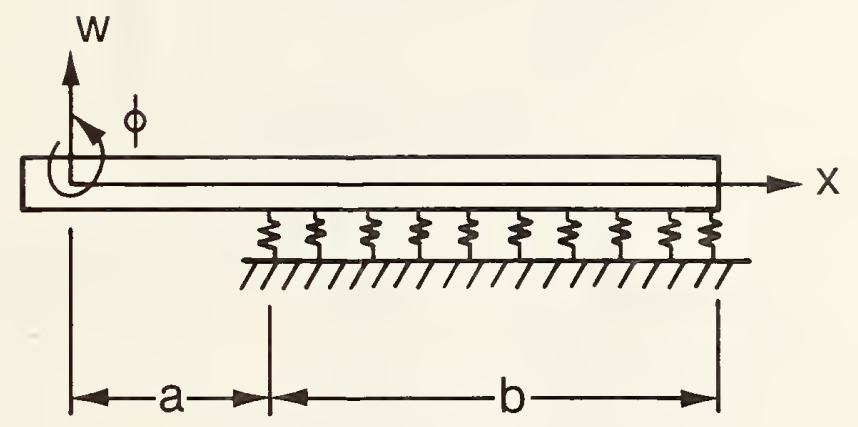

Figure 2. Timoshenko beam model with a generalized foundation. 


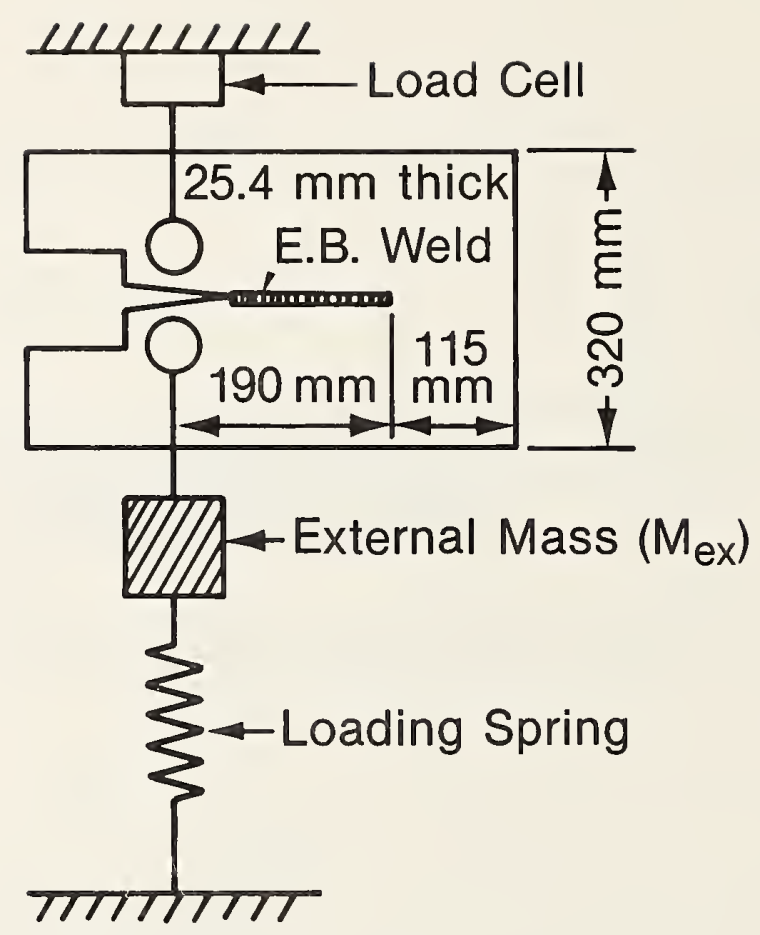

Figure 3. (a) Crack arrest reinitiation specimen and schematic loading system; 


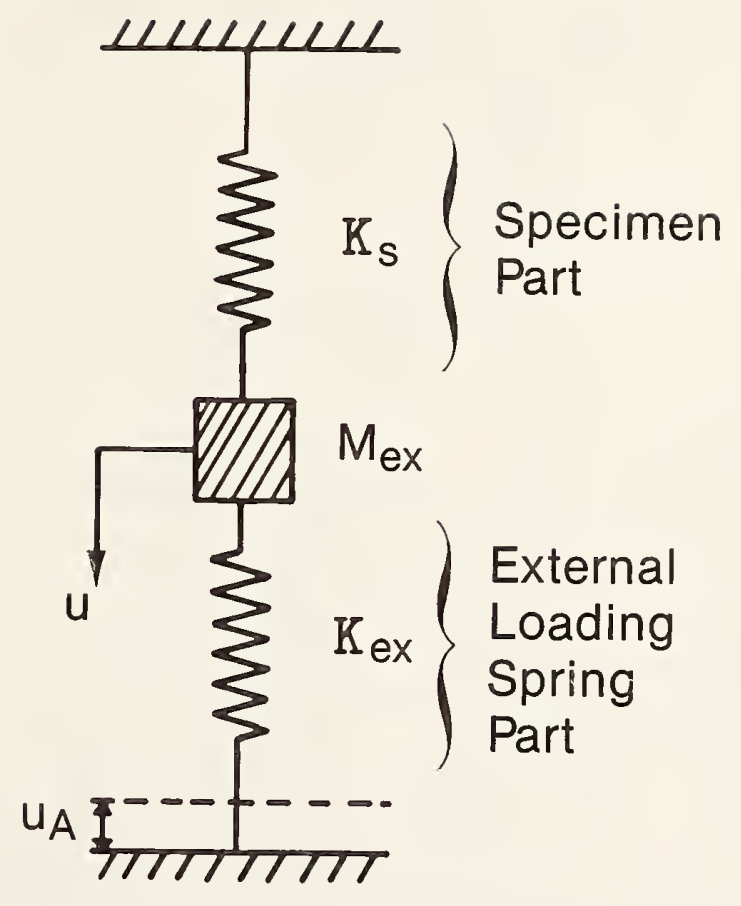

Figure 3. (b) MS model of the crack arrest reinitiation specimen. 


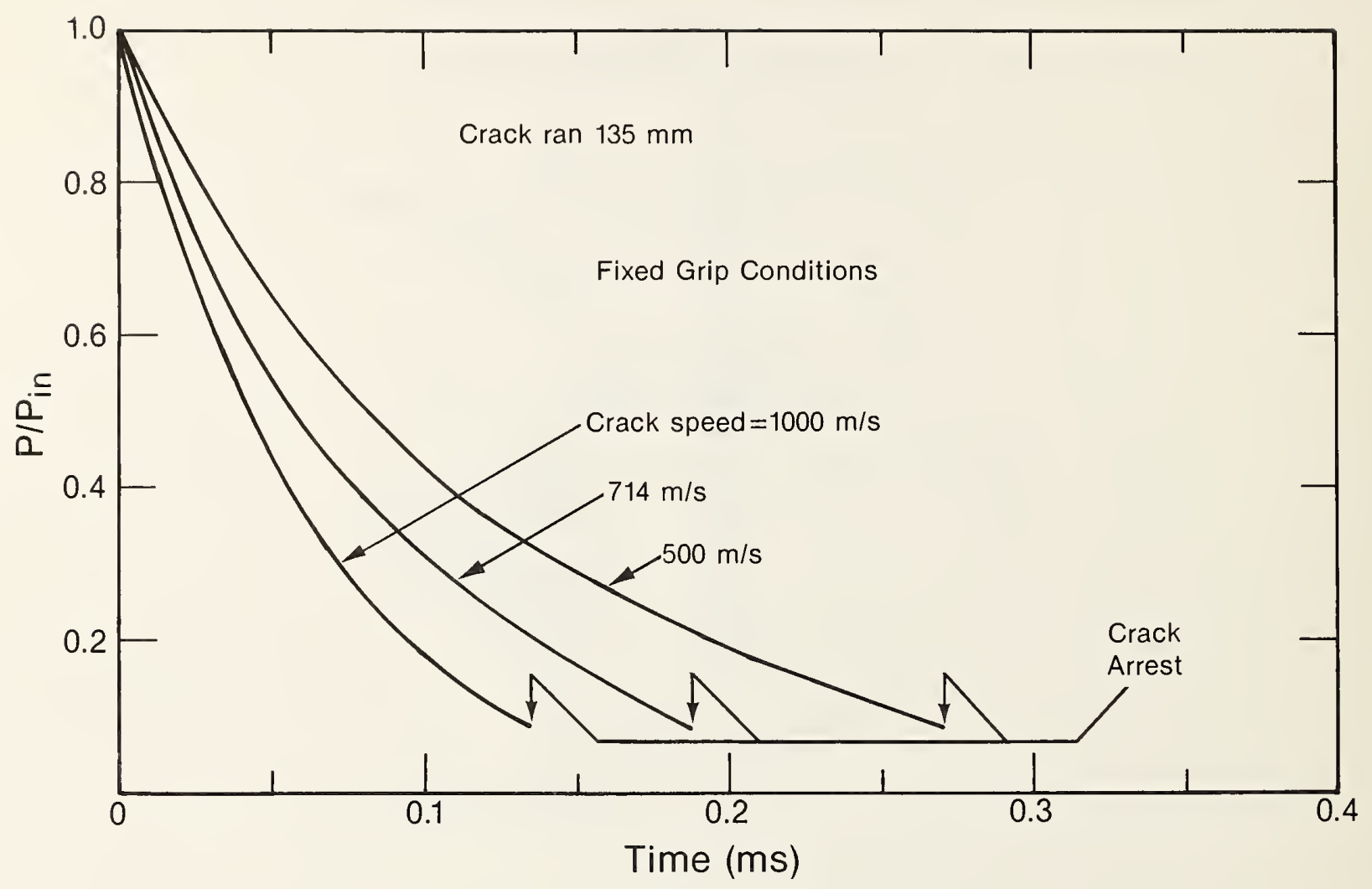

Figure 4. Change of load with time under fixed-grip conditions in the MS mode1. 


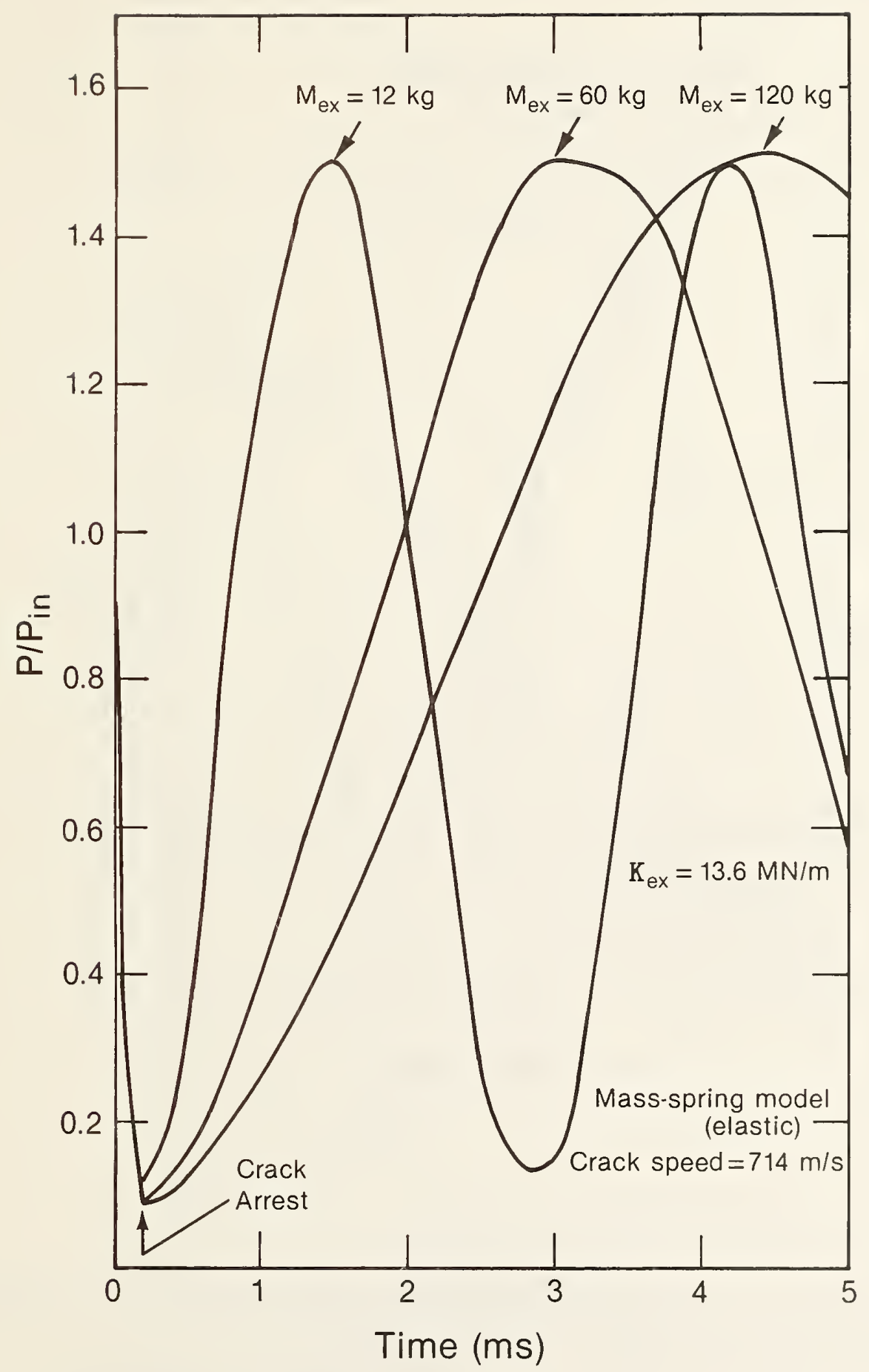

Figure 5. Chances of load with time under conditions of compliant loading for different amounts of mass. 
Mass-spring model (elastic)

Crack speed $=714 \mathrm{~m} / \mathrm{s}$

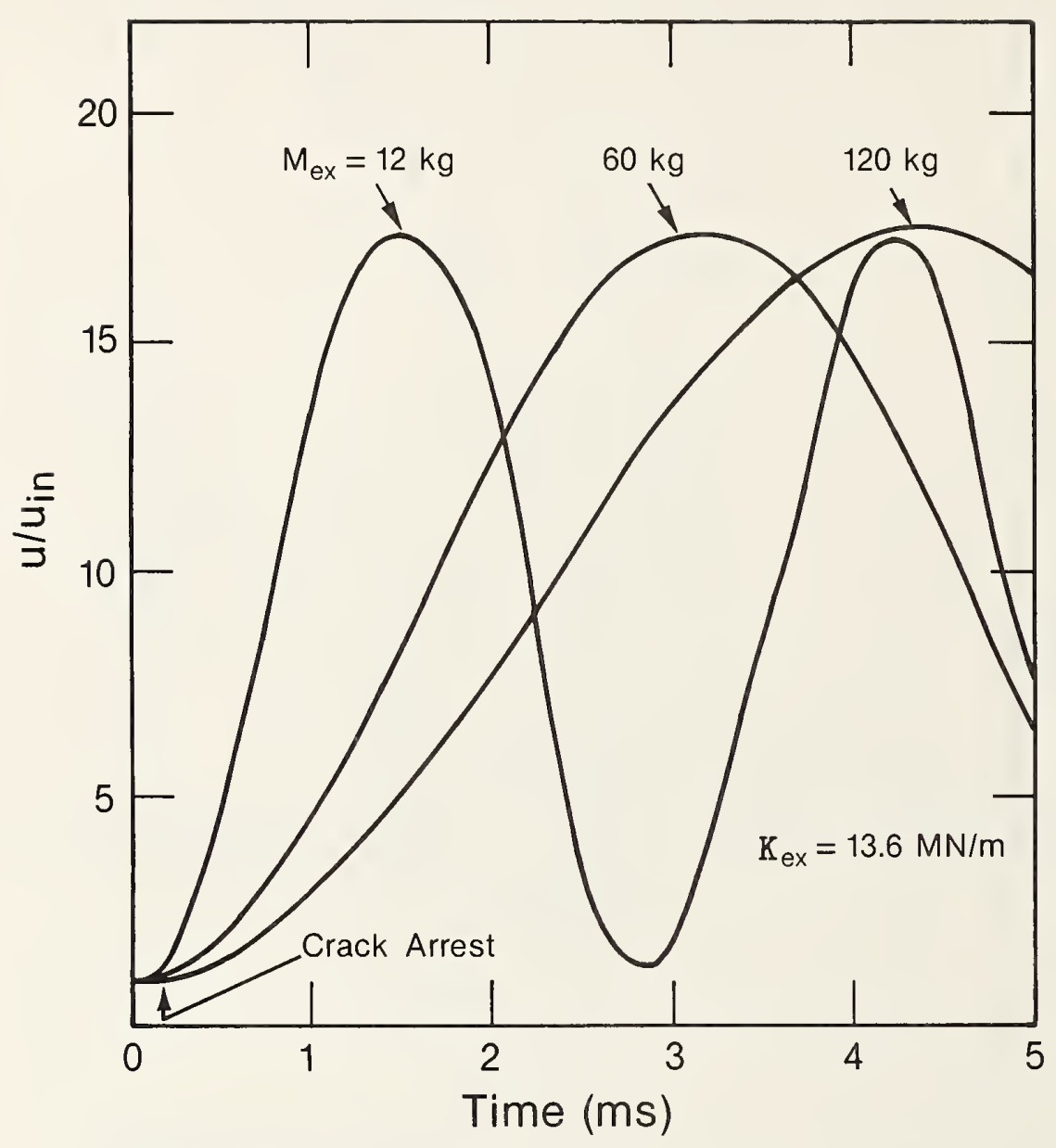

Figure 6. Changes of displacement with time under conditions of compliant loading for different amounts of mass. 


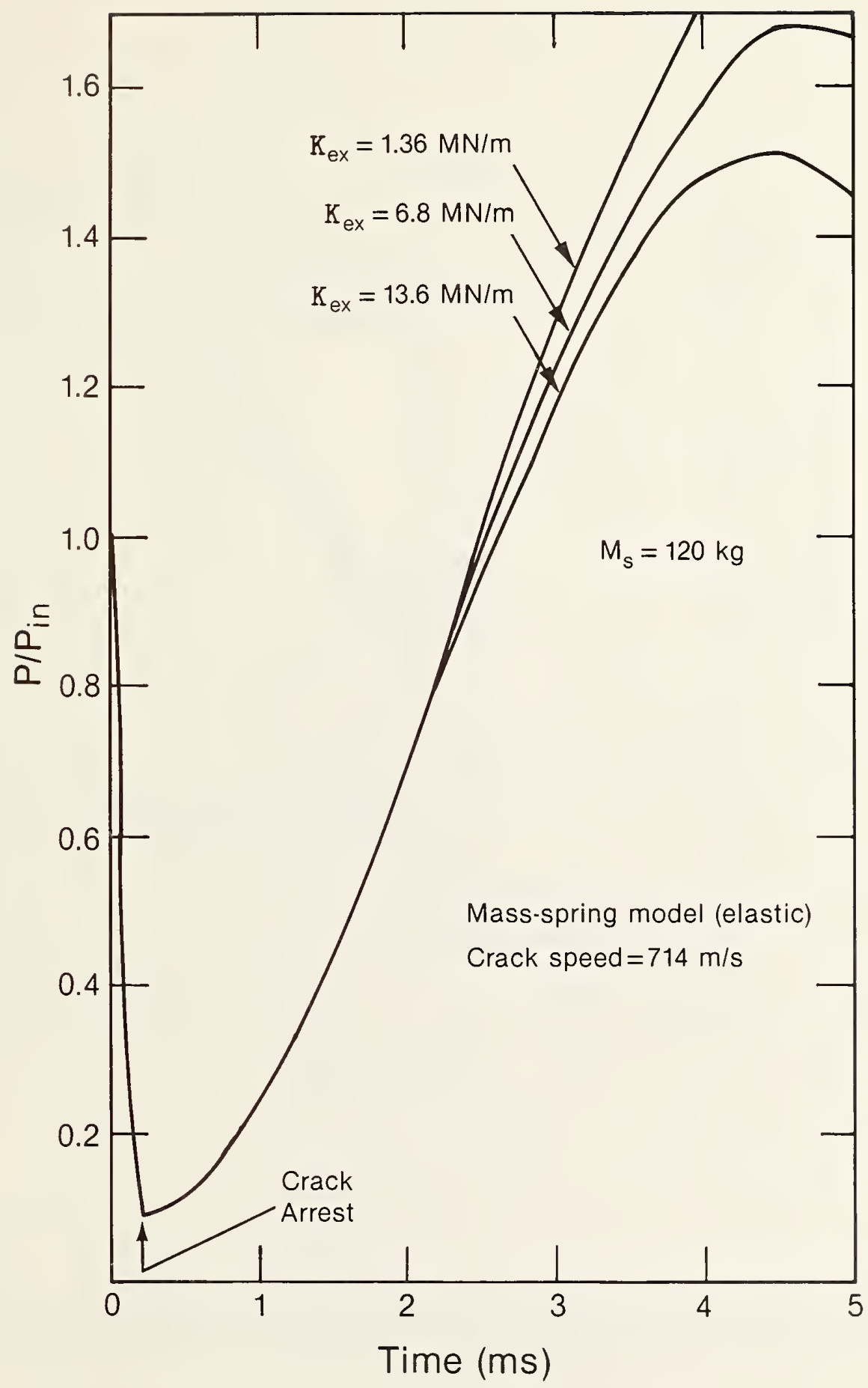

Figure 7. Changes of load with time due to spring stiffness, under conditions of compliant loading. 


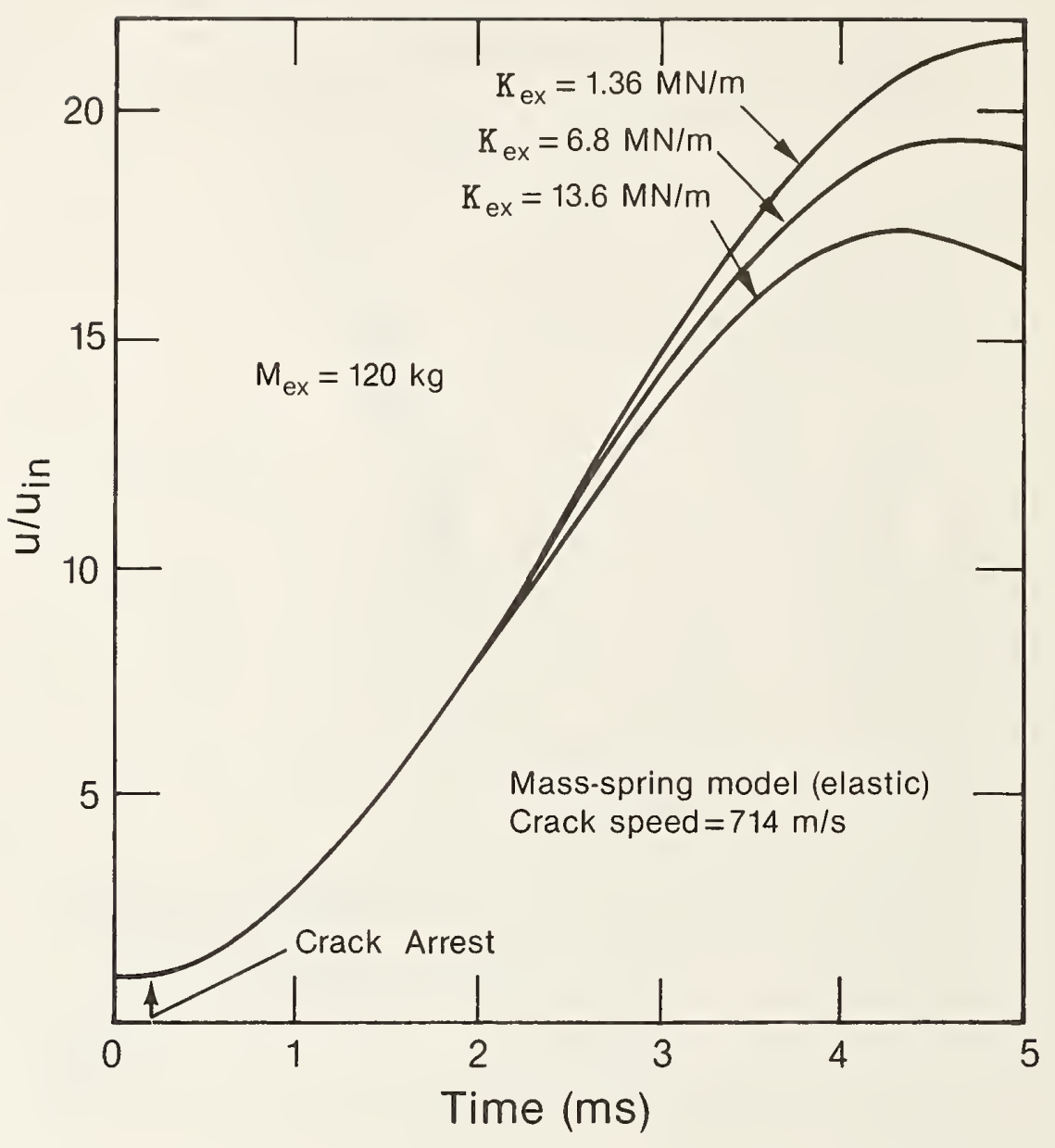

Figure 8. Changes of displacement with time due to spring stiffness, under conditions of compliant loading. 


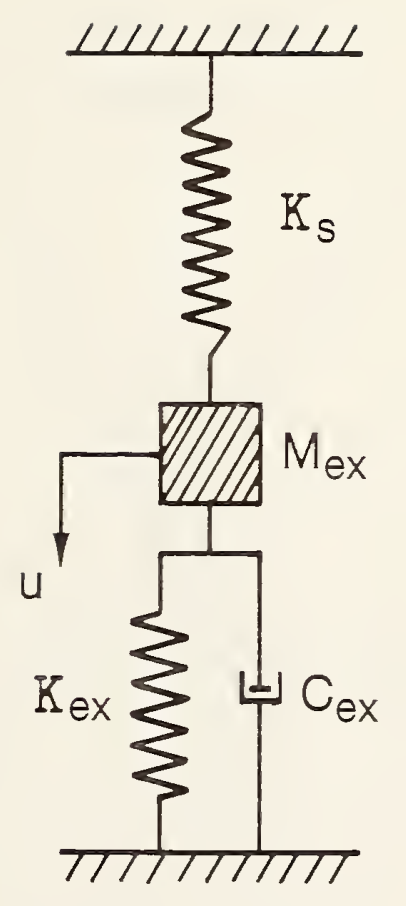

Figure 9. MS model with viscosity in the loading spring. 


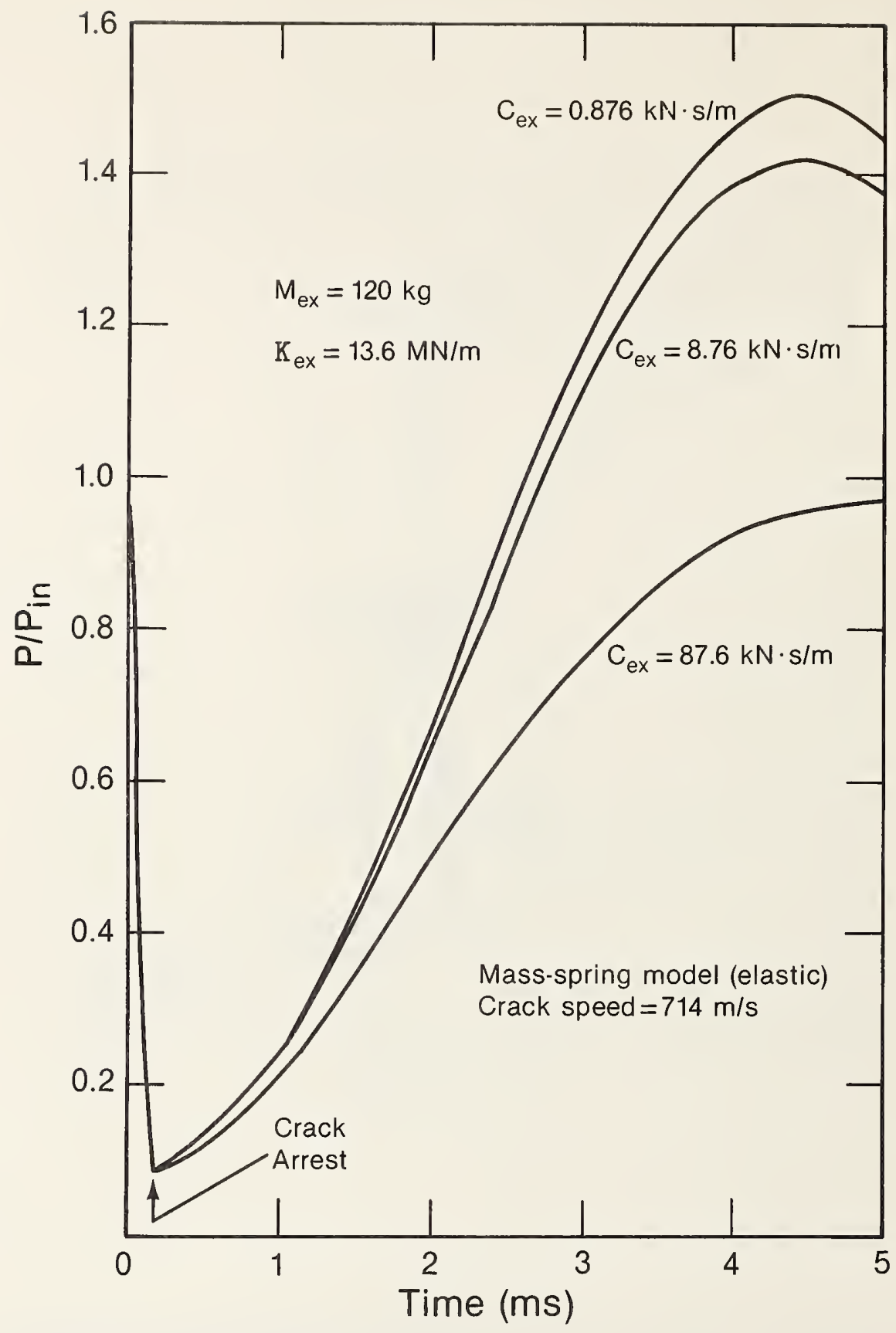

Figure 10. Changes of the load with time under conditions of compliant loading with a viscous spring. 


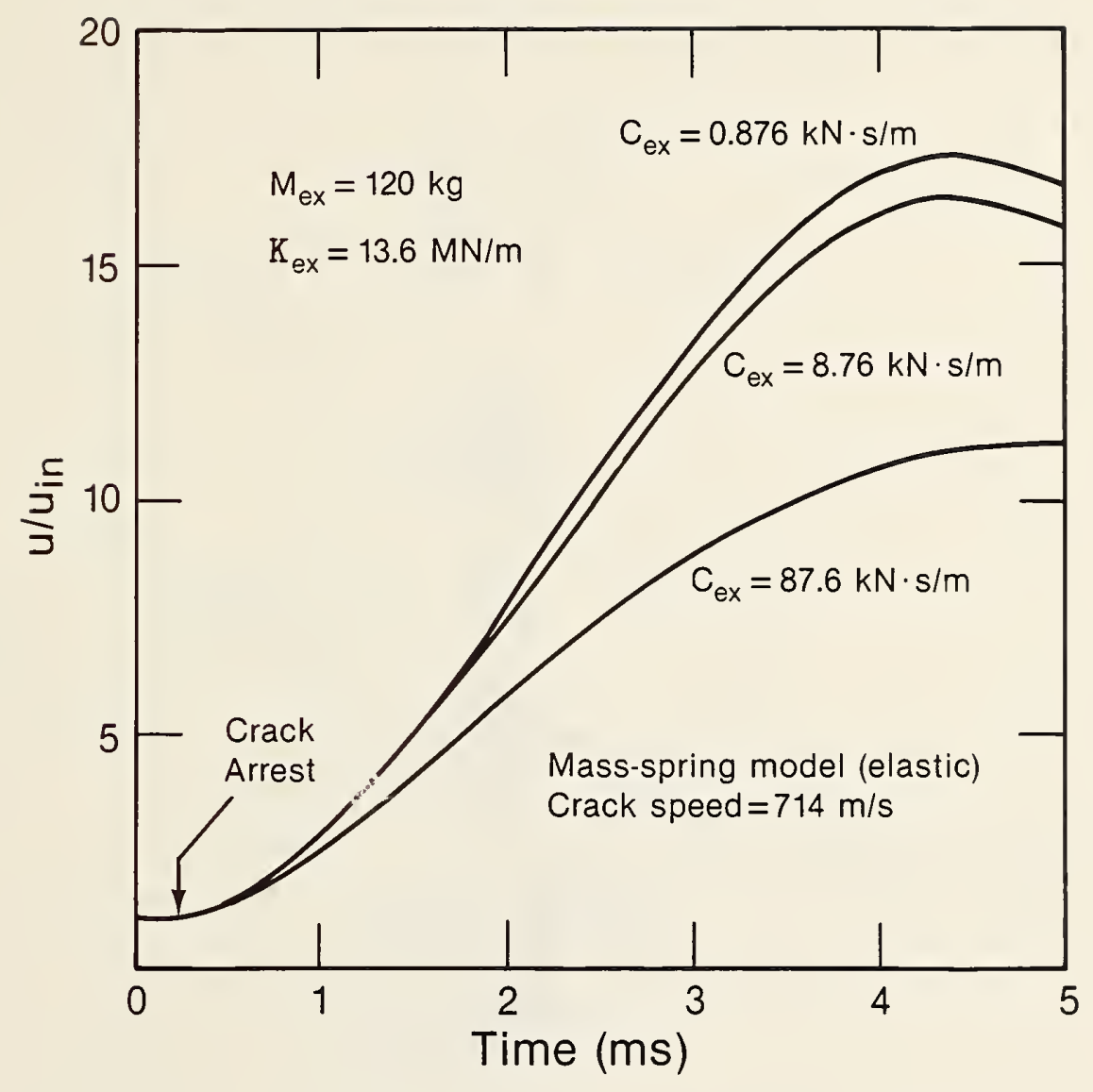

Figure 11. Changes of displacement with time under conditions of compliant loading with a viscous spring. 


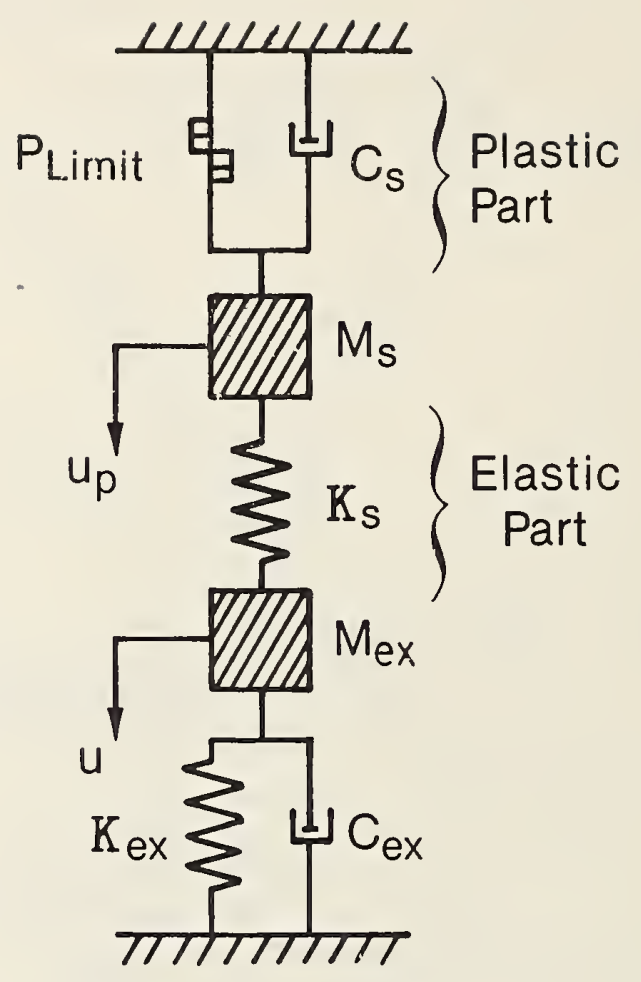

Figure 12. MS model with a viscous spring and yielding. 


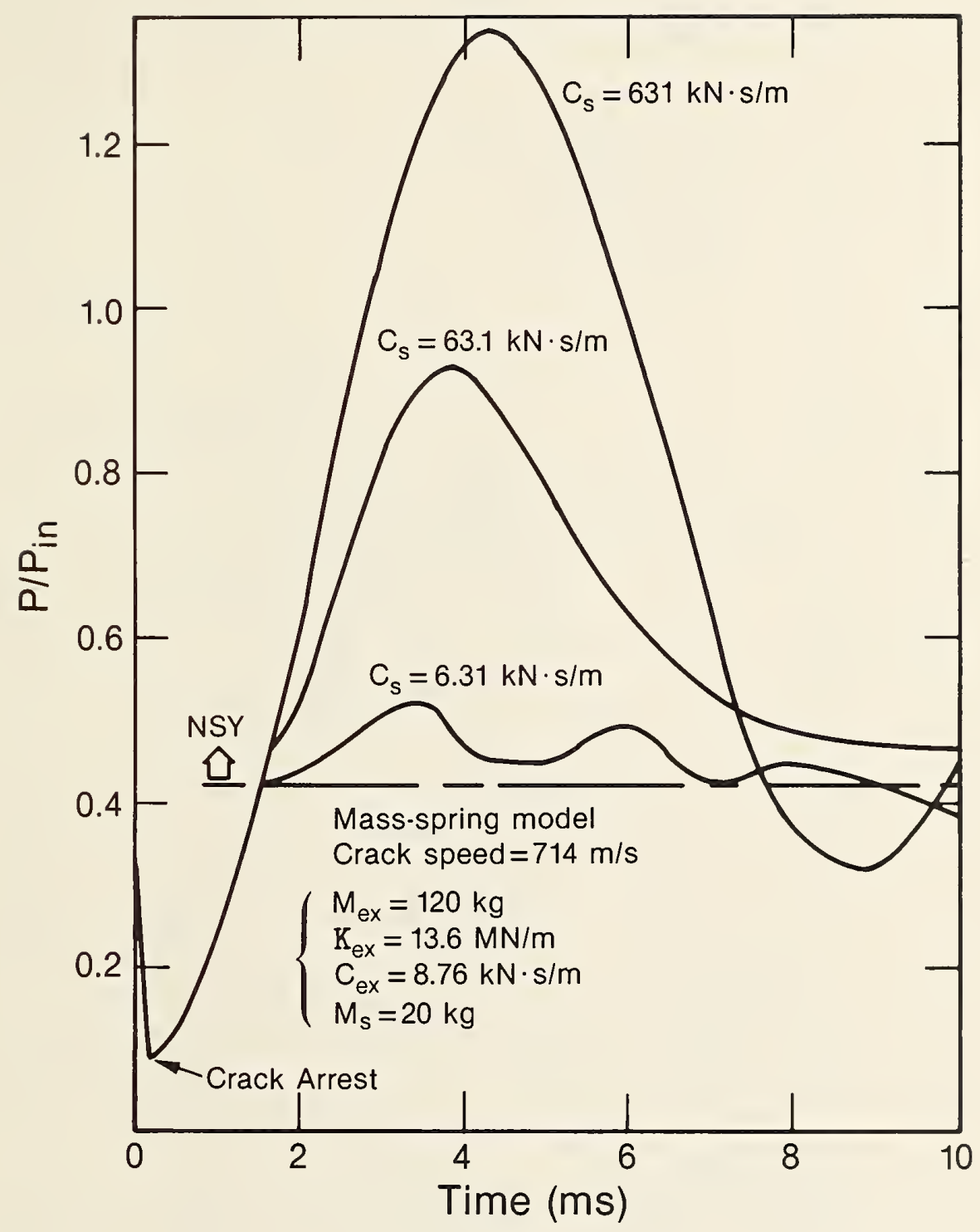

Figure 13. Changes of load with time under conditions of compliant loading with a viscous spring and yielding. 


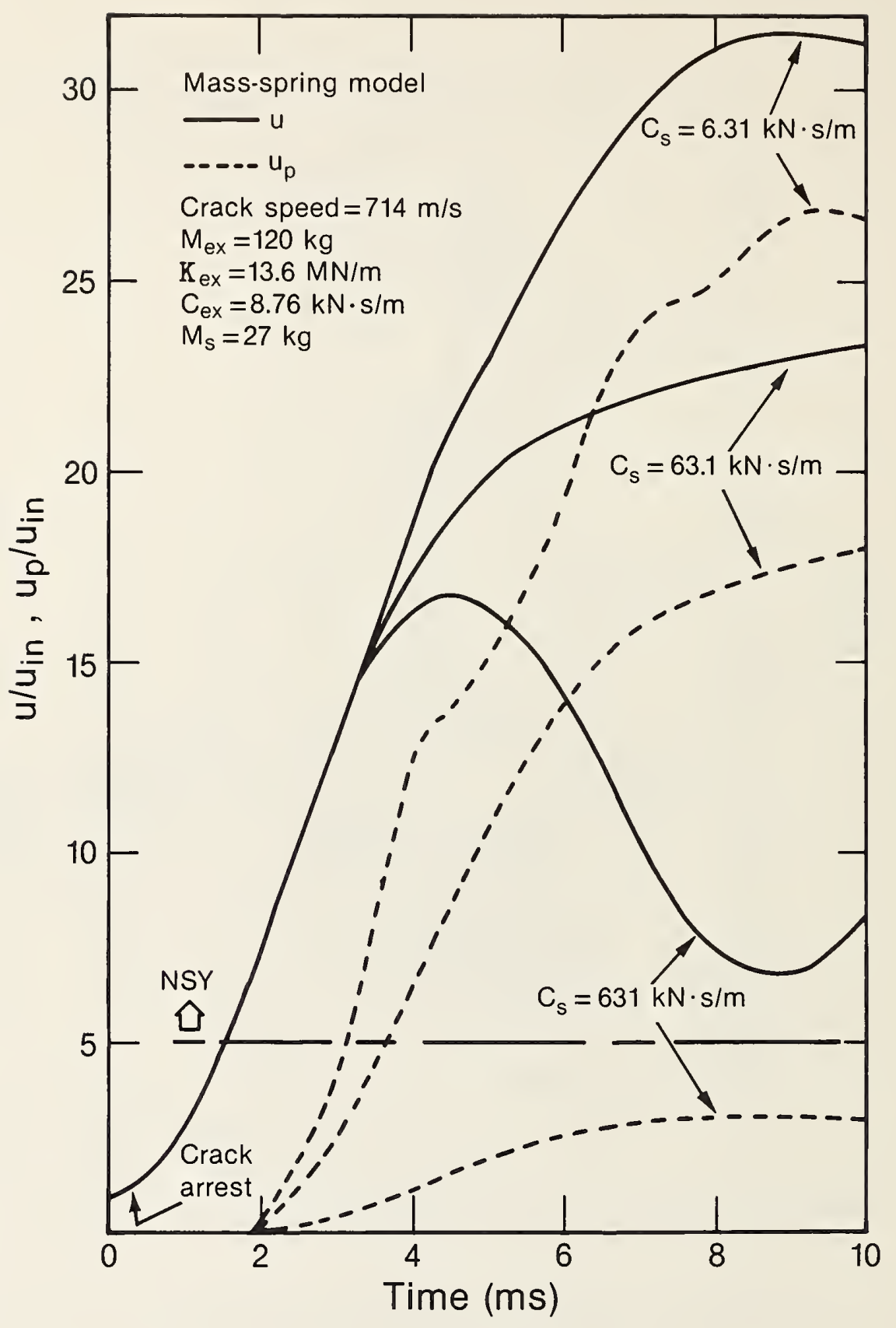

Figure 14. Changes of total and plastic displacements with time under conditions of compliant loading with a viscous spring and yielding. 


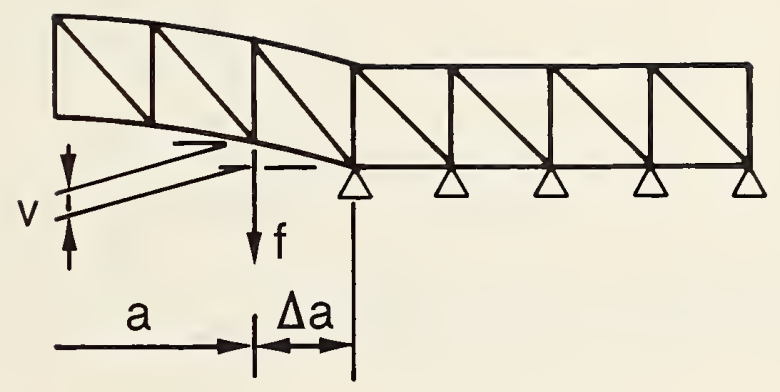

Figure 15. Crack tip neighborhood in the finite element model. 


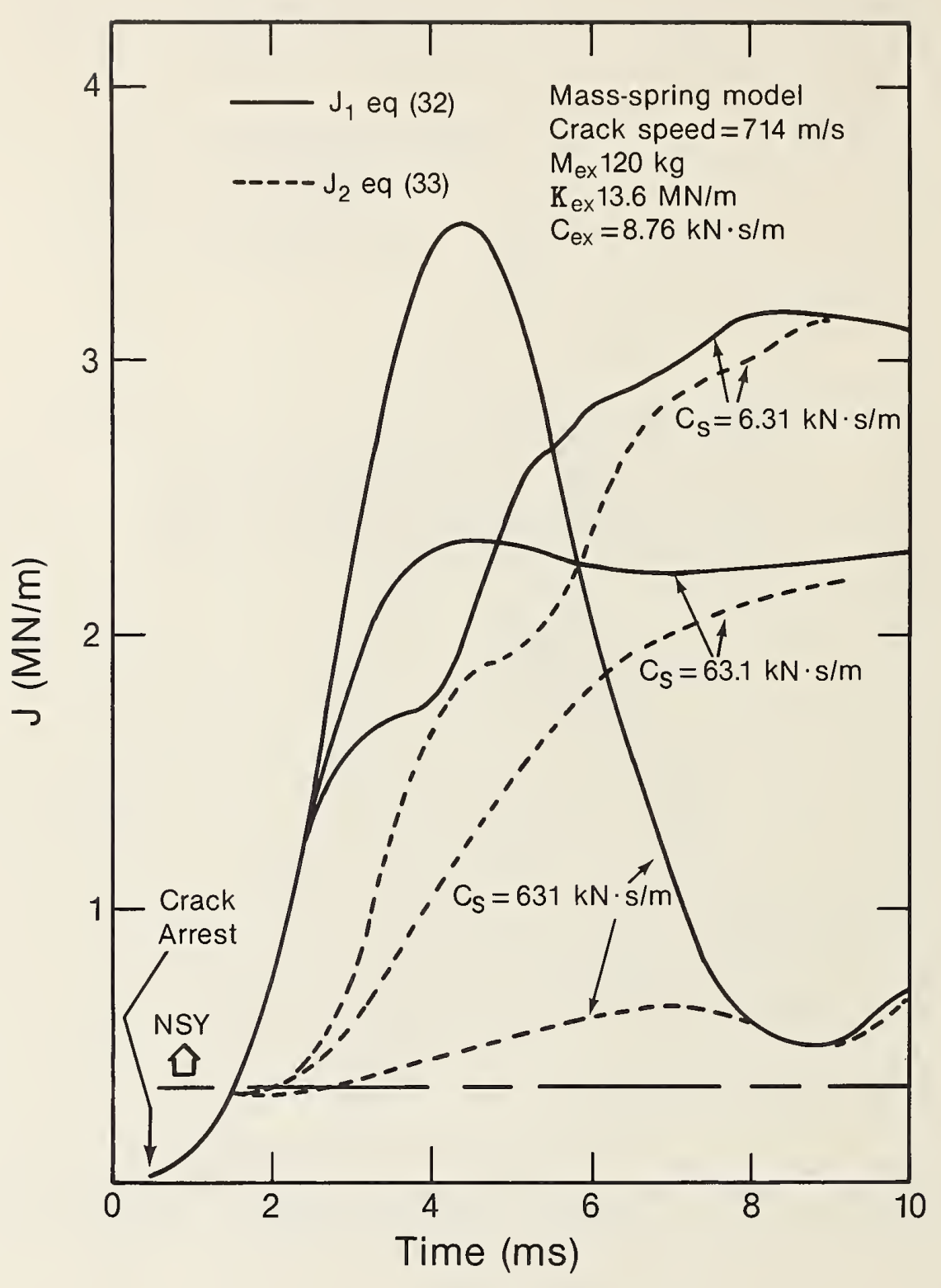

Figure 16. Change of $\mathrm{J}$ with time under conditions of compliant loading with a viscous spring and yielding, using eqs. (32) and (33). 
161 Elements

106 Nodes

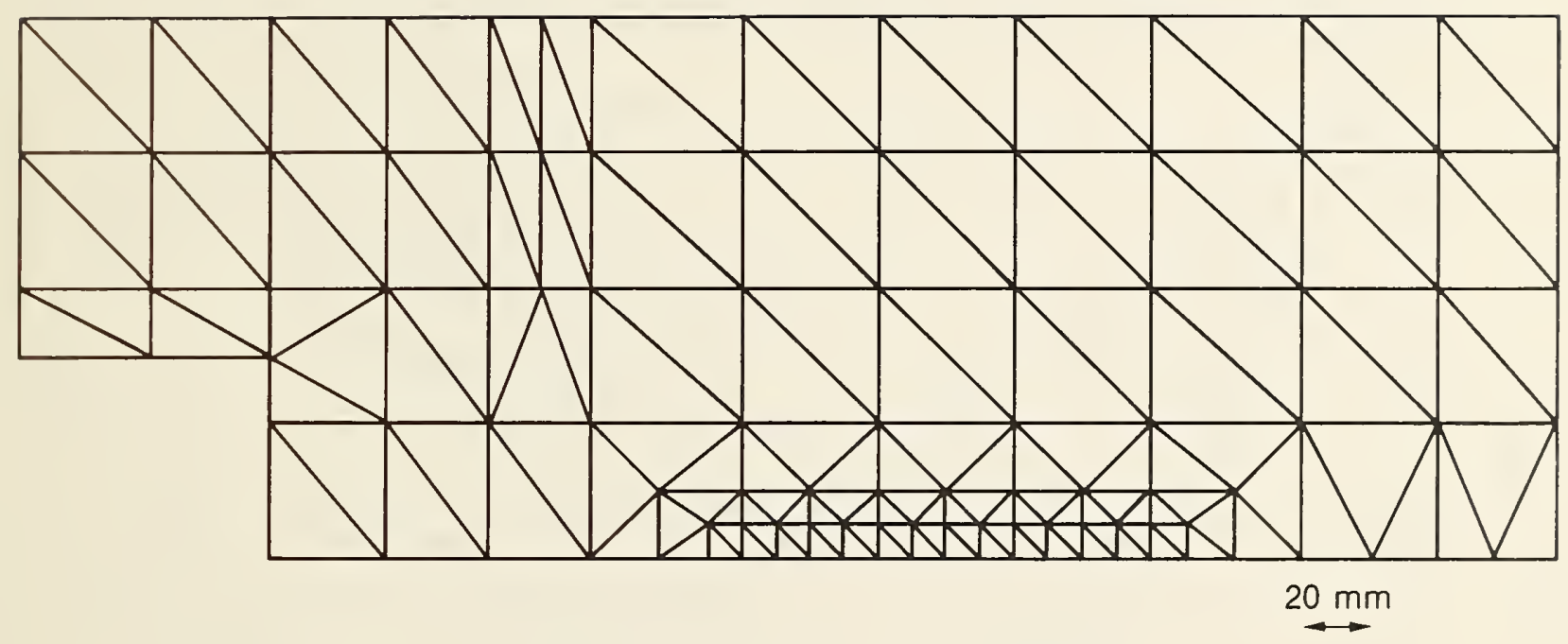

Figure 17. Finite element breakdown for the crack arrest-reinitiation test specimen. 


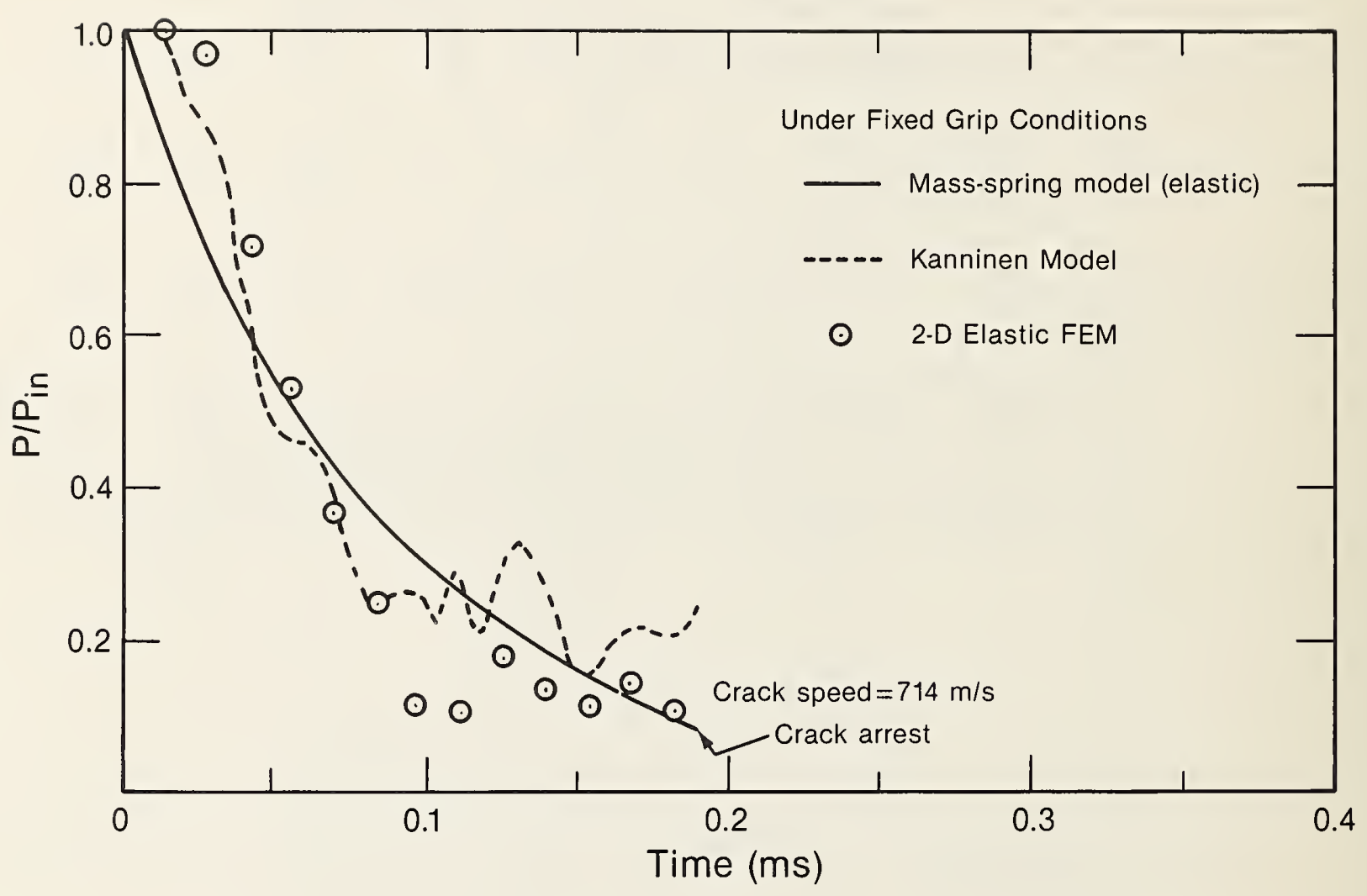

Figure 18. Comparison of load change with time between three different models under fixed-grip conditions. 


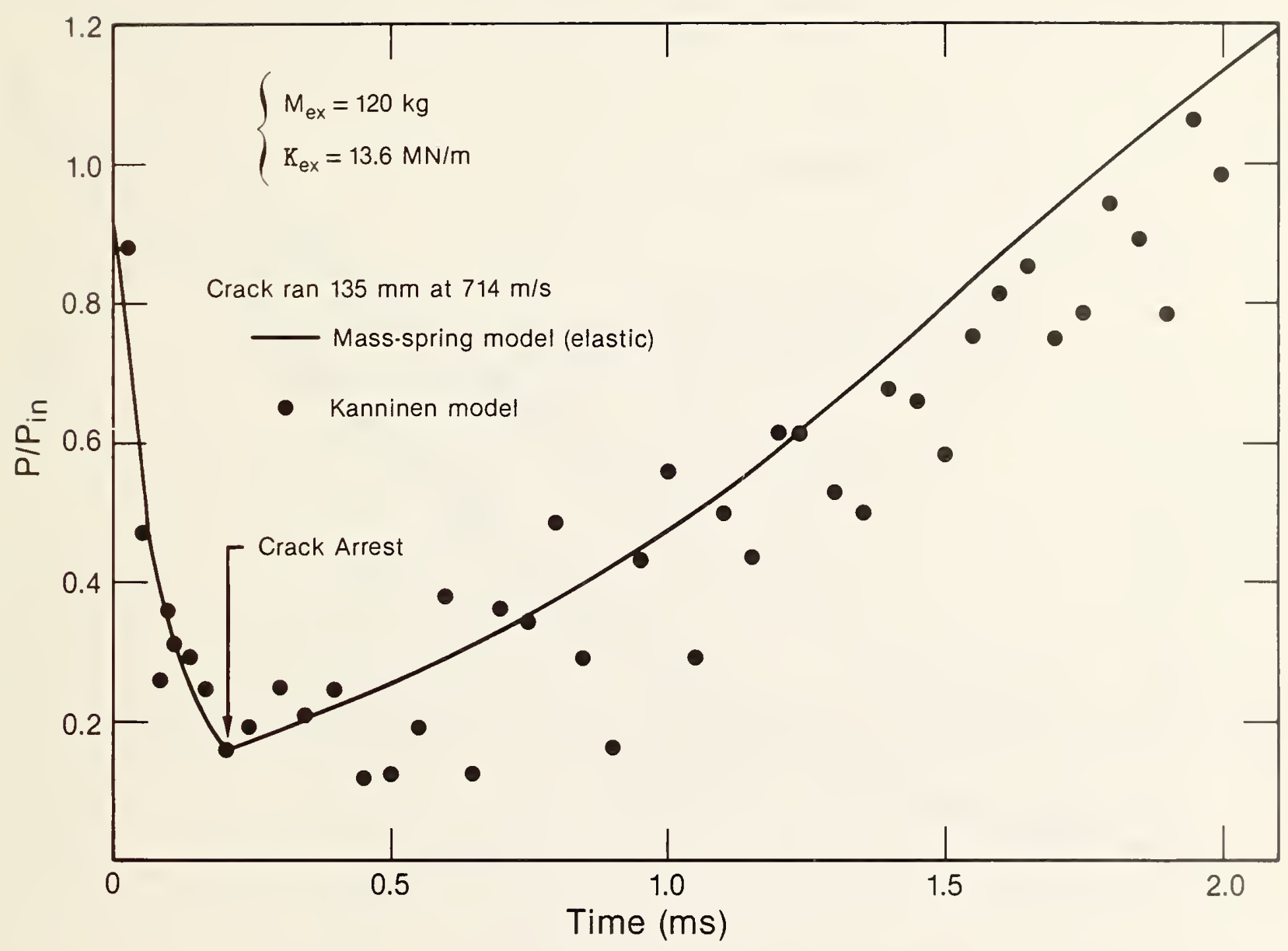

Figure 19. Comparison of load change with time between the MS and the Kanninen models under conditions of compliant loading. 


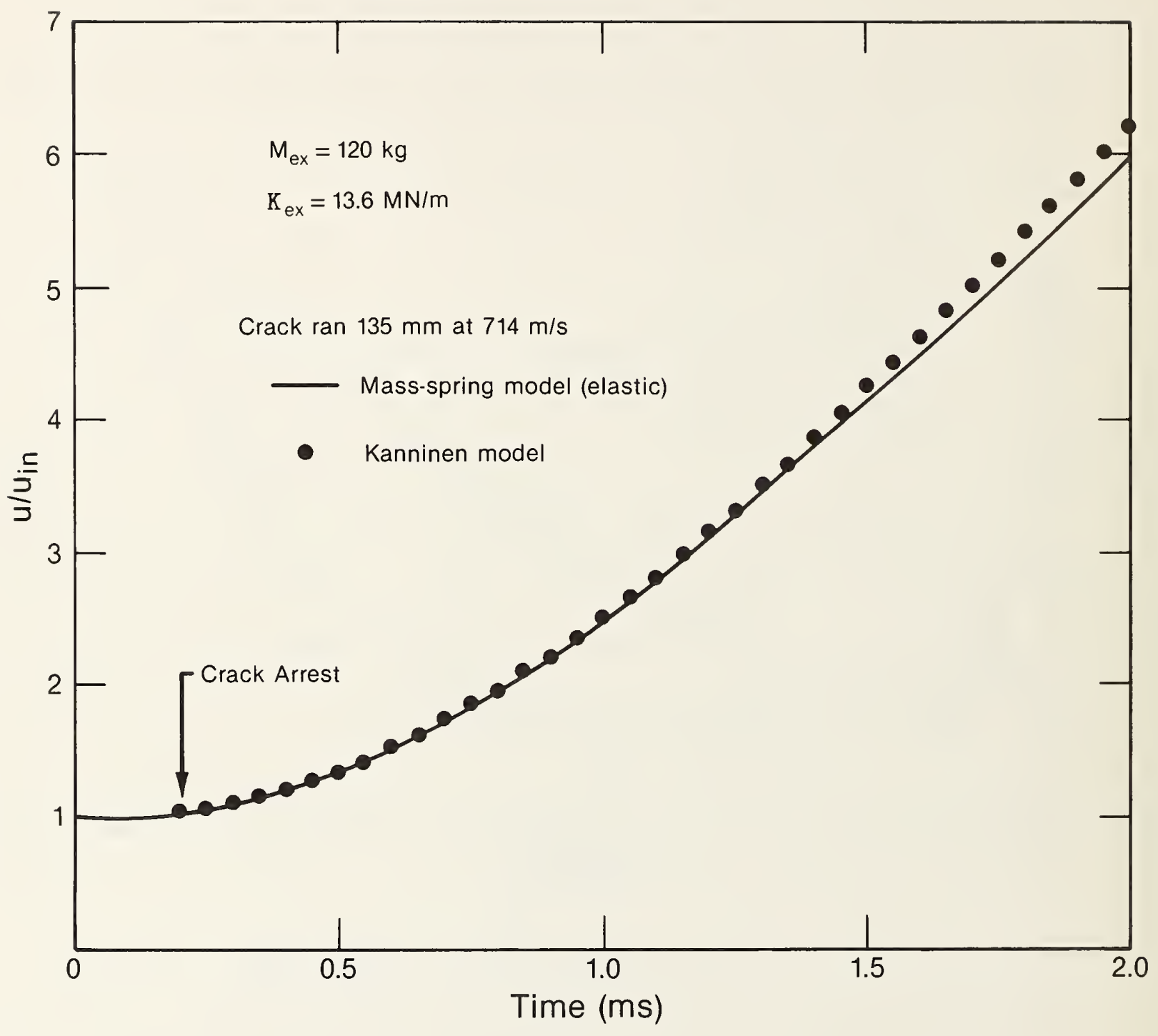

Figure 20. Comparison of displacement change with time between the MS and the Kanninen models under conditions of compliant loading. 


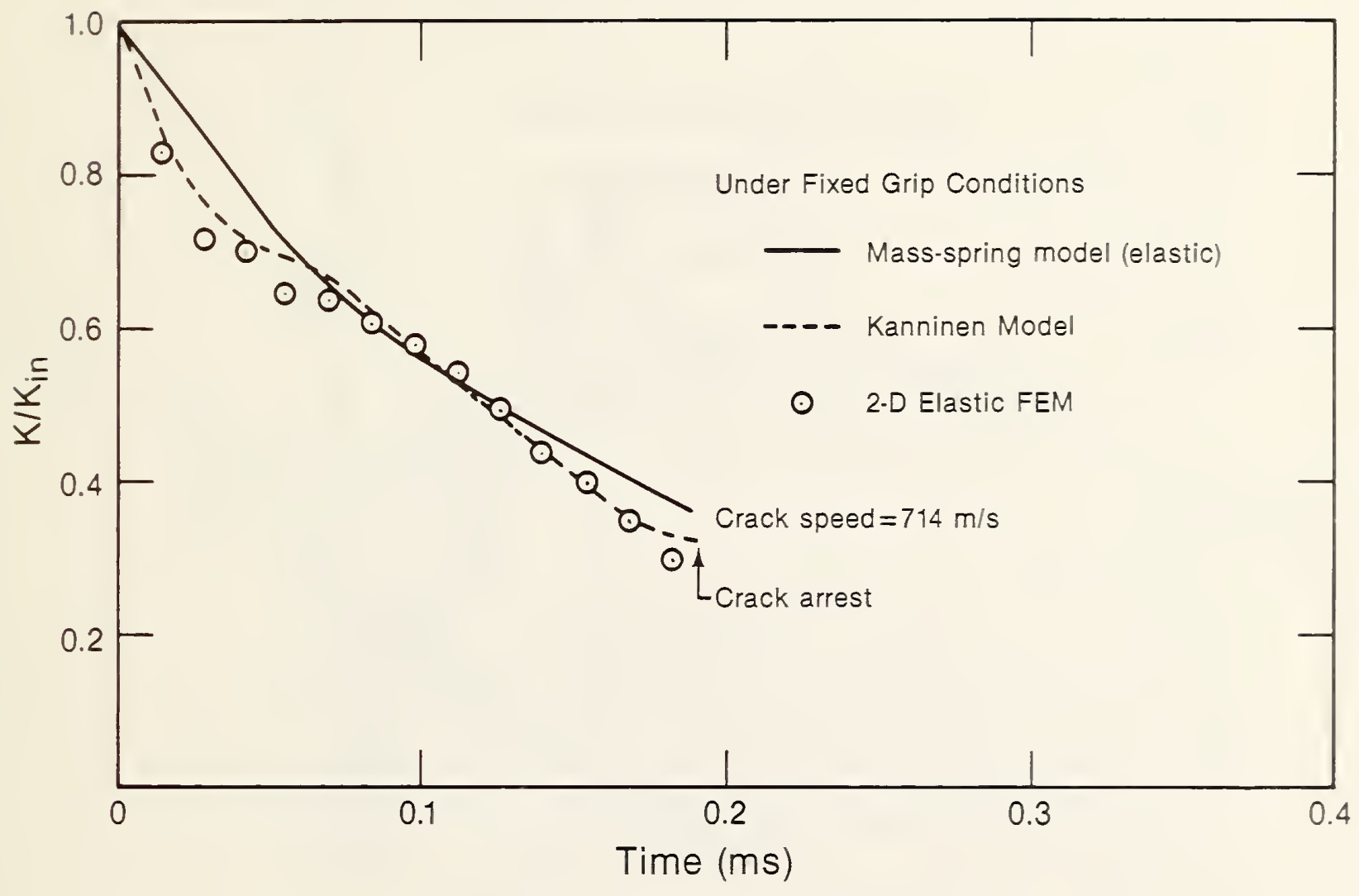

Figure 21. Comparison of change of $K$ with time between three different models under fixed-grip conditions. 


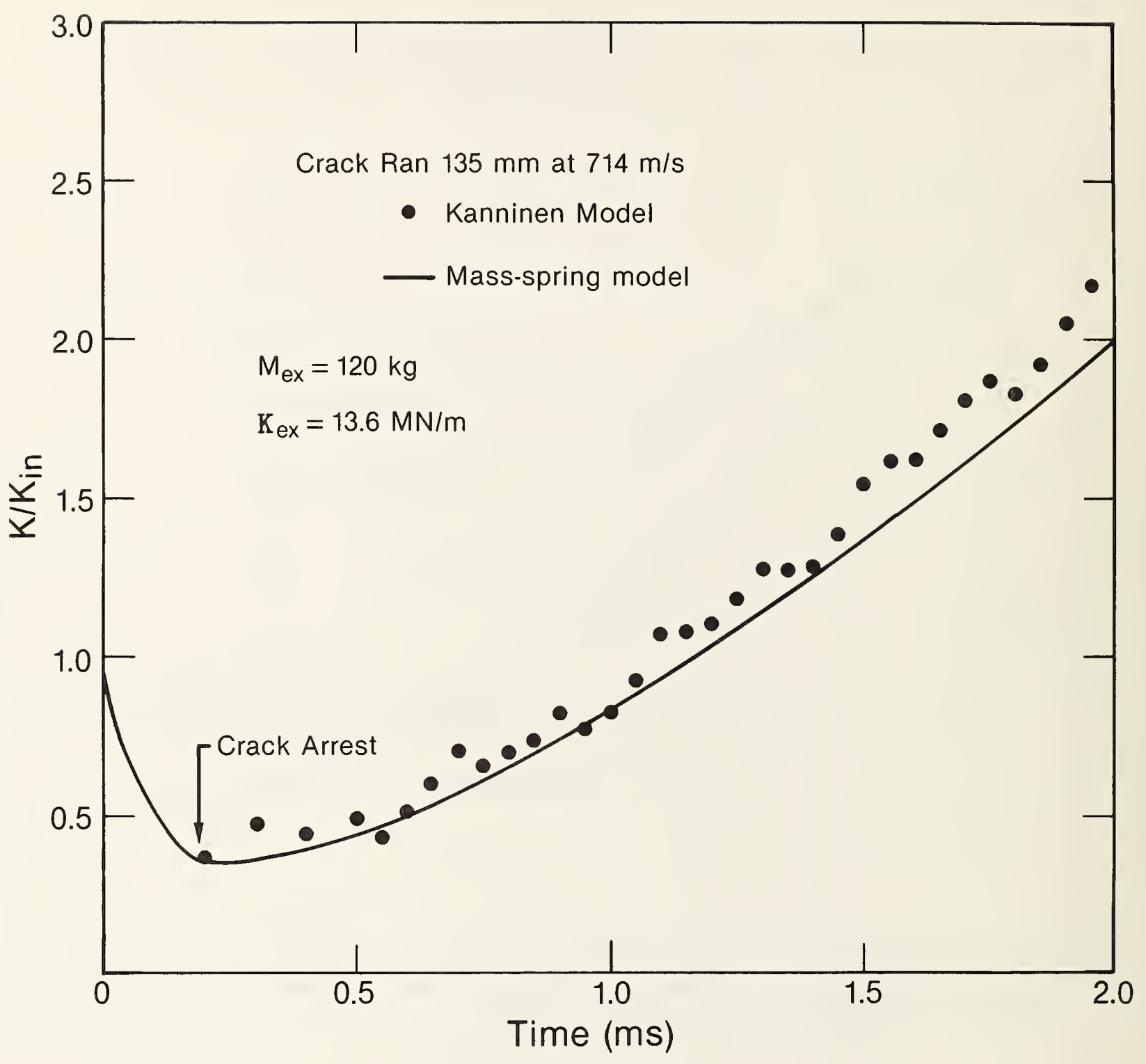

Figure 22. Comparison of change of $K$ with time between the MS and the Kanninen models under conditions of compliant loading. 


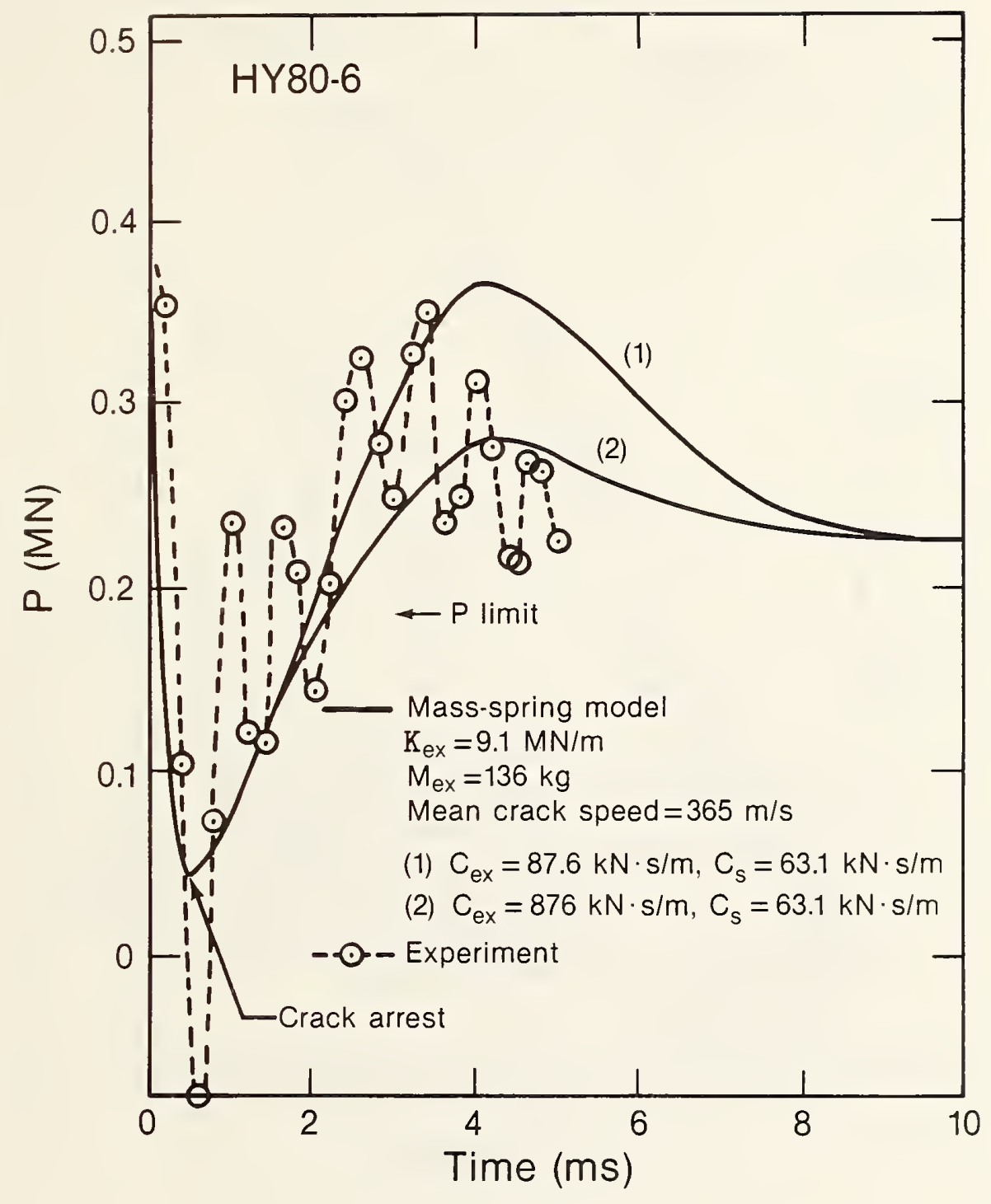

Figure 23. Comparison of numerical and experimental loads as functions of time using the MS model for HY80-6. 


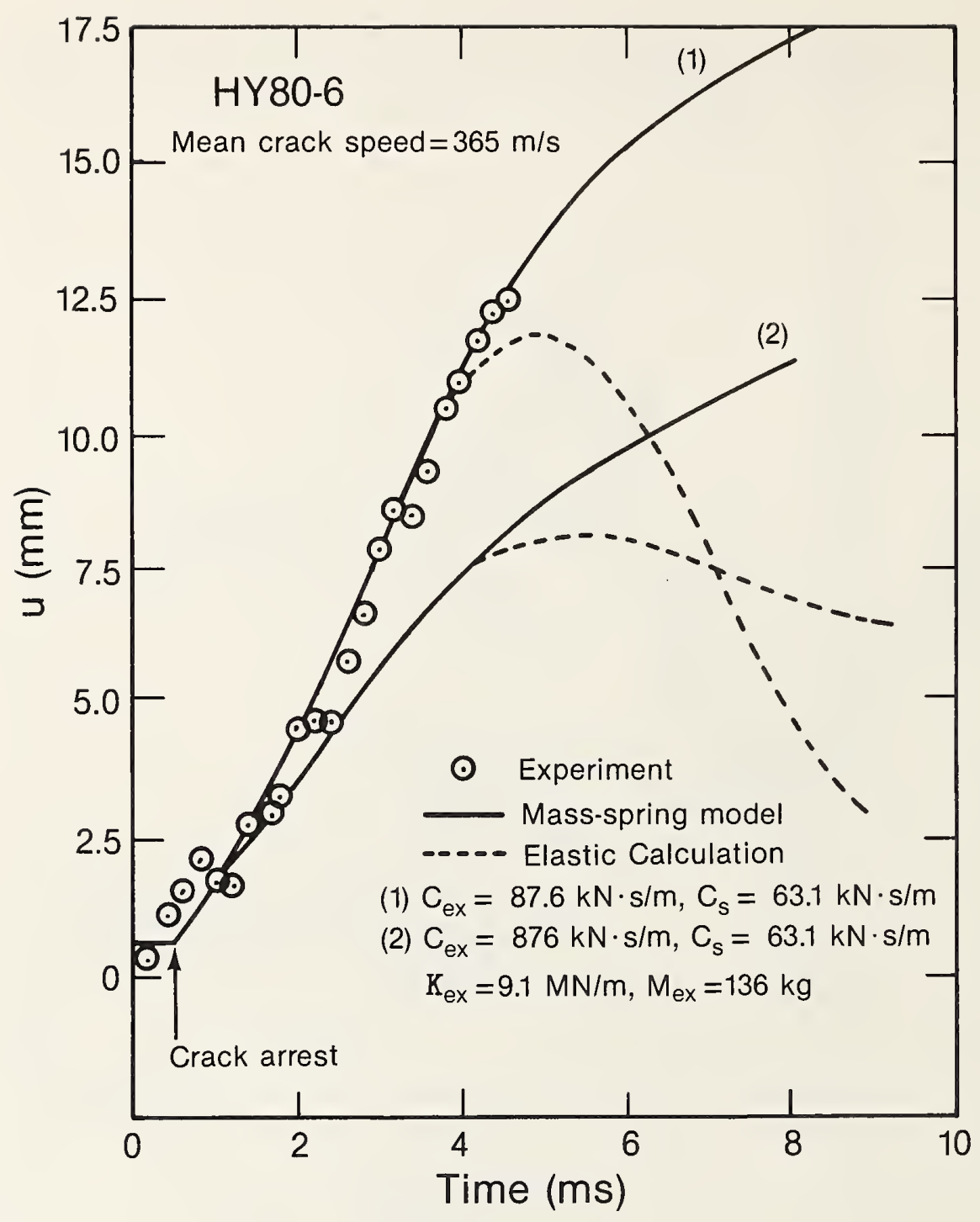

Figure 24. Comparison of numerical and experimental displacements as functions of time using the MS model for HY80-6. 


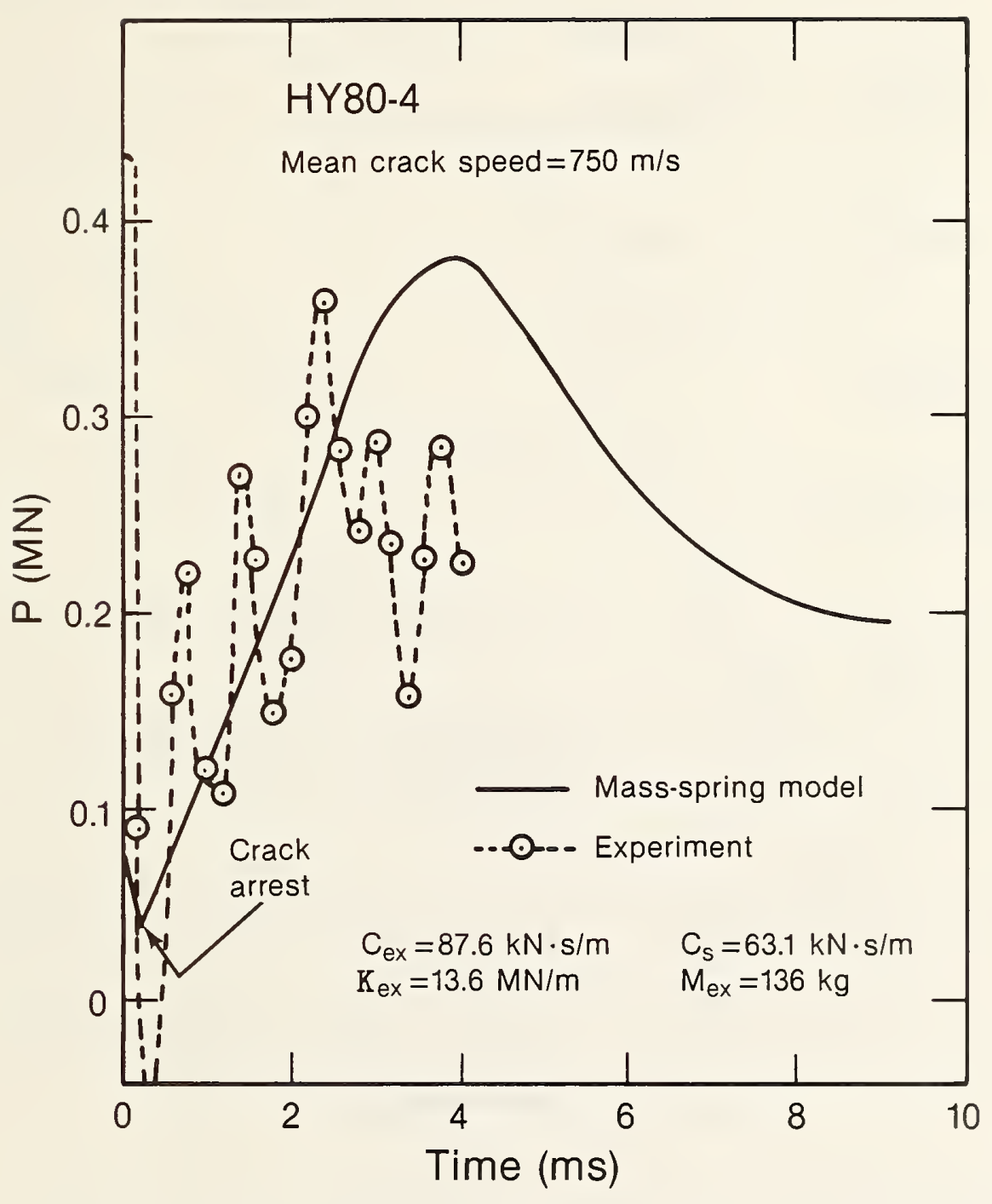

Figure 25. Comparison of numerical and experimental loads as functions of time using the MS model for HY80-4. 


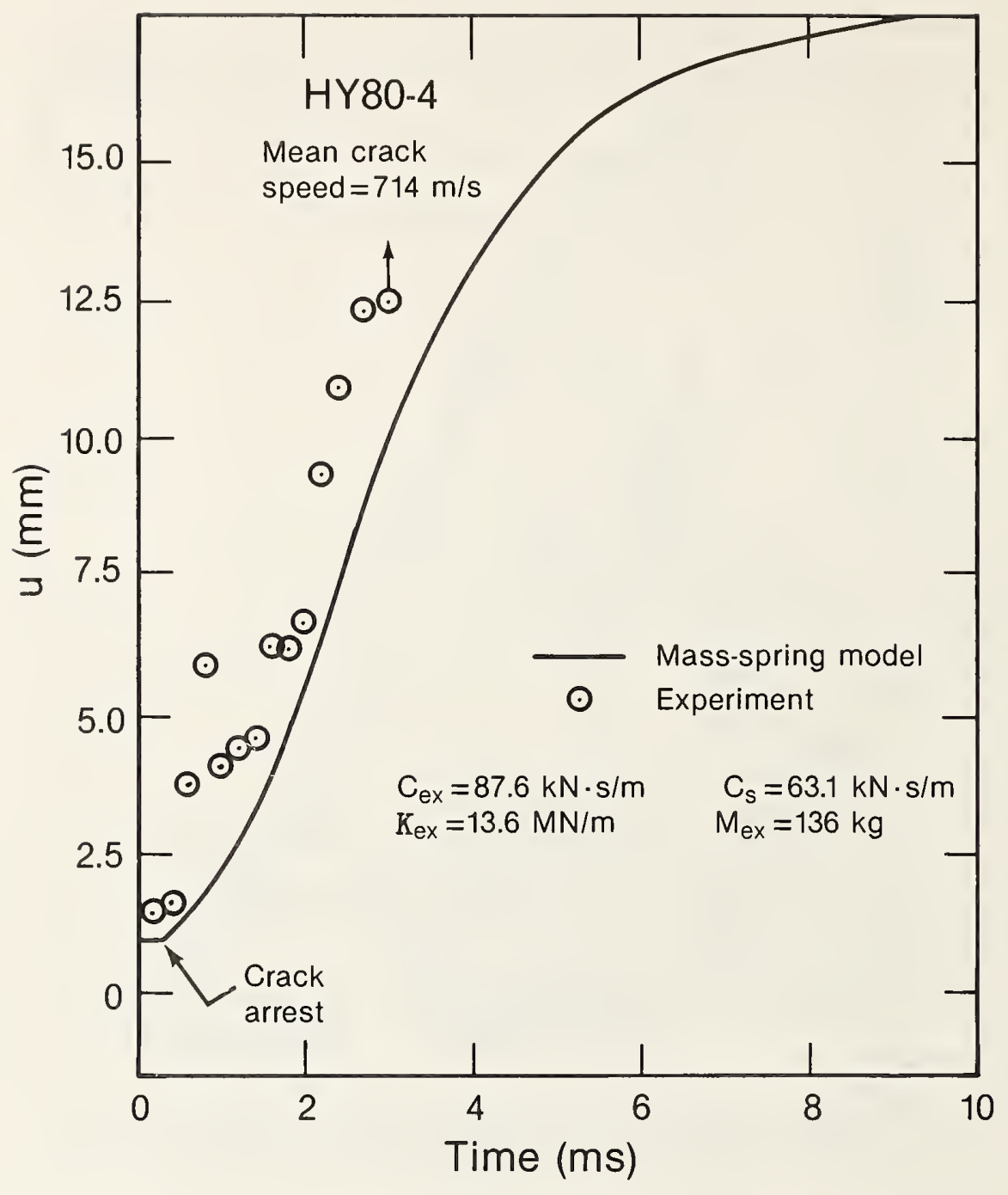

Figure 26. Comparison of numerical and experimental displacements as functions of time using the MS model for HY80-4. 


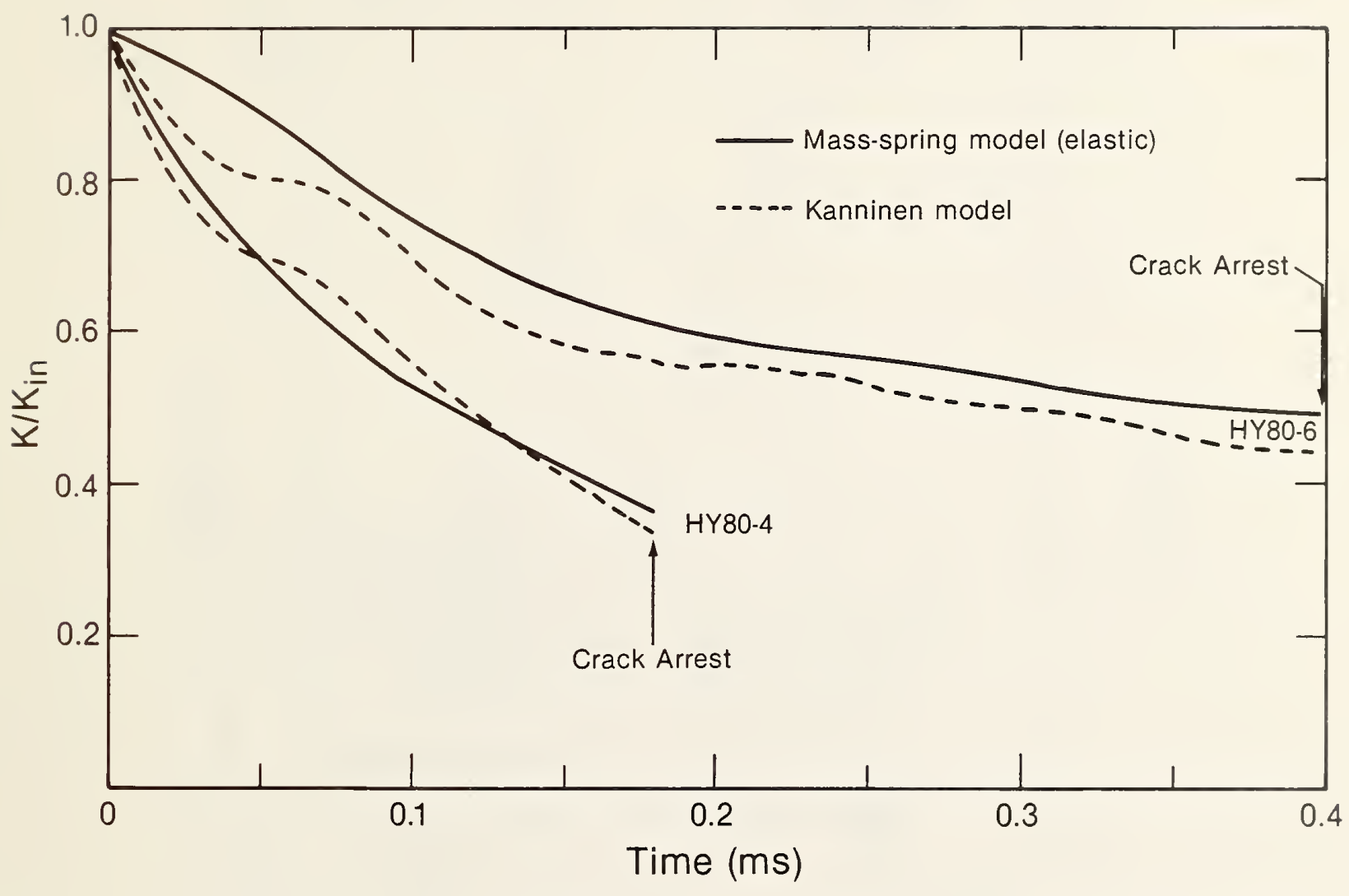

Figure 27. Cornparison of changes of $\mathrm{K}$ with time in the MS and Kanninen models for HY80-4 and HY80-6. 


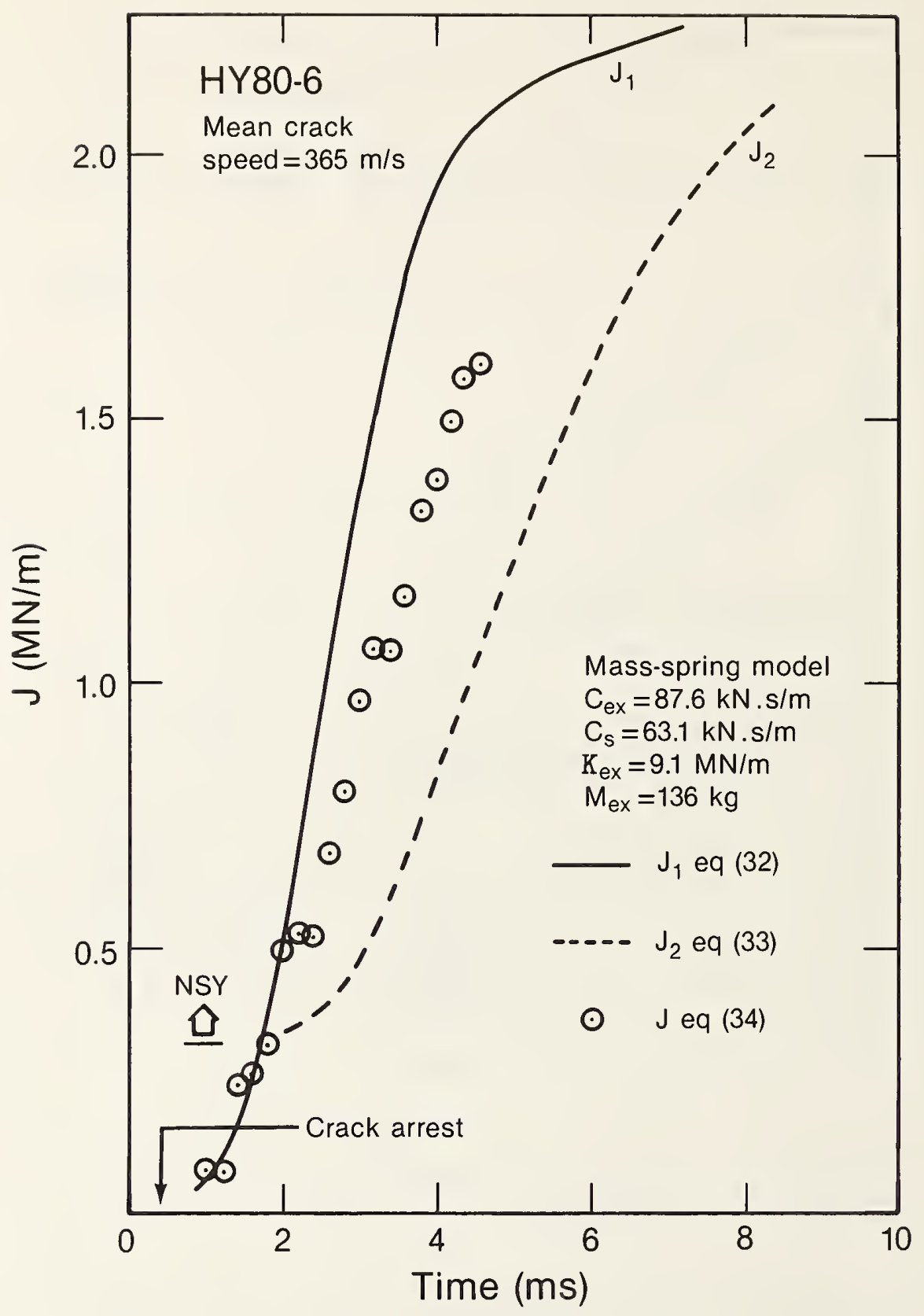

Figure 28. Comparison of changes of $J$ with time obtained by the IIS model, eas. (32) and (33), and by experiment, eq. (34), for HY80-6. 


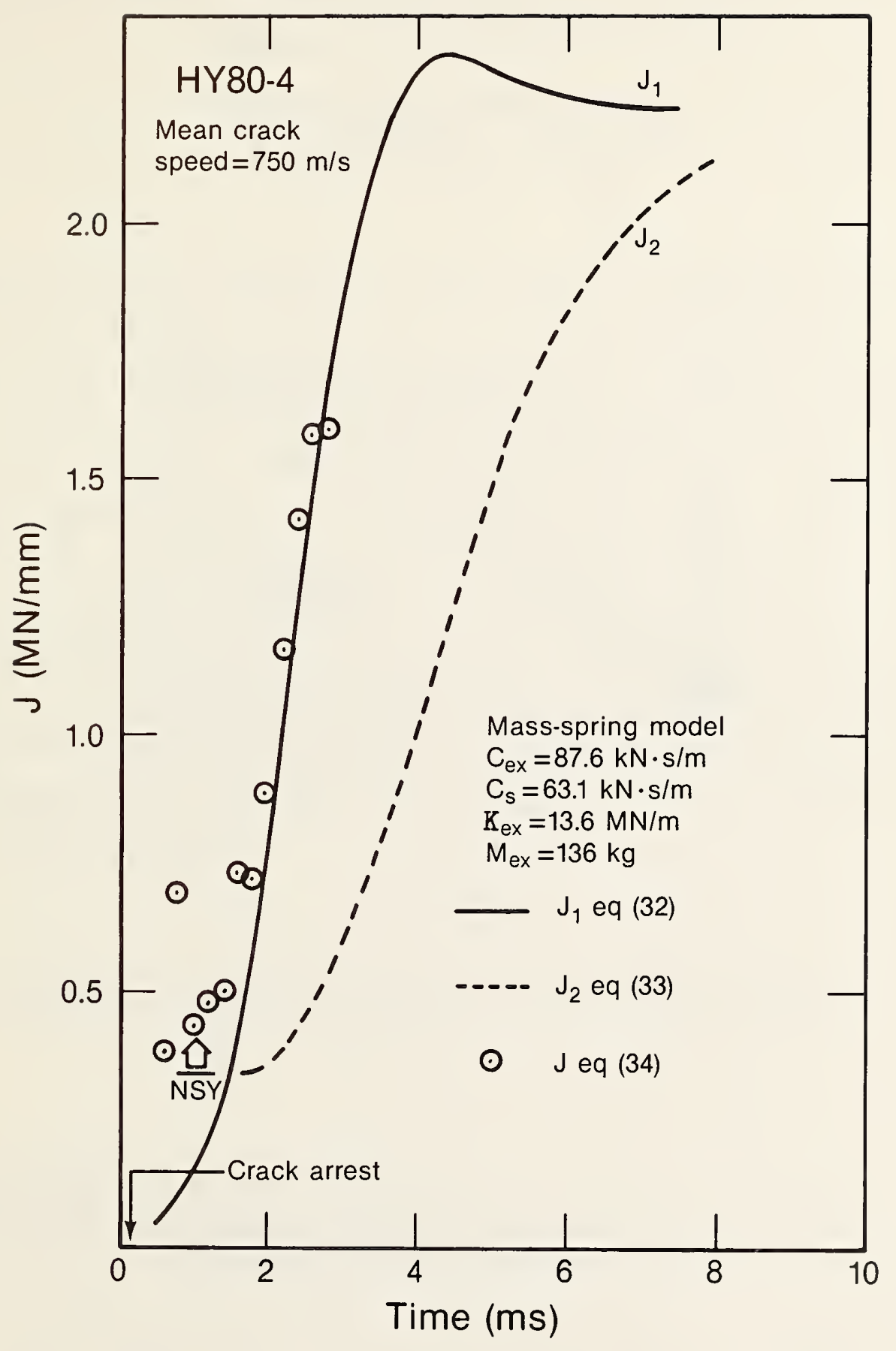

Figure 29. Comparison of changes of $J$ with time obtained by the MS model, eqs. (32) and (33), and by experiment, eq. (34), for HY80-4. 


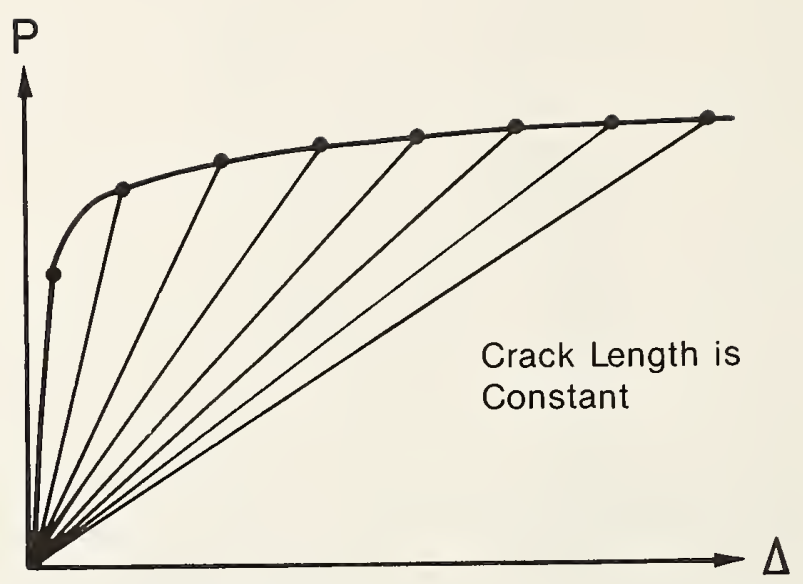

Figure 30. Schematic load-displacement characteristic for a specimen with a large plastic zone before net section yielding, and straight lines corresponding to a series of spring constants. 
II. CRACK ARREST EXPERIMENTS AND ANALYSIS WITH RISING K FIELD

T. Teramoto, D.T. Read, and R.B. King

Fracture and Deformation Division

National Bureau of Standards

Boulder, Colorado 80303

Because of recent interest in crack arrest in situations where the applied stress intensity $K$ increases with crack length ( $r$ ising $K$ field), experiments to allow observation of dynamic crack propagation and arrest in a rising $\mathrm{K}$ field have been designed, performed, and analyzed. Both crack arrest and complete dynamic fracture with no arrest were observed by changing the specimen temperature and the applied load. Therefore, this experiment was sensitive to the crack arrest toughness of the specimen material. It was concluded that using a mechanical spring in the load train effectively simulates possible structural compliance, and can cause reinitiation of a temporarily arrested crack. Finite element analysis and a simple mass-spring model were used to extract fracture mechanics parameters, including stress intensity for elastic behavior and J-integral for elastic-plastic behavior.

Key words: dynamic crack arrest; dynamic crack propagation; elastic-plastic; fracture; J-integral; mass spring model; rising $\mathrm{K}$; side groove

\section{INTRODUCTION}

High toughness crack arresters are commonly inserted at critical locations in ships so that unstable (brittle) fracture, if initiated, can be stopped. When a crack runs in brittle plate and meets a tough crack arrester, arrest occurs because of the step in toughness. In conventional crack-arrest testing, arrest occurs in a toughness gradient produced by a thermal gradient. For sufficiently long crack jumps, after crack arrest the 
recovered load is applied to the short uncracked ligament, and significant extension of the plastic zone is anticipated. Linear elastic fracture mechanics is invalid for characterizing crack tip behavior after the initial arrest because of plastic strain effects.

A new specimen has allowed observation of the crack run-arrest event in a rising $K$ (stress intensity) field. The experiments are analyzed on the basis of a dynamic, linear elastic, finite element method (FEM) model and a simple mass-spring (MS) model. The fracture parameters relevant during and after crack arrest are calculated using the MS model. This model takes into account inertia, plasticity, and strain-rate-induced elevation of flow strength.

\section{SPECIMEN}

In order to achieve a rising $\mathrm{K}$ field, the specimen configuration of Fig. 1 was chosen. This specimen is divided into two parts: the crack initiation part, under jack loading, and the crack propagation and arrest part, under the main load. Variable dimensions of the specimen are listed in Table 1. A preliminary static, linear elastic FEM analysis was performed using conventional techniques. Figure 2 shows the stress distributions along the crack propagation line. The combined stress is positive everywhere, although the stress distribution from the jack load alone is partly negative ahead of the starting crack tip. The maximum stress appears at the initial crack tip. Stress curves are given for various values of the average stress, $\sigma_{0}$, defined as main load divided by gross cross-sectional area, and the static intensity, $\mathrm{K}_{\mathrm{S}}$, at the initial crack tip.

Figure 3 shows the variation with crack length of stress intensity under static conditions, $\mathrm{K}_{\mathrm{S}}$, produced by the main load and the jack load. The differences between fixed-grip and fixed-load conditions grow with crack length. The total $\mathrm{K}_{\mathrm{S}}$ distribution includes contributions from the main load and from the jack load. $\mathrm{K}_{\mathrm{S}}$ values are given for several values of average stress $\sigma_{0}$. The stress intensity at crack initiation is controlled almost entirely by the jack load.

Electron beam (EB) melting was used in an attempt to produce a brittle crack propagation path in the EH36 carbon-manganese steel specimen material 
[1]. It was expected, from a previous study of a nickel steel, that a step in toughness would be produced between virgin material and EB-melted material. However, this proved not to be the case; therefore, the specimens were grooved all along one side to provide a crack path, and arrest occurred in a thermal gradient.

\section{ANALYTICAL METHODS}

\subsection{Finite Element Model}

A conventional finite element model (FEM), consisting of constant strain triangular elements, was employed to analyze dynamic crack propagation and arrest behavior. Linear elastic analysis was used. The equations of motion of each element were synthesized into an equation of motion of the whole specimen as follows:

$$
[M]\{\ddot{u}\}+[\kappa]\{u\}=\{f\},
$$

where [M] and [K] are mass and stiffness matrices, respectively, and $\{\ddot{u}\}$, $\{u\}$ and $\{f\}$ are the acceleration, displacement and force vectors of model points. Eq. (1) was solved by Newmark's $B$ method using $\beta=1 / 4$.

All four specimens were analyzed using a dynamic elastic FEM, since the crack behavior was assumed to be elastic at least during crack propagation. Figures 4 (a) and (b) show the finite element breakdown of the specimens. The crack tip position vs time relation was employed as an input condition in the FEM computations. The external mass and the loading spring stiffness were assumed to be $120 \mathrm{~kg}$ and $13.6 \mathrm{MN} / \mathrm{m}$, respectively.

crack extension was numerically simulated as follows. A crack was propagated through the FEM idealization at a preselected velocity. The reaction force, $f$, of the node corresponding to the crack tip (Fig. 5) was decreased gradually and vanished when the crack reached the next node. The stress intensity was obtained from the work done by the reaction force. The dissipated energy, $D$, is

$$
D=\int f d v
$$


where $d v$ is the increment of crack opening displacement of the node behind the crack tip. Then the dynamic stress intensity, $K_{D}$, was obtained from [2]

$$
K_{D}=[(E / B \Delta a) \& f d v]^{1 / 2},
$$

where $\Delta a$ is the crack growth step. E and B are Young's modulus and specimen thickness, respectively. After crack arrest, $K_{D}$ is evaluated by Keegstra's technique [3] as follows:

$$
K_{D}=6.414 \mathrm{f}(2 \Delta \mathrm{a} / \pi)^{1 / 2 / B}
$$

\subsection{Mass-Spring Model [4]}

Although the dynamic, linear elastic FEM model is the best method for treatment of rapid crack propagation and initial arrest, which occur under predominantly linear elastic conditions, the model cannot treat reinitiation. Dynamic, elastic-plastic FEM models are cumbersome and expensive. Accordingly, a simplified mass spring (MS) model has been developed [3]; it can account for both linear elastic and plastic strain effects.

Since elastic behavior is dominant during initial rapid crack propagation, the simple elastic mass spring model (Fig. 6) was also used to analyze this phase of the crack propagation. The equation of motion is

$$
M_{e x} \ddot{u}+\left(\kappa_{e x}+\kappa_{S}\right) u=k_{e x} u_{A},
$$

where $\ddot{\mathrm{u}}$ and $\mathrm{u}$ are acceleration and displacement, respectively, of the load point in the specimen. $M_{e x}$ and $\kappa_{e x}$ are external mass and spring stiffness. $u_{A}$ is initially applied displacement. $\kappa_{S}$ means the stiffness at the load point of the specimen, varying with crack length. $\kappa_{S}$ is given for the specimen with side groove (side groove depth is $7.62 \mathrm{~mm}$ ) as

$$
\begin{aligned}
\kappa_{S} & =\left[686.76-46.797(a / w)-544.39(a / w)^{2}\right. \\
& \left.+174.72(a / W)^{3}-8408.4(a / W)^{4}+10151.0(a / W)^{5}\right](M N / m)
\end{aligned}
$$


where $a$ is crack length and $W$ is the specimen width ( $=260 \mathrm{~mm})$. Stress intensity (static) is given as

$$
\begin{aligned}
& K_{S}=P\left[69.647+158.99(a / W)+324.21(a / W)^{2}\right. \\
& \left.+446.22(a / W)^{3}+624.45(a / W)^{4}+897.28(a / W)^{5}\right](M P a / m),
\end{aligned}
$$

where $\mathrm{P}$ is the magnitude of the applied load in meganewtons. Expressions (6) and (7) for compliance and stress intensity factor for the specimen with side groove, shown in Fig. 4b, were obtained from the results of twodimensional linear-elastic finite element analyses of a series of model specimens with different crack lengths. The calculated compliance and stress intensity factors were approximated by best fit polynomials in relative crack size $a / W$. Equations (6) and (7) refer to this specimen geometry only.

Next, plastic deformation was introduced into this model to analyze the crack behavior after crack arrest. As shown in Fig. 7, a limit load element and a viscous element were included. Their displacement is the plastic part of the total displacement. The added elements accounted not only for friction, but also for strain-rate-induced elevation of yield stress [1]. The equations of motion used were:

$$
M_{e x} \ddot{u}+C_{e x} \dot{u}+\left(\kappa_{e x}+\kappa_{s}\right) u=\kappa_{e x} u_{A} \text {, for } P<P_{\text {limit }}
$$

and

$$
\begin{aligned}
& M_{e x} \ddot{u}+c_{e x} \dot{u}+\left(\kappa_{e x}+\kappa_{S}\right) u=\kappa_{e x} u_{A}+\kappa_{s} u_{p} \\
& M_{S} \ddot{u}_{p}+C_{S} \dot{u}_{p}+\kappa_{s} u_{p}=\kappa_{S} u-P_{\text {limit }}, \text { for } P \geqq P_{\text {limit }}
\end{aligned}
$$

Where $u_{p}$ is the plastic part of the displacement, $C_{S}$ and $C_{e x}$ are the viscosity coefficients, $M_{S}$ is specimen mass, and $P$ is the applied load. Limit load (for DCB specimens only) is evaluated as follows:

$$
P_{\text {limit }}=\left\{\left[(w-b)^{2}+b^{2}\right]^{1 / 2}-(w-b\} \sigma_{f} \cdot B\right.
$$

where $b$ is uncracked ligament length and $\sigma_{f}$ is the flow stress. 
After $P$ exceeds $P_{\text {limit, }}$ an elasto-plastic fracture mechanics parameter is needed to characterize the crack. The modified J-integral is defined as

$$
J=K_{S}^{2} / E+2 P \text { limit } u_{p} / B \cdot b
$$

where $K_{S}$ is the stress intensity evaluated at load $P$ using eq. (7). $P$ is given by the elastic part of the displacement as

$$
P=k_{s} \cdot\left(u-u_{p}\right)
$$

\section{MATERIAL AND TECHNIQUES}

The material used was classed as ABS-EH36, a ship steel. Its chemical composition and mechanical properties are shown in Table 2. Its yield and flow strengths are assumed to be $370 \mathrm{MPa}$ and $520 \mathrm{MPa}$, respectively, at the temperatures used for crack-arrest experiments. Its Charpy impact energy has a step-like brittle/ductile transition at a temperature of about $-70^{\circ} \mathrm{C}$. Stress-relief heat treatment and a deep side groove were used for specimens EH36-5, -6 , and -7 , because the initiated crack was apt to turn and deviate from the EB-melted zone as is in specimens without a side groove. The side groove was cut on one side only, to allow installation of crack propagation gauges on the other side of the specimen. The side-groove depth was $7.6 \mathrm{~mm}$, leaving a net ligament of $5.1 \mathrm{~mm}$. Specimens were cooled with liquid nitrogen and dry ice so that the desired temperature was achieved at the EB-melted zone tip. The initial crack tip was supercooled so that the crack was easily initiated in a completely brittle manner, without noticeable macroscopic plastic deformation.

After the main load was applied to the specimen through the loading spring by the testing machine (1-MN capacity) and was maintained at the specified level, a sub-load was applied to the crack-initiation part of the specimen by two jacks. These two loads were separate; the main load was expected to be maintained during and after crack propagation by the highly compliant loading spring. The jacks were so stiff that fixed grip conditions were assumed at the jack loading point. However, this did not affect the crack tip after crack arrest; the specimen was deformed because of large-scale 
yielding of the net section, so that the jack load was relieved.

The crack velocity was measured from the change in the electrical resistance of crack detector trip wires, which were connected in parallel, using a resistance network, and were placed normal to the crack propagation line. Strain gauges were placed near the EB-melted zone tip, to monitor not only the crack tip location with time but the extension of plastic zone after crack arrest. The main load was monitored by the test machine load cell. The load line displacement over a guage length of $260 \mathrm{~mm}$ was measured by a clip-on gauge. Transient data from all instruments were stored in digital oscilloscopes. The temperature distribution along the crack propagation line was monitored with several thermocouples.

\section{RESULTS}

Table 3 shows the experimental results. Dynamic fracture toughness, $\mathrm{K}_{\mathrm{D}}$, at first arrest is obtained by using dynamic linear elastic FEM analysis. For EH36-2, the crack was arrested temporarily inside the EB-melted line. However, it was observed that the crack became slanted; that is, it deviated slightly from EB-melted line into base plate, on one side of the specimen although it remained in the EB-melted zone. Therefore, it is believed that the slightly tougher base plate contributed to the crack arrest. For EH36-5, the crack was continuous on the grooved side of the specimen, but was discontinuous on the other side. The crack was arrested with in the EB-melted zone. Arrest may have been due to the relatively low applied load and to toughness increase because of the temperature gradient. For EH36-6, tested at a very low temperature, the crack severed the specimen completely. The fracture surface indicated brittle fracture along the crack path. For EH36-7, the crack was successfully arrested at the EB-melted zone tip because of the difference in toughness; and then the crack was reinitiated after the load, which had dropped during crack propagation, began to be recovered. The relation between the crack velocity and crack tip position are discussed in Sec. 6.

Figures 8 (a), (b), (c) and (d) show the change of crack velocity with crack length and temperature distribution for EH36-2, $-5,-6$ and -7 . It was found that the crack velocity decreased quickly just before crack arrest. 
These plots show that arrests occurred for temperatures between approximately $-40^{\circ} \mathrm{C}$ and $-60^{\circ} \mathrm{C}$. No arrest occurred for a specimen cooled to $-80^{\circ} \mathrm{C}$ along the whole crack path. Average stress before crack propagation in the ligament remaining after side-grooving ranged from 142 to $217 \mathrm{MPa}$ in specimens in which arrest occurred. The stress in specimen EH36-6 for which arrest did not occur, was $117 \mathrm{MPa}$.

Figures 9 (a), (b), (c) and (d) show the change of the load with time for EH36-2, $-5,-6$ \& and -7 . The experimental load data for EH36-2 were lost, so only calculated values are shown. The load values calculated by FEM generally agree with experimental values before crack arrest, except for specimen EH36-5. The load calculated by the MS model was found useful in spite of the simplicity of the model.

Figures 10 (a), (b), (c) and (d) show the change of the y-direction strain with time. The difference between numerical and experimental strain increases with crack extension, except for EH36-6. This difference is regarded as intrinsic, even though the FEM mesh is somewhat coarse. It is interpreted to mean that a different model is necessary to incorporate plasticity effects. For EH36-6, however, elastic analys is is adequate to analyze the running crack, because it did not arrest.

Figures 11 (a), (b), (c) and (d) show the change of the applied dynamic stress intensity and crack velocity with time. Static, dynamic FEM (eq. 4), and mass-spring model (eqs 7 and 10) values of $K_{D}$ are shown. It seems that the dynamic stress intensity calculated by FEM is affected strongly by crack velocity [5] for this material. Although $K_{D}$ is not strictly correct after crack arrest, because of plasticity effects, it seems reasonable because of the small deviation of $K_{D}$ from the static stress intensity factor $K_{S}$. The MS model was found inappropriate to evaluate $\mathrm{K}_{\mathrm{D}}$ during initial crack propagation because the effect of the jack was not considered.

Recall that the temperature varies across each specimen; therefore the toughness varies along the crack path. This means that a correlation between material resistance to dynamic crack propagation and crack velocity cannot be obtained from the data of Figs. 8 and 11 . 
Plastic zone extension occurred as load increased under nearly static conditions after arrest, as shown in Figs. 12 (a) and (b). Quite a high load was necessary to produce net section yield for EH36-2. In the other specimens, the plastic zone concentrated only in the narrow net section left by the side groove and net section yielding occurred at lower loads. Numerical results were obtained from the MS model incorporating plasticity. Figure 13 compares calculated and experimental loads as functions of time for EH36-5. The experimental load oscillates at a high frequency, believed to be the natural frequency the specimen's mouth-opening mode of resonance oscillation. The trend, however, seems to indicate that the MS model accurately treats the lowest normal mode of the specimen-spring system as a whole. Two values of the viscosity parameter $\mathrm{C}_{\mathrm{S}}$ were used. These had been found by trial and error to bracket the range of values that most closely simulated the actual specimen behavior [4]. Figure 14 plots the calculated total and plastic displacement against time. It was concluded that the plastic displacement for EH36-5 was so small that the elastic deformation was dominant. Figure 15 shows the relation between $J$ and $t i m e$. It was found that computed $\mathrm{J}$ is of the order of $\mathrm{K}_{\mathrm{NSY}}{ }^{2} / \mathrm{E}$, corresponding with the onset of net section yielding.

Figure 16 compares results of the MS model and the experiment as a function of time for EH36-7, for three values of the friction parameter. The experimental load results, in general, tend to approach the MS model prediction when the middle friction value is used, although the experimental load oscillates. In this case, the applied load is higher than limit load after crack arrest. Plastic deformation must be accounted for in the MS model for EH36-7. The relationship between the total and plastic displacements and time is shown in Fig. 17. The experimental load line displacement seems to grow while oscillating. This high amplitude oscillation is believed to result from the natural frequency of the clip gauge. Figure 18 shows the

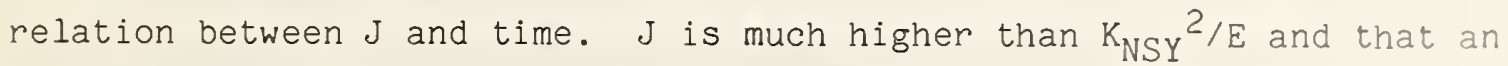
elastic plastic fracture mechanics parameter is necessary after crack arrest. The experimental J-integral, $\mathrm{J}$, is introduced as follows [6]:

$$
J=K_{N S Y}{ }^{2} / E+2 P_{\text {limit }} \cdot\left(\Delta-\Delta_{N S Y}\right) / B \cdot b
$$


where $\Delta$ is load line displacement and $\Delta_{\text {NSY }}$ is load line displacement at the limit load from Eq. (6).

Experimental $J$ in general seems to agree with the model result using the intermediate value for the friction parameter.

\section{DISCUSSION}

For EH36-7, brittle crack propagation, arrest, and reinitiation occurred. That is, the worst case in actual ship failure was simulated in a laboratory experiment. The following discussion of crack arrest and reinitiation is based on the behavior of the specimen in that simulation.

From Fig. 7 (d) crack arrest seems to occur at the EB-melted zone tip. The crack velocity decreases quickly just before the EB-melted zone tip. The variation of strains, from strain gauges placed 12 and $30 \mathrm{~mm}$ ahead of the EB-melted zone tip, shows that after the measured strain increased quickly because of the approaching crack, the strains remained almost constant (Fig. 18). This means that the crack was arrested at least temporarily. If the crack had passed the location of the strain gauges, the strains would have dropped immediately, as shown in Fig. 10 (c) for EH36-6. Since the strain exceeded the yield strain, a large plastic zone must have been formed, indicating a high crack driving force.

It is hard to judge exactly when the arrested crack was reinitiated from the oscilloscope photographs of the strain and load traces (Figs. 18 and 19). The load dropped to 44 percent of the initially applied load because of crack propagation, that is, rapid change of the specimen compliance, and then was recovered by the loading spring. Since the recovered load was as large as the initial load, it was large enough to deform the uncracked ligament after crack arrest and produce crack reinitiation. The crack reinitiation probably should be considered to occur at the time of maximum strain ( $\cong 2 \mathrm{~ms}$ ) or load ( $\equiv 3 \mathrm{~ms}$ ), because compliance is changed by the reinitiation. The apparent time difference between these two maxima is due to the delay produced by elastic wave propagation. For example, when the elastic wave velocity is assumed to be $500 \mathrm{~m} / \mathrm{s}$ (approximately the bar wave velocity) and the distance from the arrested crack to the load cell is about $50 \mathrm{~cm}$, the elastic wave from the crack tip takes $1 \mathrm{~ms}$ to reach the load cell. 
The J-integral during reinitiation is shown in Fig. 20. Although complete ductile tearing (or slant fracture) was observed after the crack reinitiation, we believe that the repropagation velocity was very low and that the reinitiated crack temporarily stopped and then propagated again. The strains appear to remain nearly constant until $8 \mathrm{~ms}$ in Fig. 18, as the load does in Fig. 19. The specimen seems to have deformed gradually after reinitiation as there is little oscillation of the load or strain. The repropagation velocity is estimated from Fig. 18 to be $18 \mathrm{~m} / \mathrm{s}$, using the time difference ( $\cong 1 \mathrm{~ms}$ ) between the two strain gauge strains. This value is close to that observed in unstable ductile fracture experiments.

\section{CONCLUSIONS}

From this study of crack arrest, the following conclusions about the present specimen design and experimental results were drawn:

(i) Introduction of a deep side groove resulted in a straighter-running crack, as desired; the cracks were apt to turn in specimens without a side groove.

(ii) The residual stress, which may have caused the crack to turn, was relieved by a conventional heat treatment. However, the toughness difference between EH36 base plate and EB-melted zone seemed sma11, both before and after heat treatment.

(iii) The applied load, having decreased during crack propagation, was recovered by the loading spring and caused reinitiation after crack arrest.

(iv) A crack can be arrested even in a rising $K$ field if the temperature, and thus the material toughness, is high enough.

(v) The MS model, with appropriately chosen viscosity parameter, successfully simulates the behavior in time of the lowest frequency component of the load and displacement, and therefore appears to be useful for extracting fracture mechanics parameters from test data.

(vi) It is possible that the dynamic arrest toughness changes with the depth of the side groove, although it is known that side grooves have little effect on the plane strain fracture toughness [7]. The presence of the single side groove may affect the measured crack arrest toughness in 
this specimen, because only two-dimensional analyses have been done. However, it is known that side grooves have little effect in the static plane strain fracture toughness [7].

\section{ACKNOWLEDGMENTS}

Financial support from the Office of Naval Research (for the first author) and the Naval Sea Systems Command, 05R25, (for the coauthors), is gratefully acknowledged. Technical assistance from D. P. Vigliotti and J. D. McColskey is deeply appreciated.

9. REFERENCES

[1] R. B. King, T. Teramoto and D. T. Read, "Material Selection Criteria for Crack Arrester Strakes in Naval Vessels, Second Interim Progress Report," NBSIR 84-3012.

[2] J. F. Malluck and W. W. King, "Fast Fracture Simulated by Conventional Finite Elements: A Comparison of Two Energy-Release Rate Algorithms." ASTM STP 711, American Society for Testing and Materials, Philadelphia, 1980 , pp. 38-53.

[3] P. N. R. Keegstra, "A Transient Finite Element Crack Propagation Model for Nuclear Pressure Vessel Steels", J. Inst. Nuc. Eng. Vol. 17 - No. 14, pp. 89-96, 1976.

[4] T. Teramoto, D. T. Read and R. B. King, "Fracture Mechanics Parameters in Crack Arrest Specimens," companion paper in this NBSIR.

[5] R. G. Hoagland, A. R. Rosenfield, P. C. Gehler and G. T. Hahn, "A Crack Arrest Measuring Procedure for $\mathrm{K}_{\mathrm{Im}}$, $\mathrm{K}_{\mathrm{IO}}$, and $\mathrm{K}_{\mathrm{Ia}}$ Properties," ASTM STP 627. American Society for Testing and Materials, Philadelphia, pp. 177$202,1977$. 
[6] J.R. Rice, P. C. Paris, and J. G. Merkle, "Some Further Results of J-Integral Analysis and Estimates," Progress in Flaw Growth and Fracture Toughness Testing, ASTM STP 536, American Society for Testing and Materials, Philadelphia, 1973, pp. 231-245.

[7] V. Dantam and G. T. Hahn, "Definition of Crack Arrest Performance of Tough Alloys," presented at the U.S.-Japan Seminar on "Fracture Tolerance Evaluation," Honolulu, HI, Dec. 7-11, 1981. 
Table 1. Variable dimensions of rising $K$ crack arrest specimen.

$$
\begin{aligned}
& w=275 \mathrm{~mm} \text { for } \mathrm{EH} 36-2 \\
& \mathrm{w}=260 \mathrm{~mm} \text { for } \mathrm{EH} 36-5,-6,-7 \quad \text { (1 strain gauge) } \\
& c_{1}=25 \mathrm{~mm} \text { strain gauges) } \\
& \mathrm{d}=25 \mathrm{~mm} \text { for EH } 36-2 \\
& c_{1}=12 \mathrm{~mm} \\
& c_{2}=18 \mathrm{~mm} \text { for EH36-5, -6, -7 } \\
& d=15 \mathrm{~mm} \text {. }
\end{aligned}
$$


Table 2. Chemical composition in wieght per cent and mechanical properties for EH36.

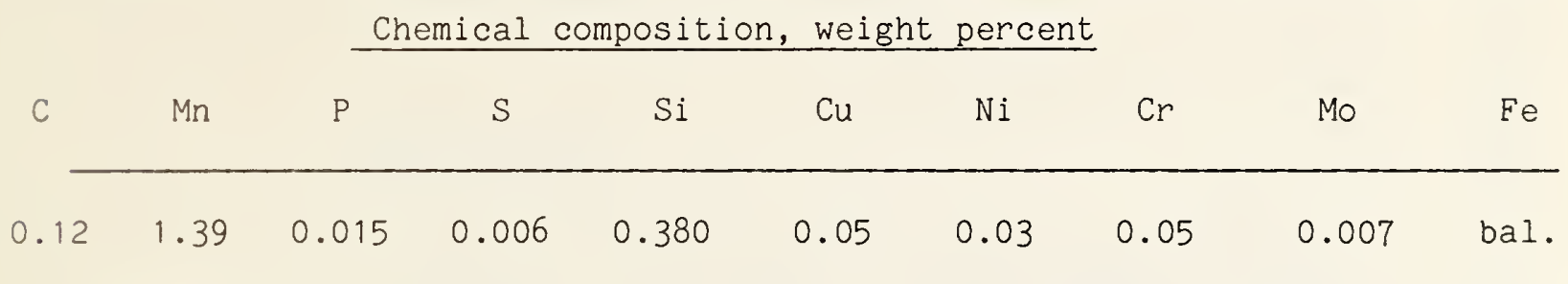

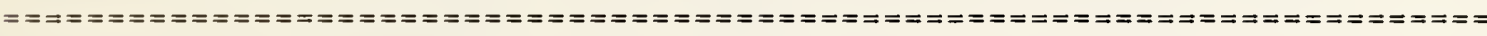

Mechanical Properties at Room Temperature

Yield Tensile Elongation

Stress Stress (per cent)

$(\mathrm{MPa}) \quad(\mathrm{MPa})$

$365 \quad 482 \quad 29$




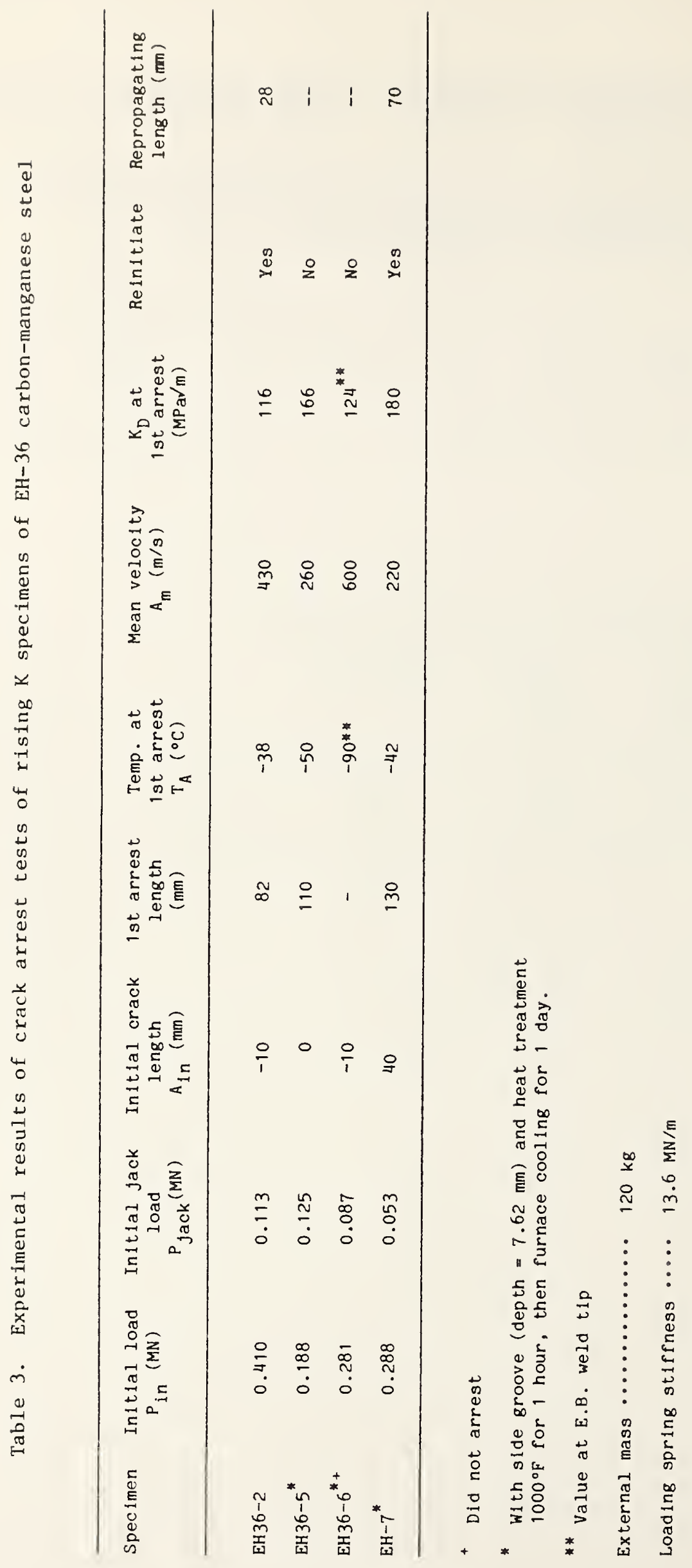




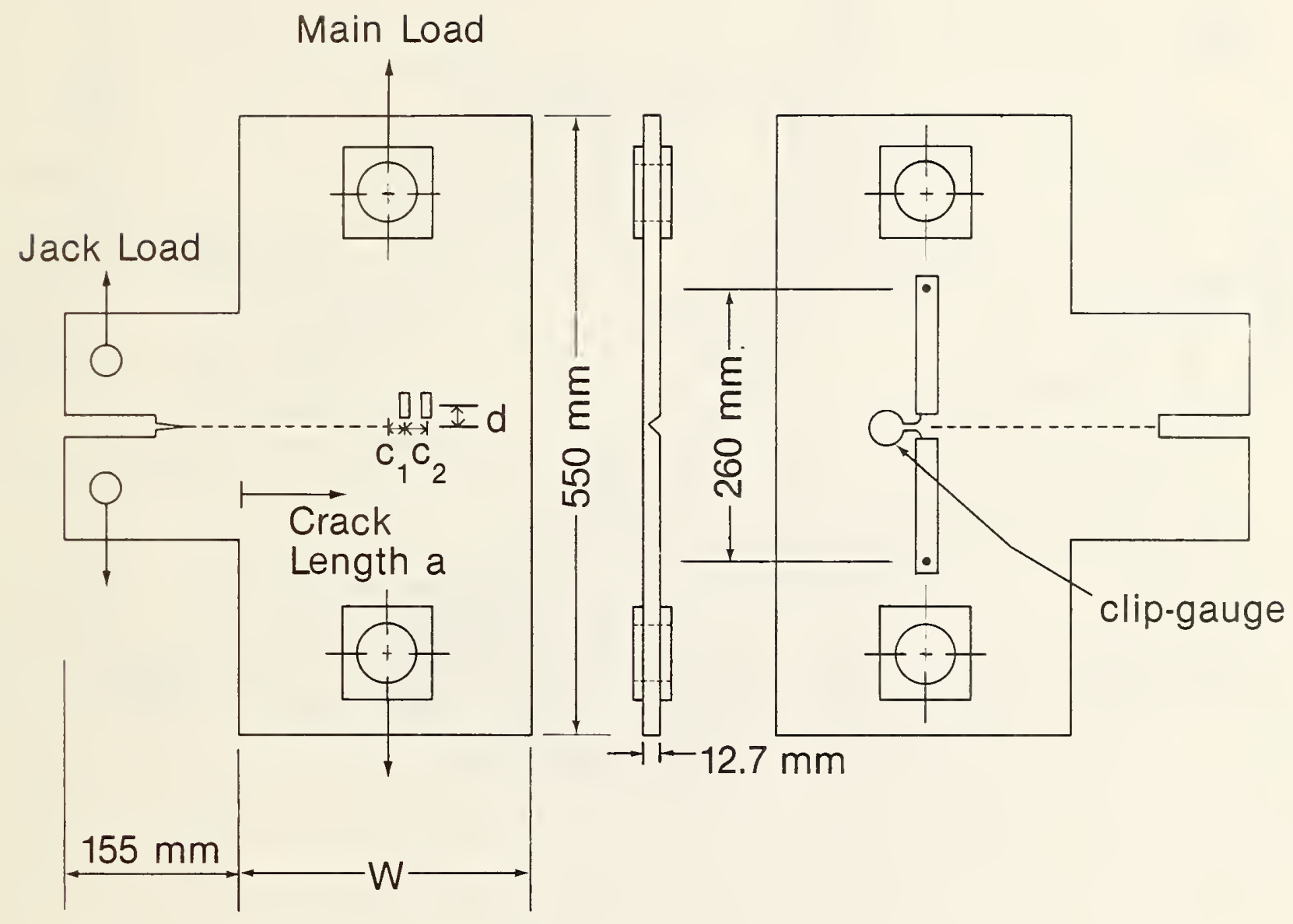

Figure 1. Specimen configuration and instrumentation. 


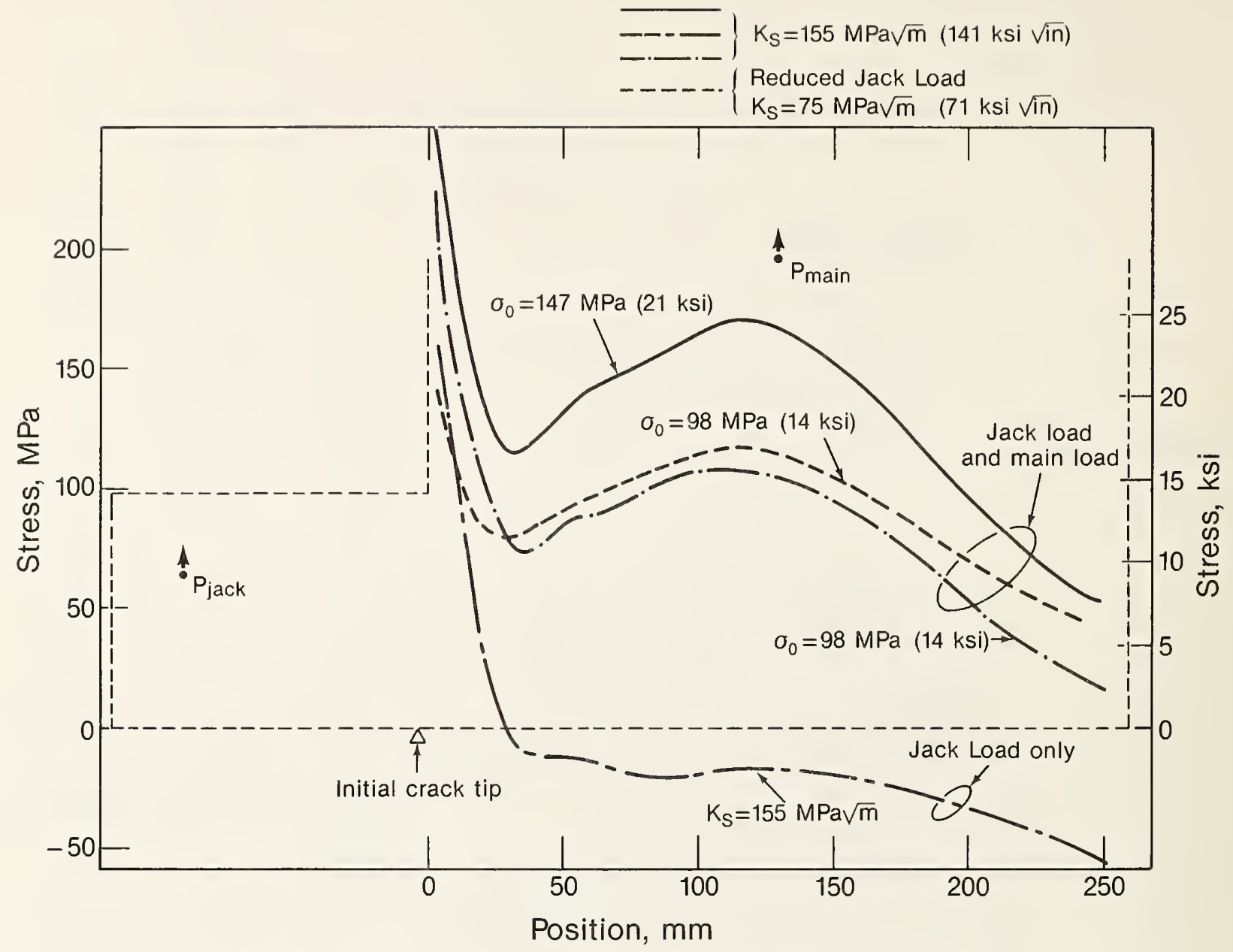

Figure 2. Stress distribution along crack propagation line from main load and/or jack load. 


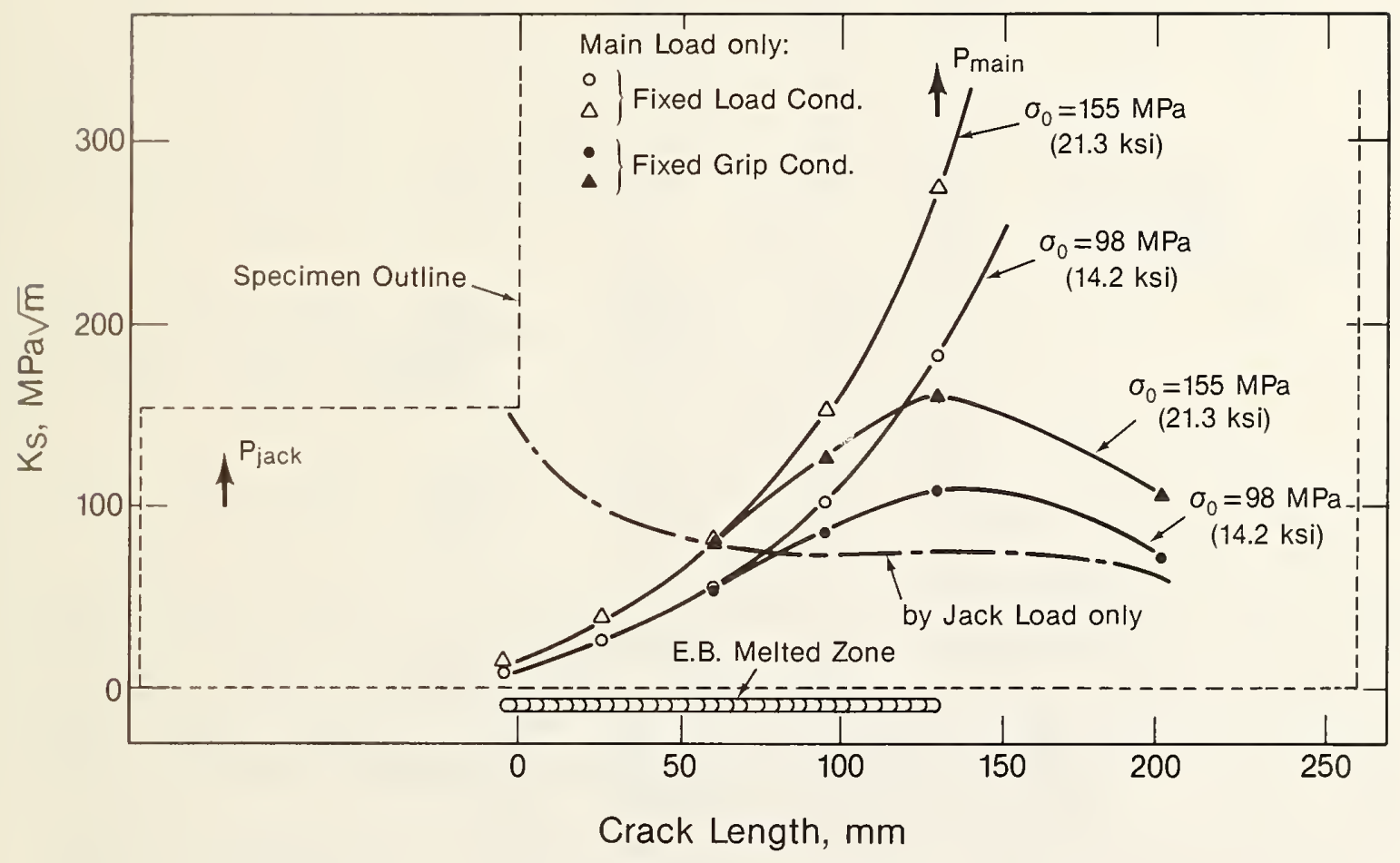

Eigure 3. Variation with crack length of stress intensity factor from main load or jack load. 
For EH36-2

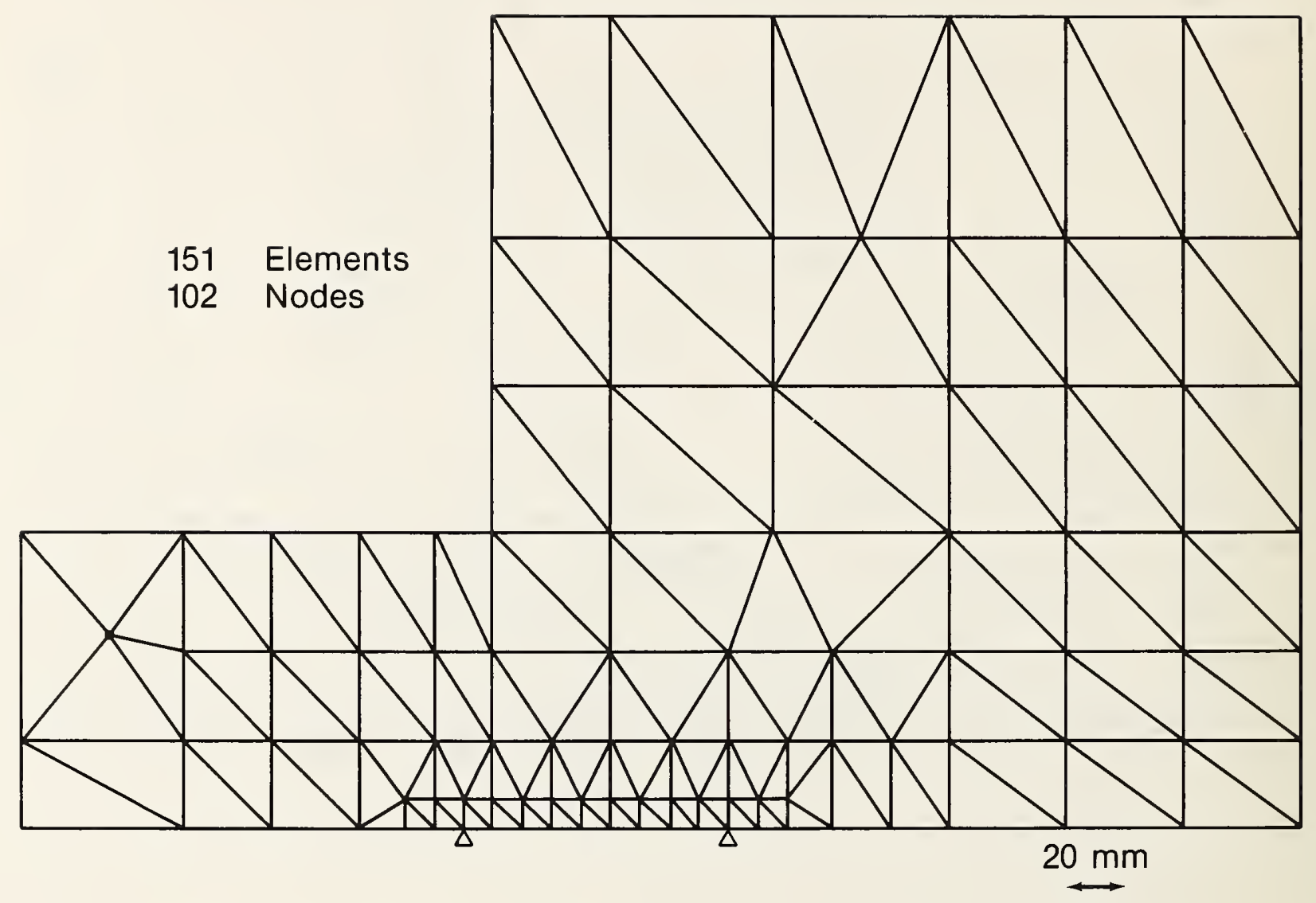

Figure 4a. Finite element breakdown for EH36-2. 
For $\mathrm{EH} 36-5,6$ \& 7

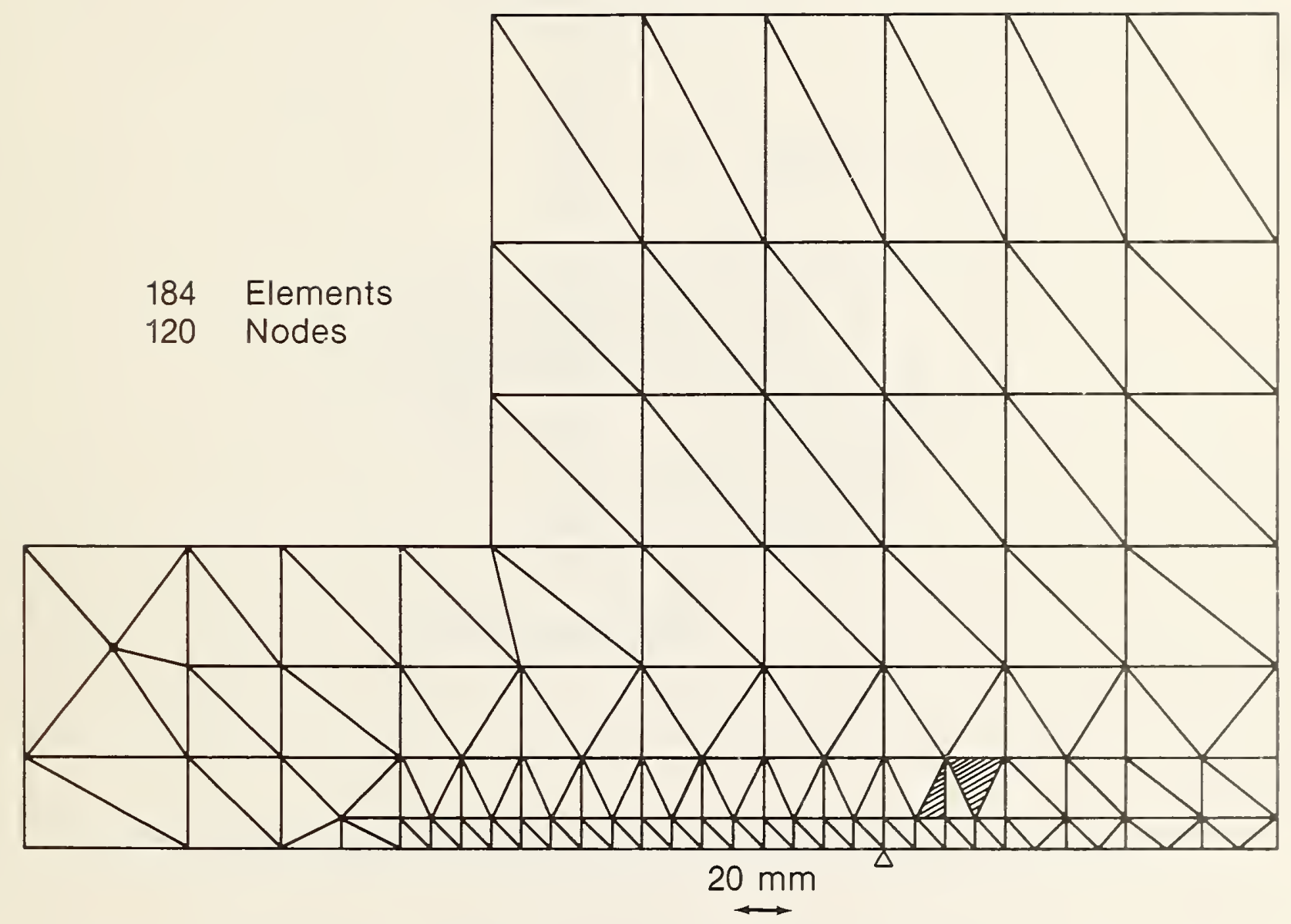

Figure 4b. Finite element breakdown for EH36-5, -6 , \& -7 . 


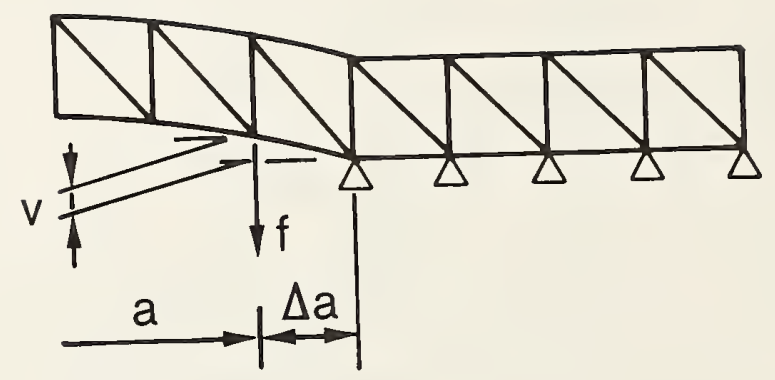

Figure 5. Crack opening near crack tip in finite element model. 


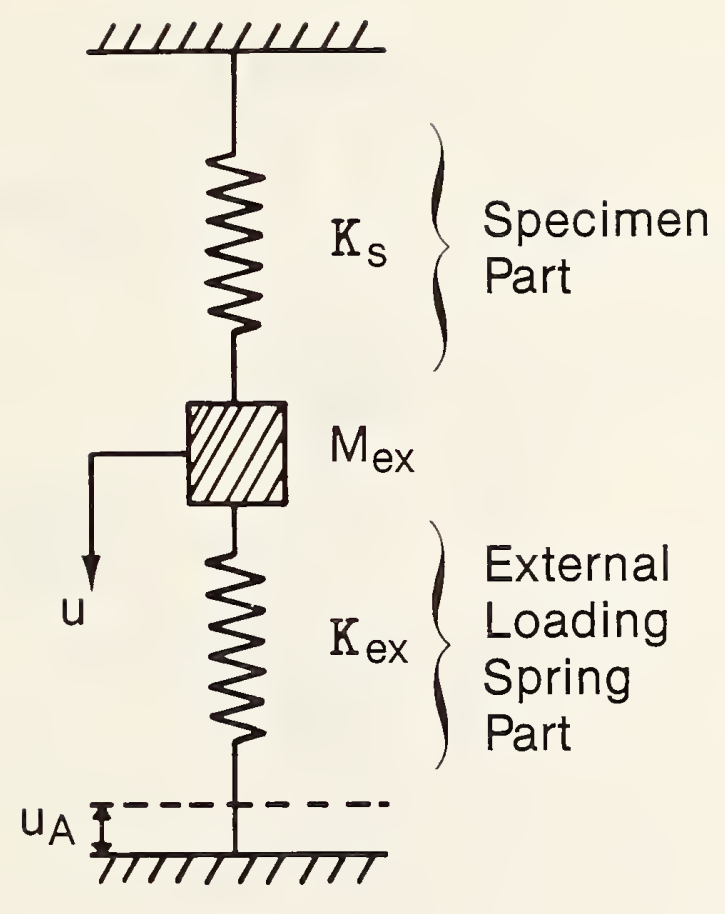

Figure 6. Mass spring model for elastic behavior. 


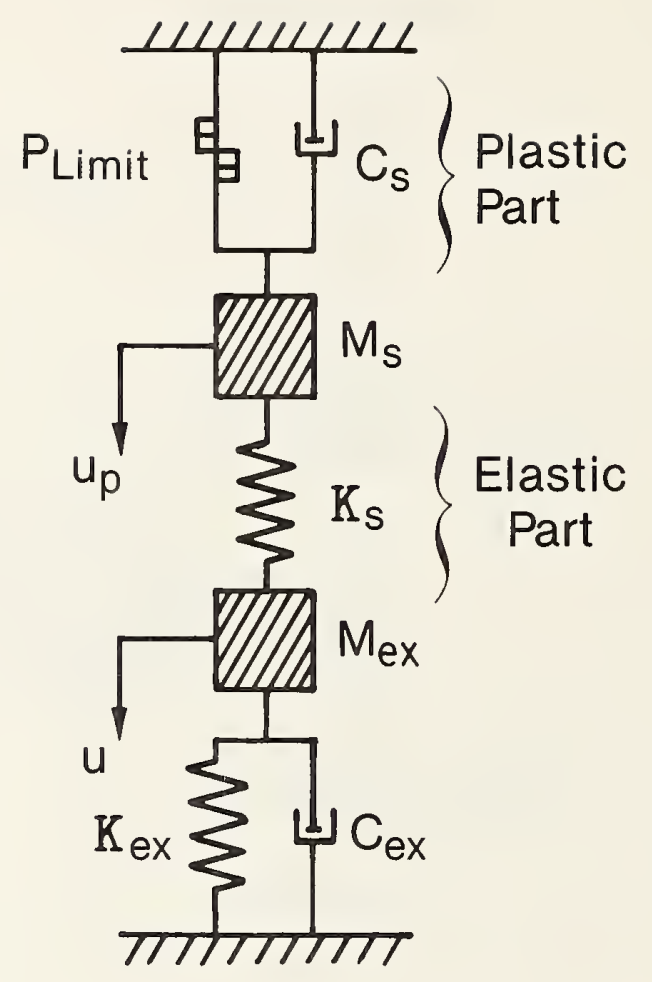

Figure 7. Mass spring model for elasto-plastic behavior. 


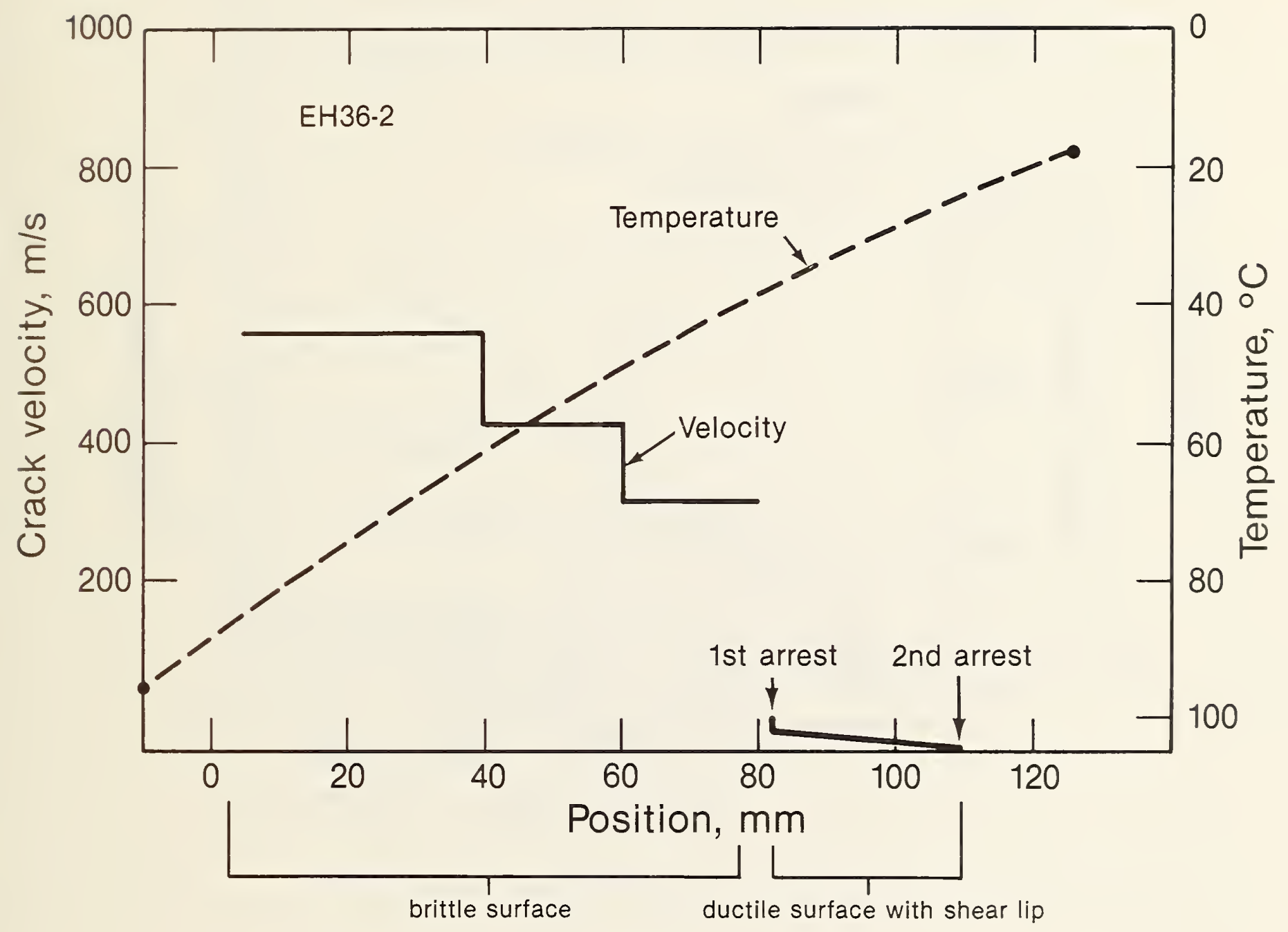

Figure 8a. Variation of crack velocity with crack length and temperature distribution for specimen EH36-2. 


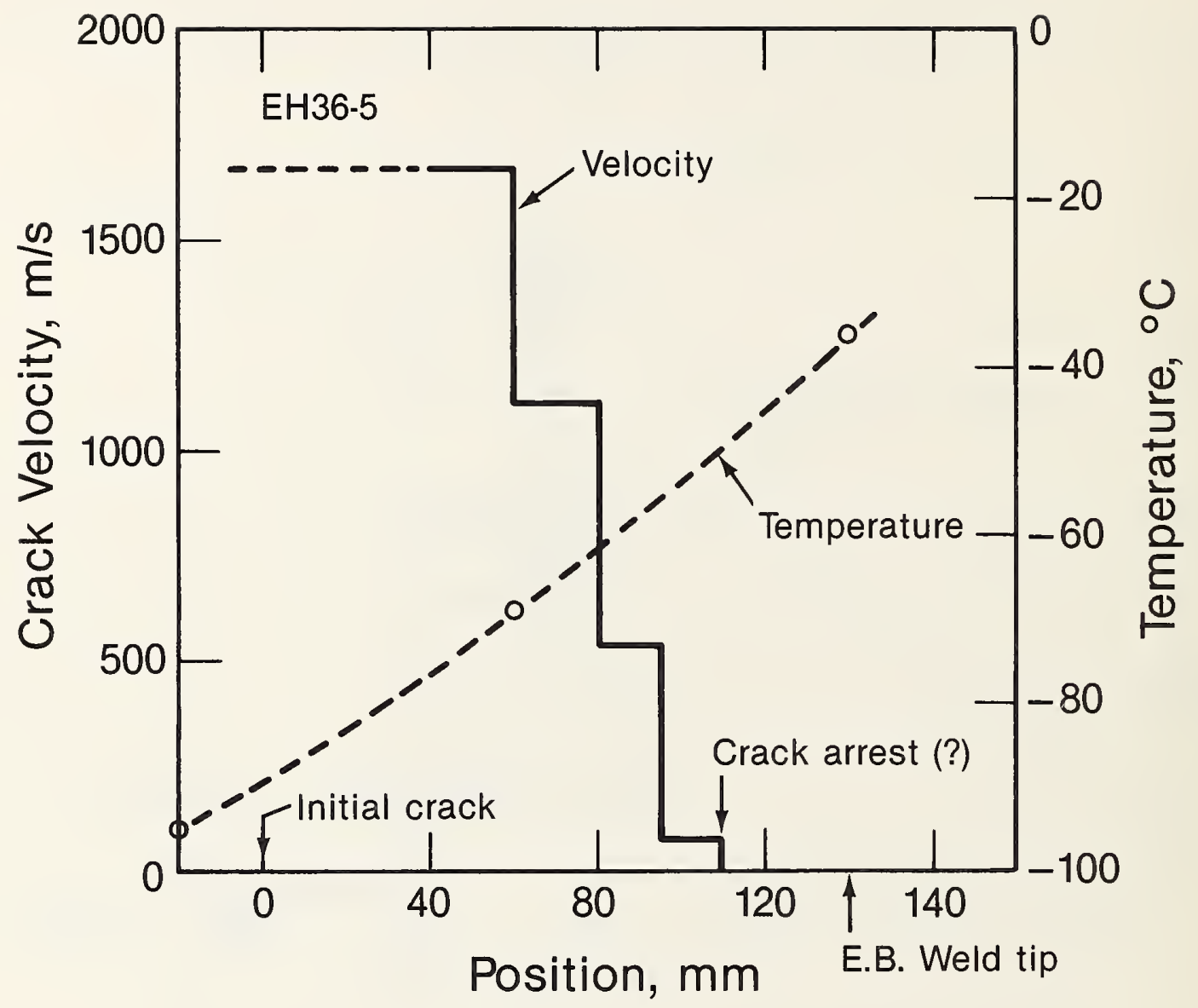

Figure 8b. Variation of crack velocity with crack length and temperature distribution for specimen EH36-5. 


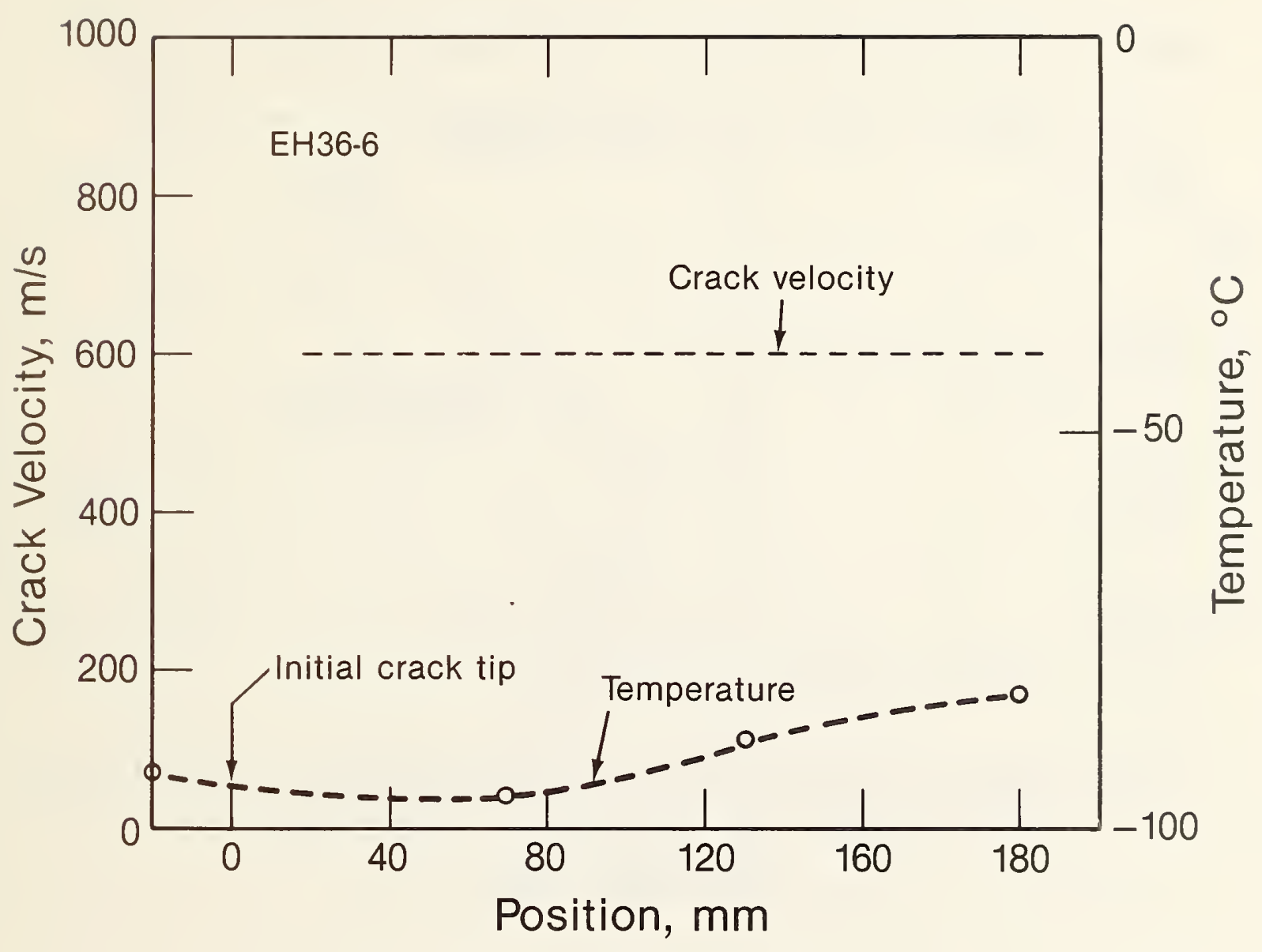

Figure 8c. Variation of crack velocity with crack length and temperature distribution for specimen EH36-6. 


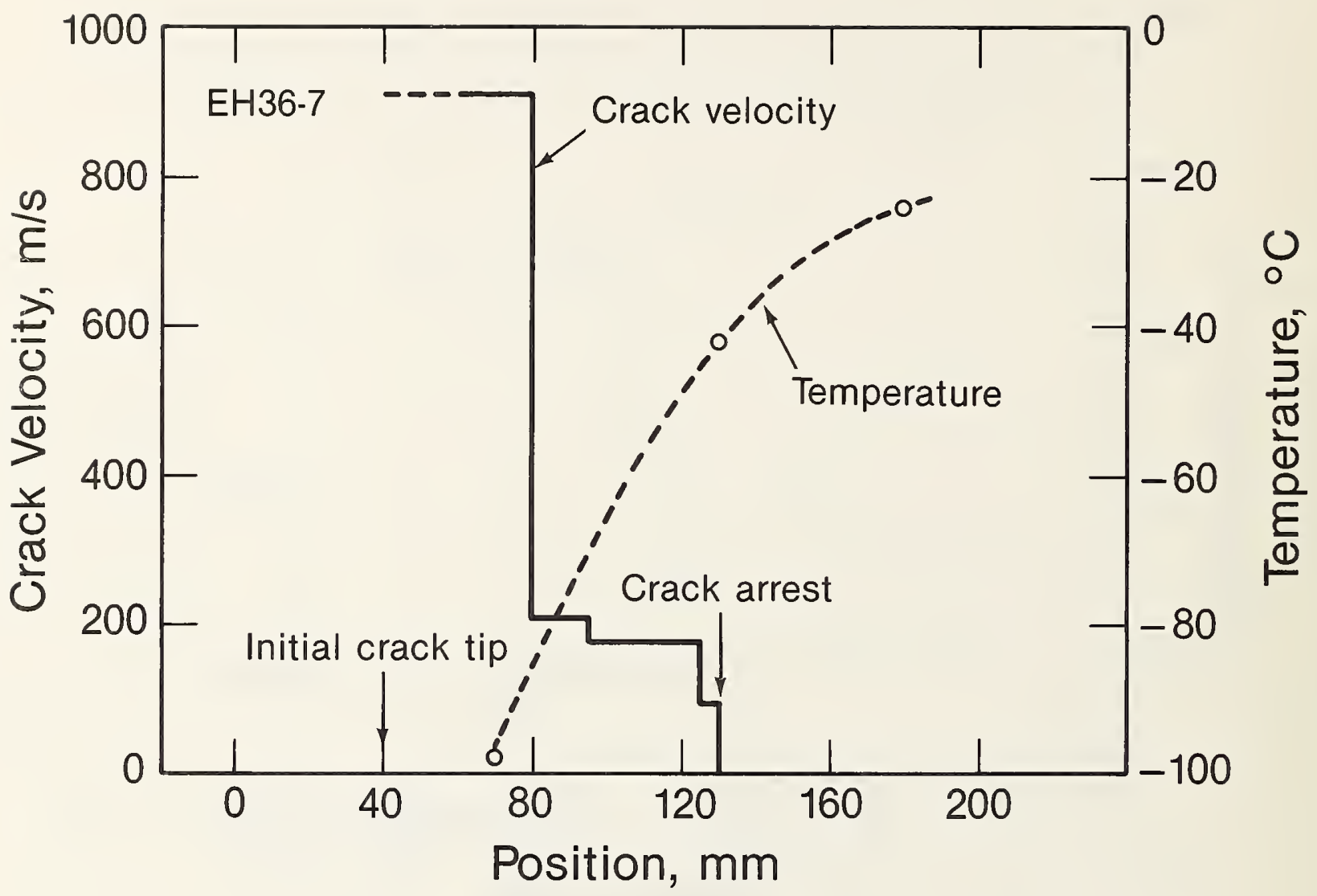

Figure 8d. Variation of crack velocity with crack length and temperature distribution for specimen EH36-7. 


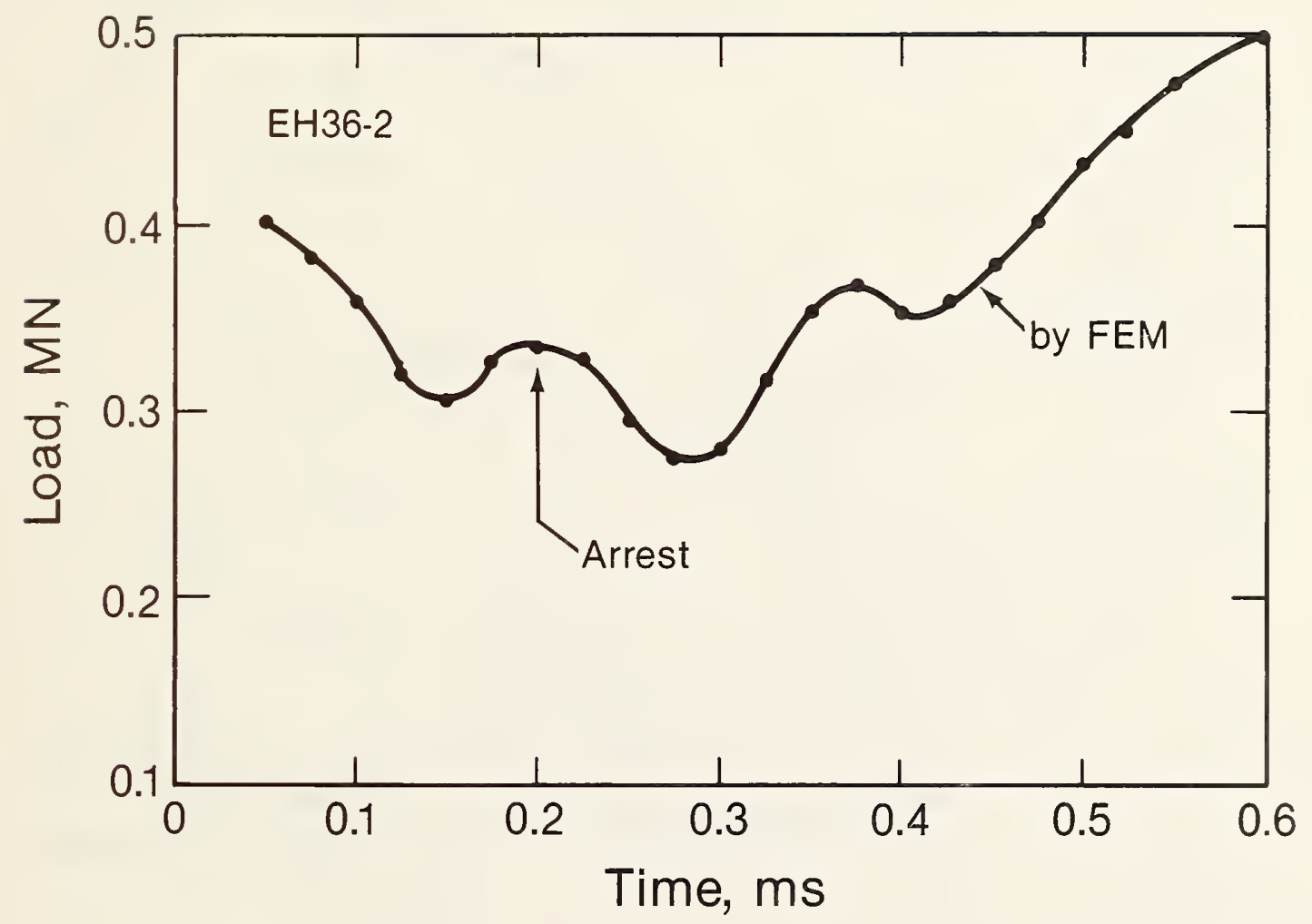

Figure 9a. Calculated load as a function of time for specimen EH36-2. 


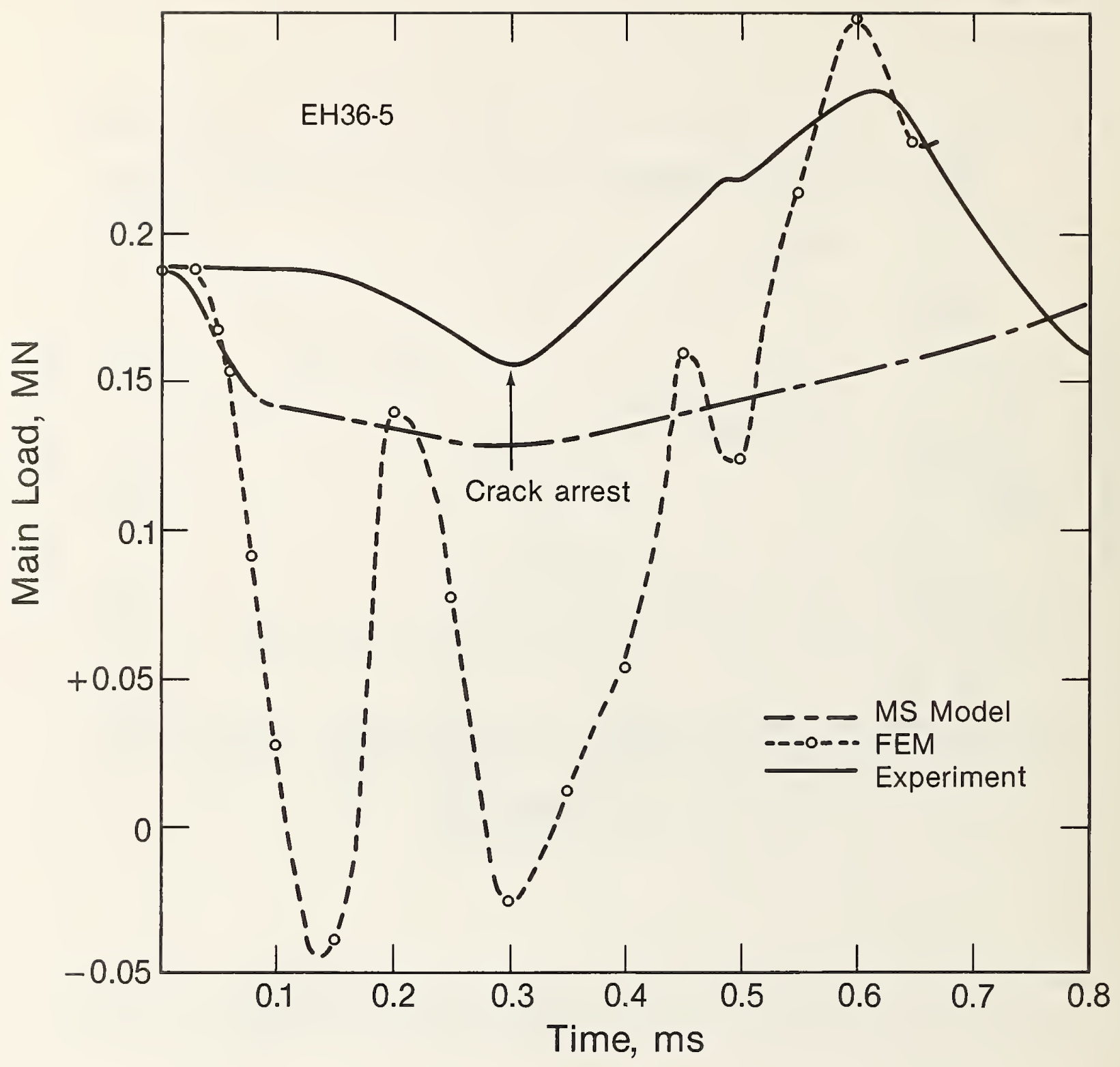

Figure 9b. Comparison of measured and calculated load as a function of time for specimen EH36-5. 


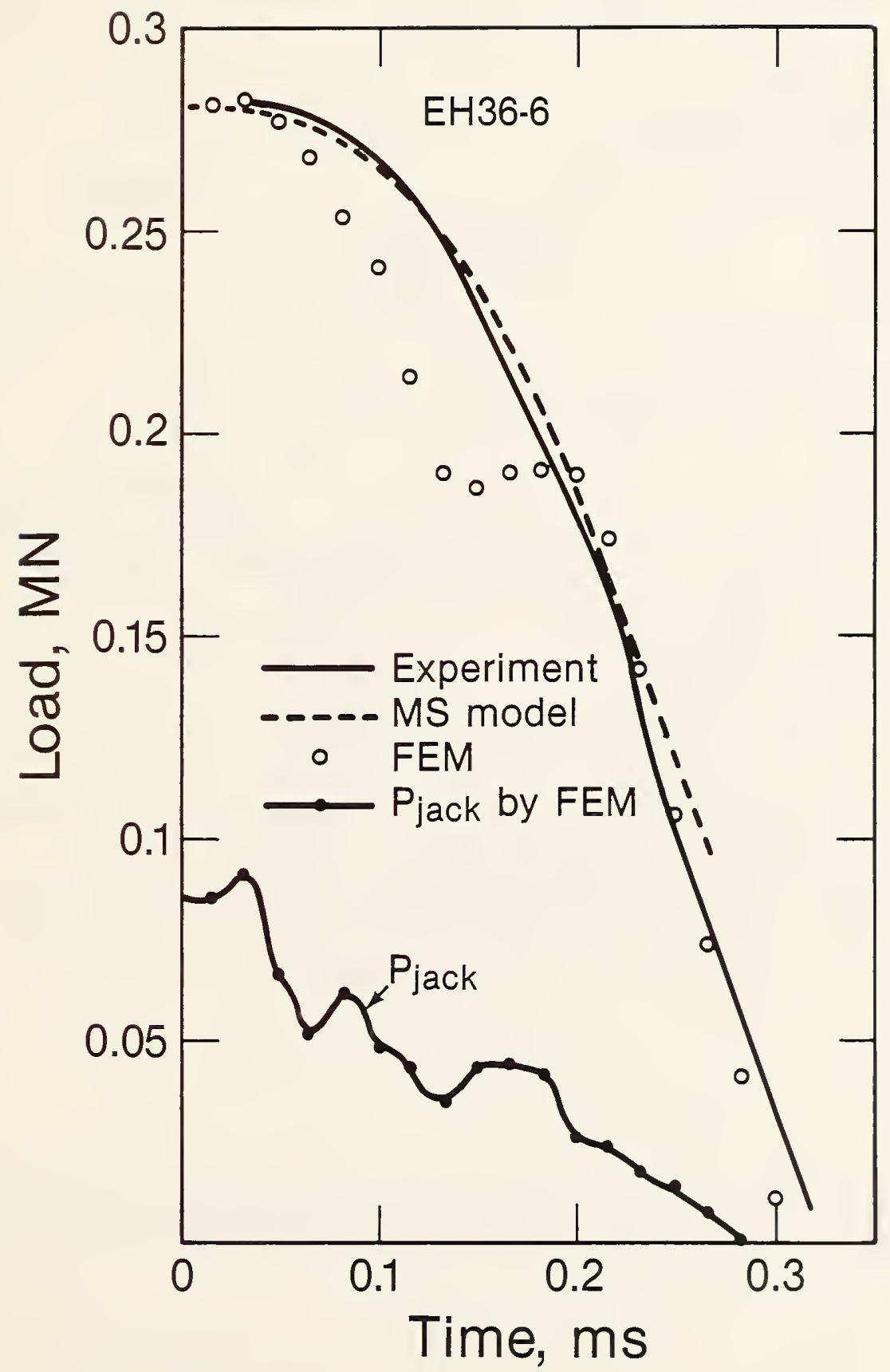

Figure 9c. Comparison of measured and calculated load as a function of time for specimen EH36-6. 


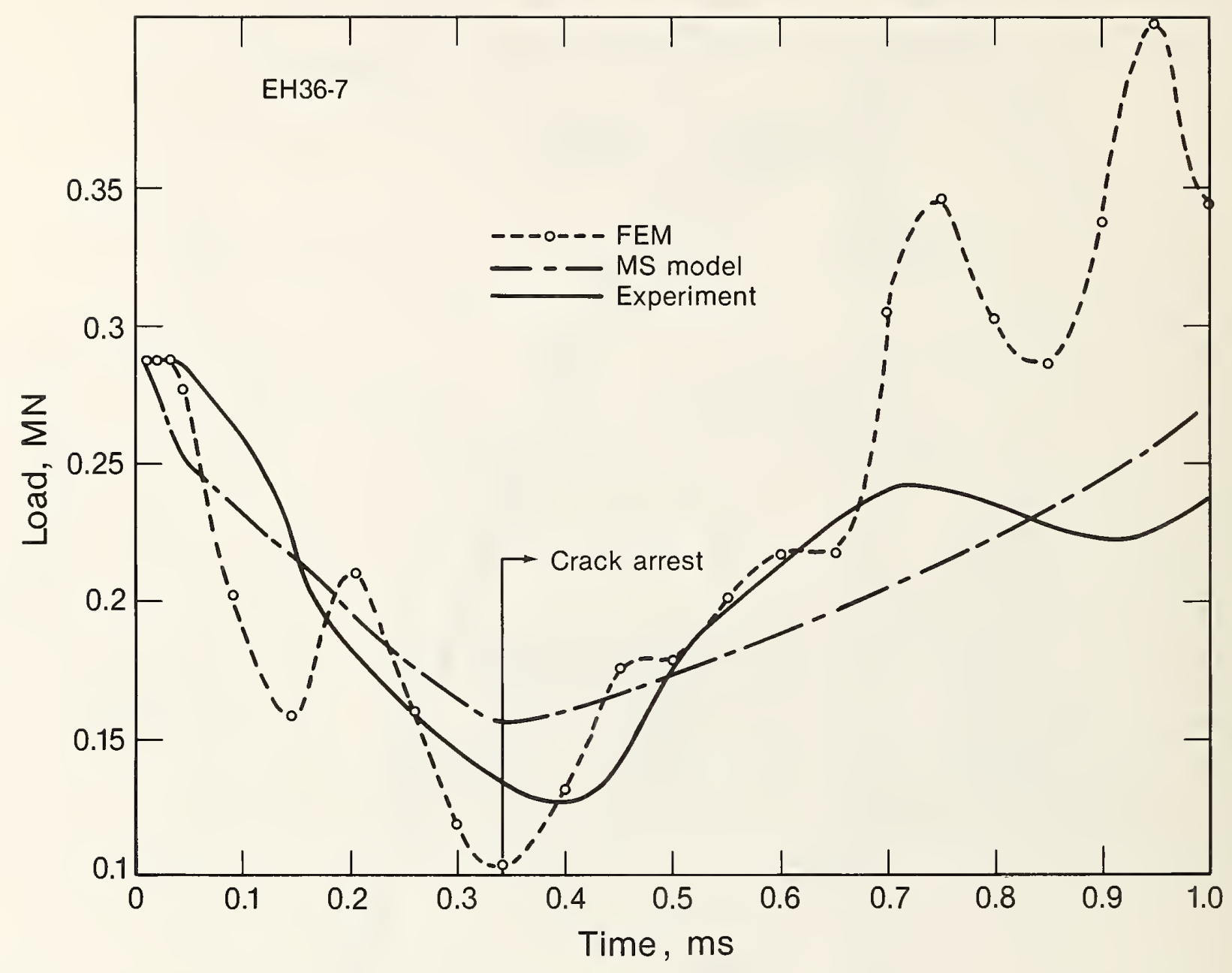

Figure 9d. Comparison of measured and calculated load as a function of time for specimen $\mathrm{EH} 36-7$. 


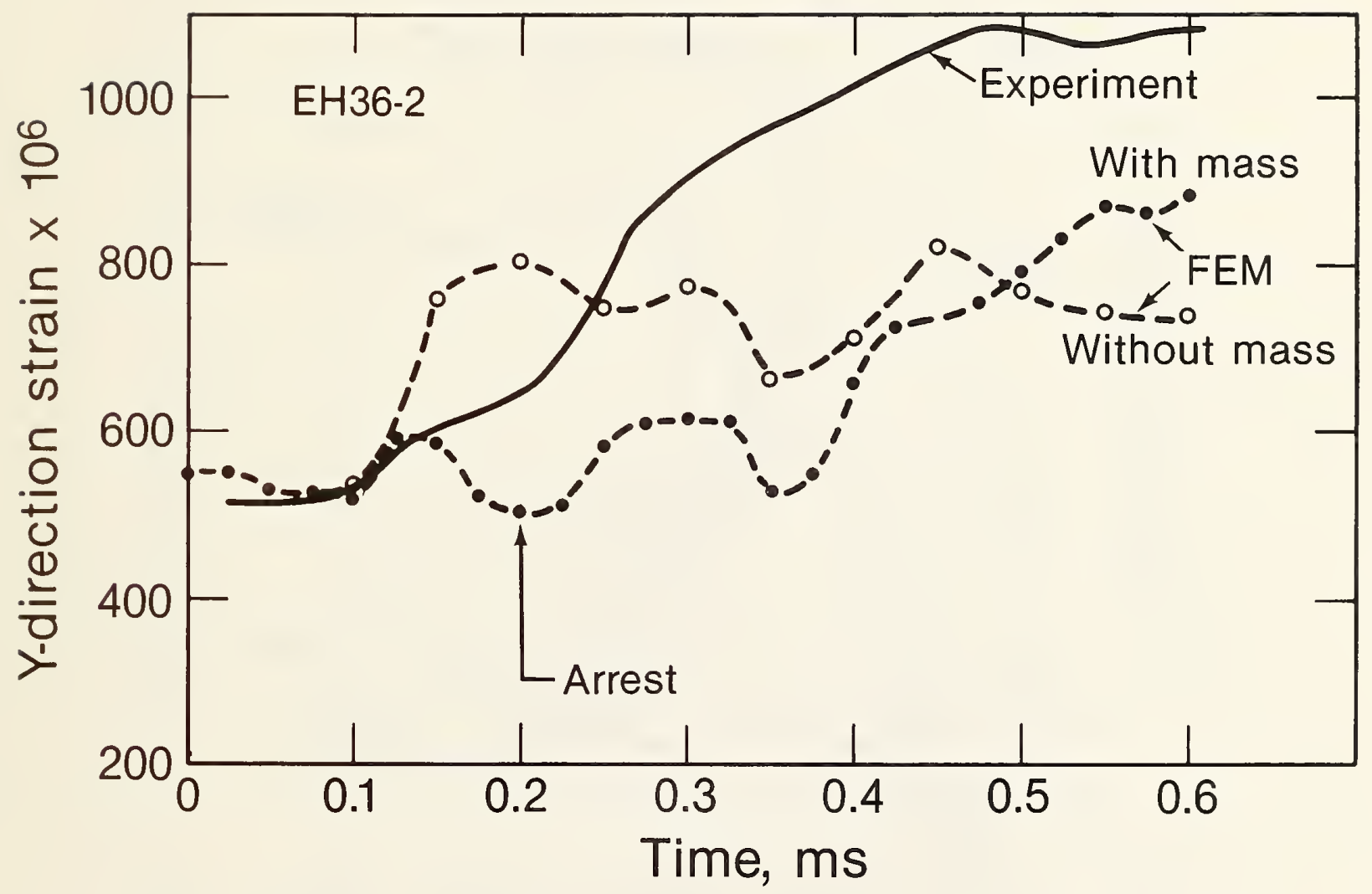

Figure 10a. Comparison of experimental and calculated strain, specimen EH36-2. 


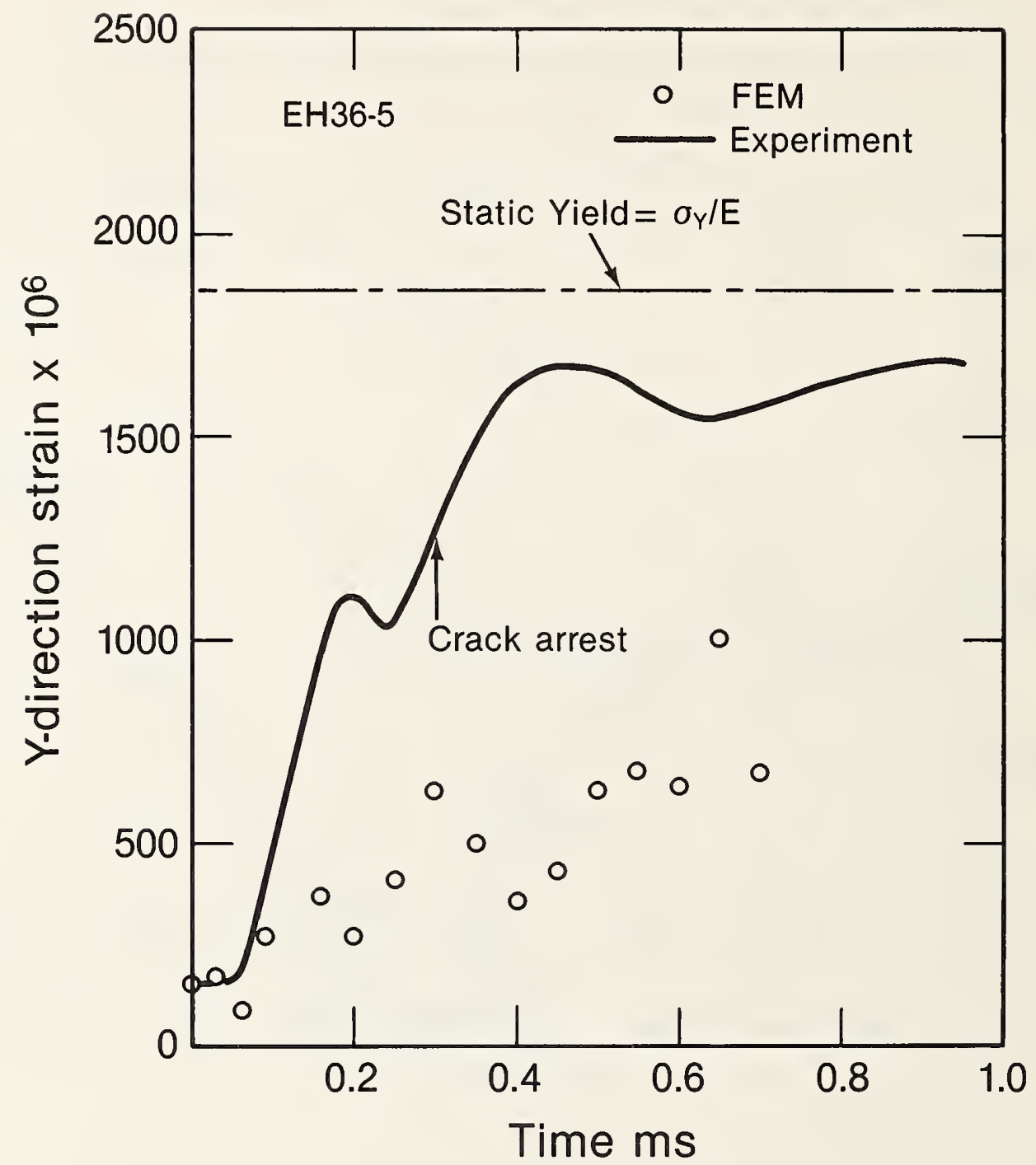

Figure 10b. Comparison of experimental and calculated strain, specimen EH36-5. 


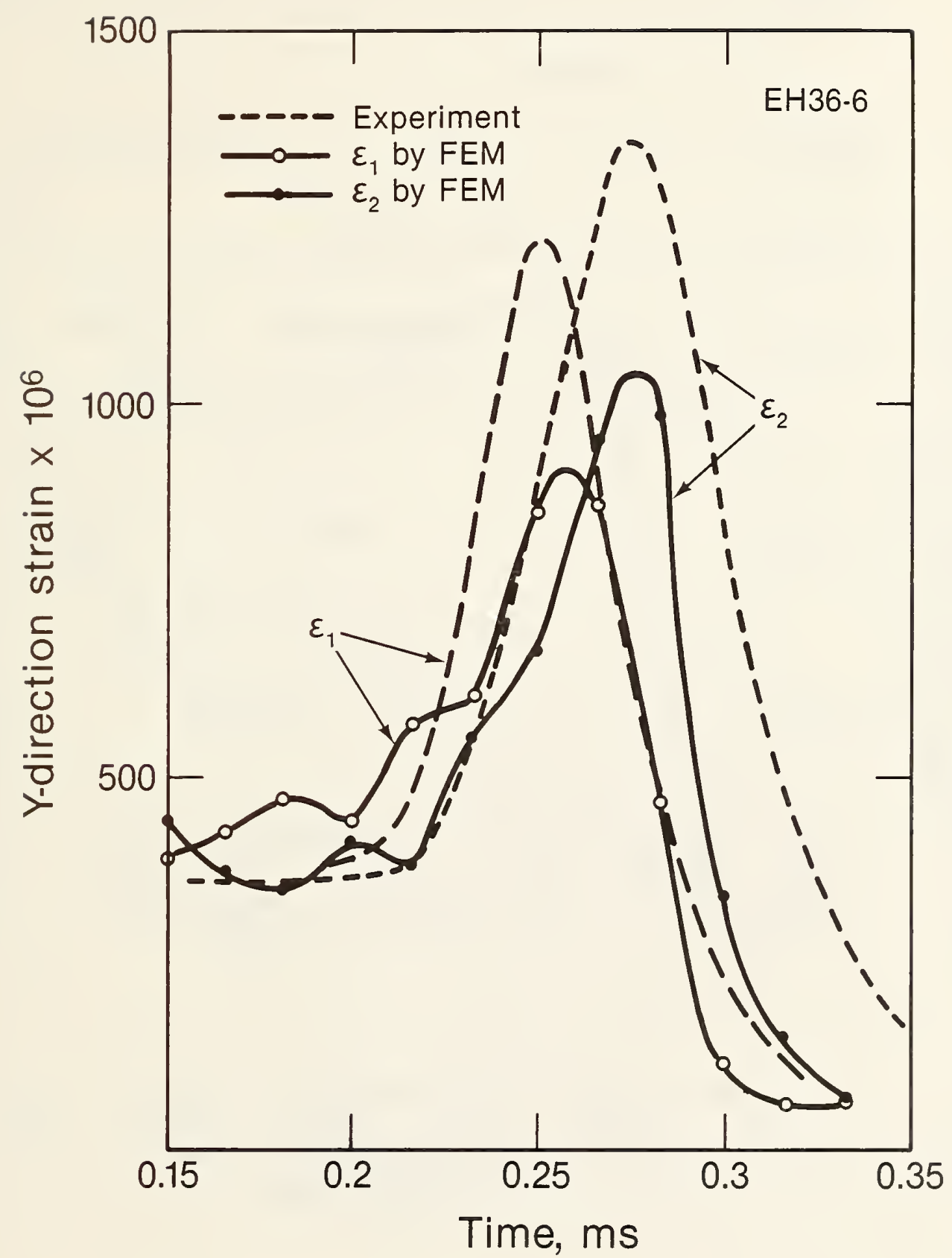

Figure 10c. Comparison of experimental and calculated strain, specimen EH36-6. 


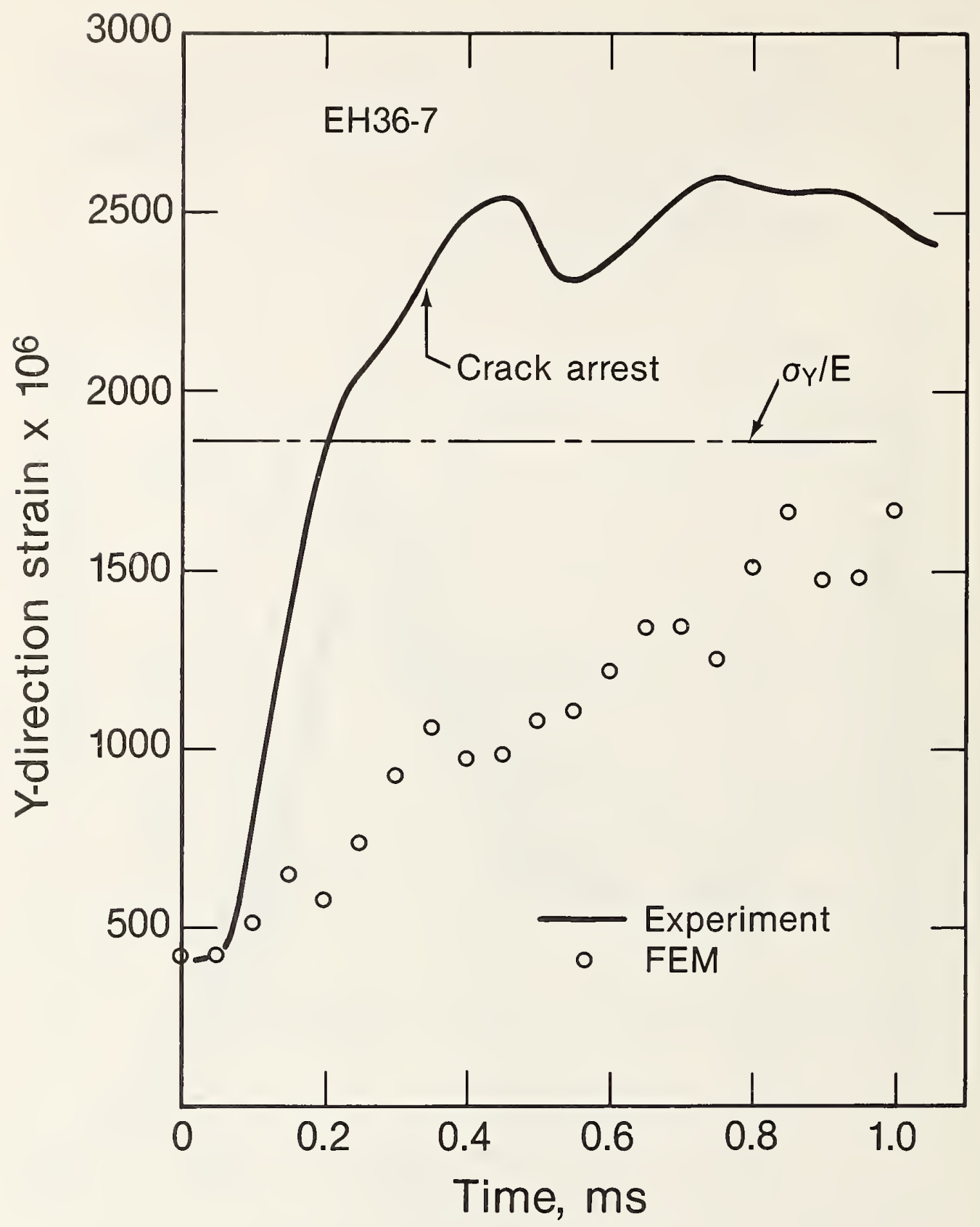

Figure 10d. Comparison of experimental and calculated strain, specimen EH36-7. 


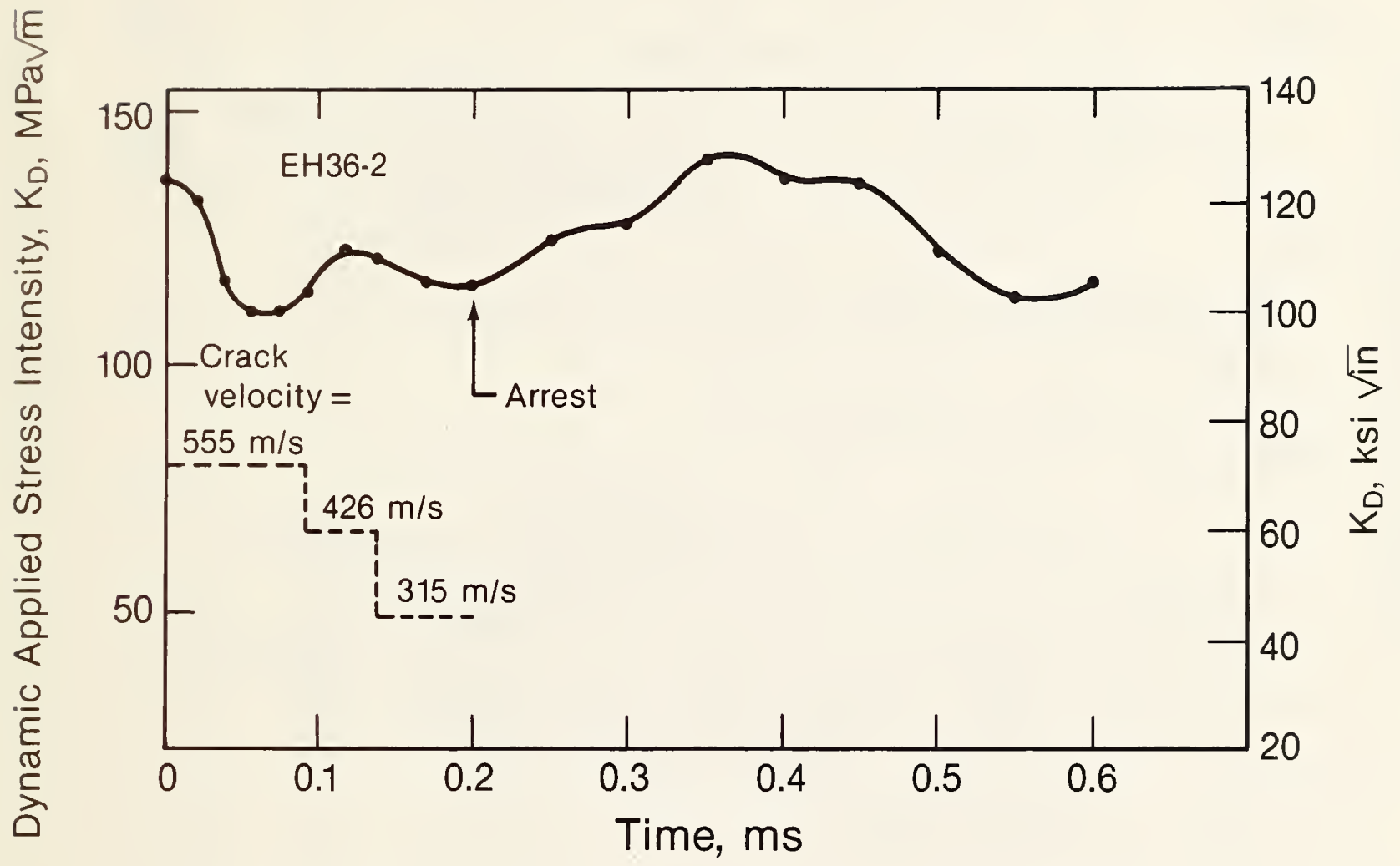

Figure 11 a. Variation of stress intensity with time, specimen EH36-2. 


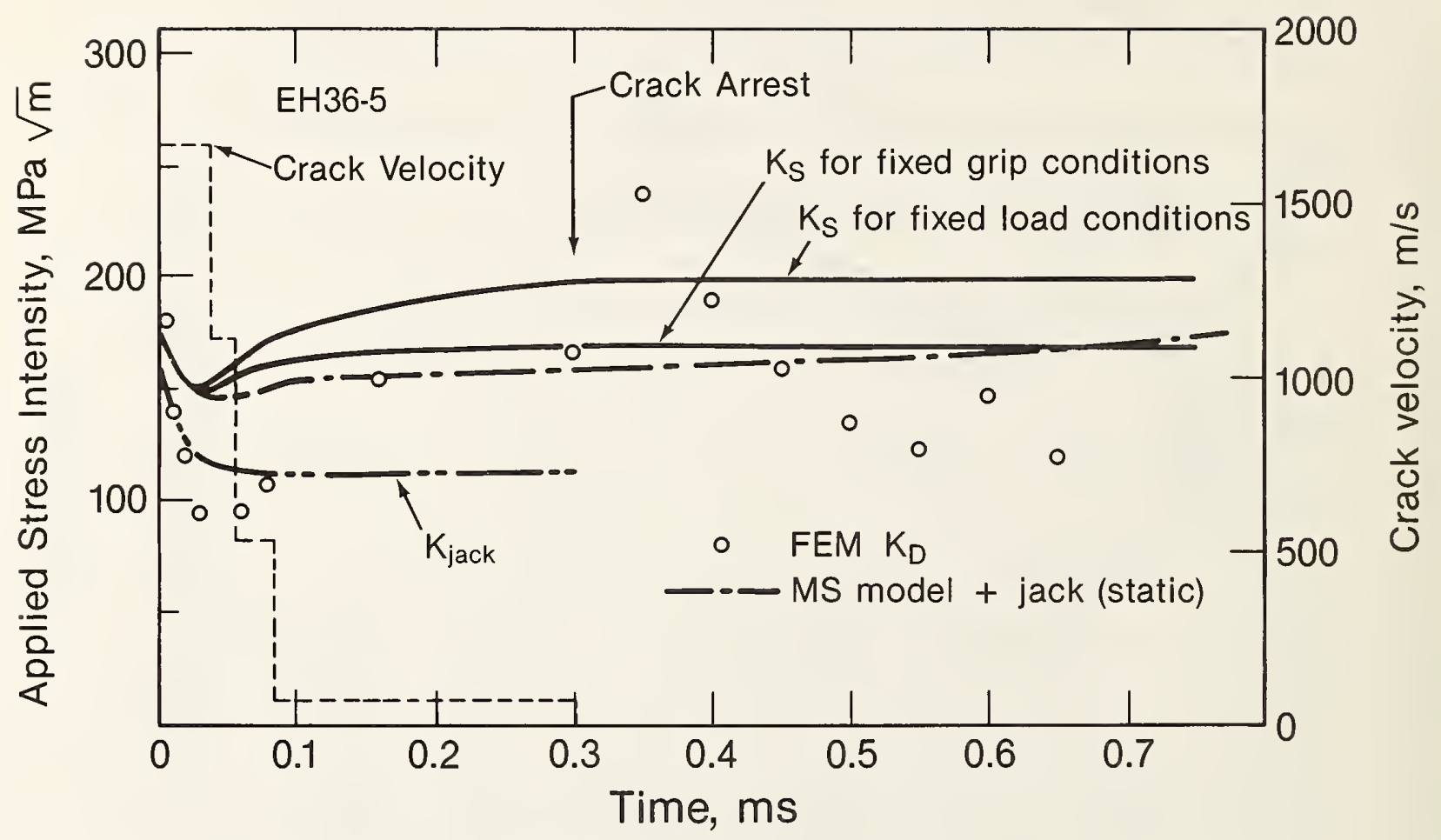

Figure 11b. Variation of stress intensity with time, specimen EH36-5. 


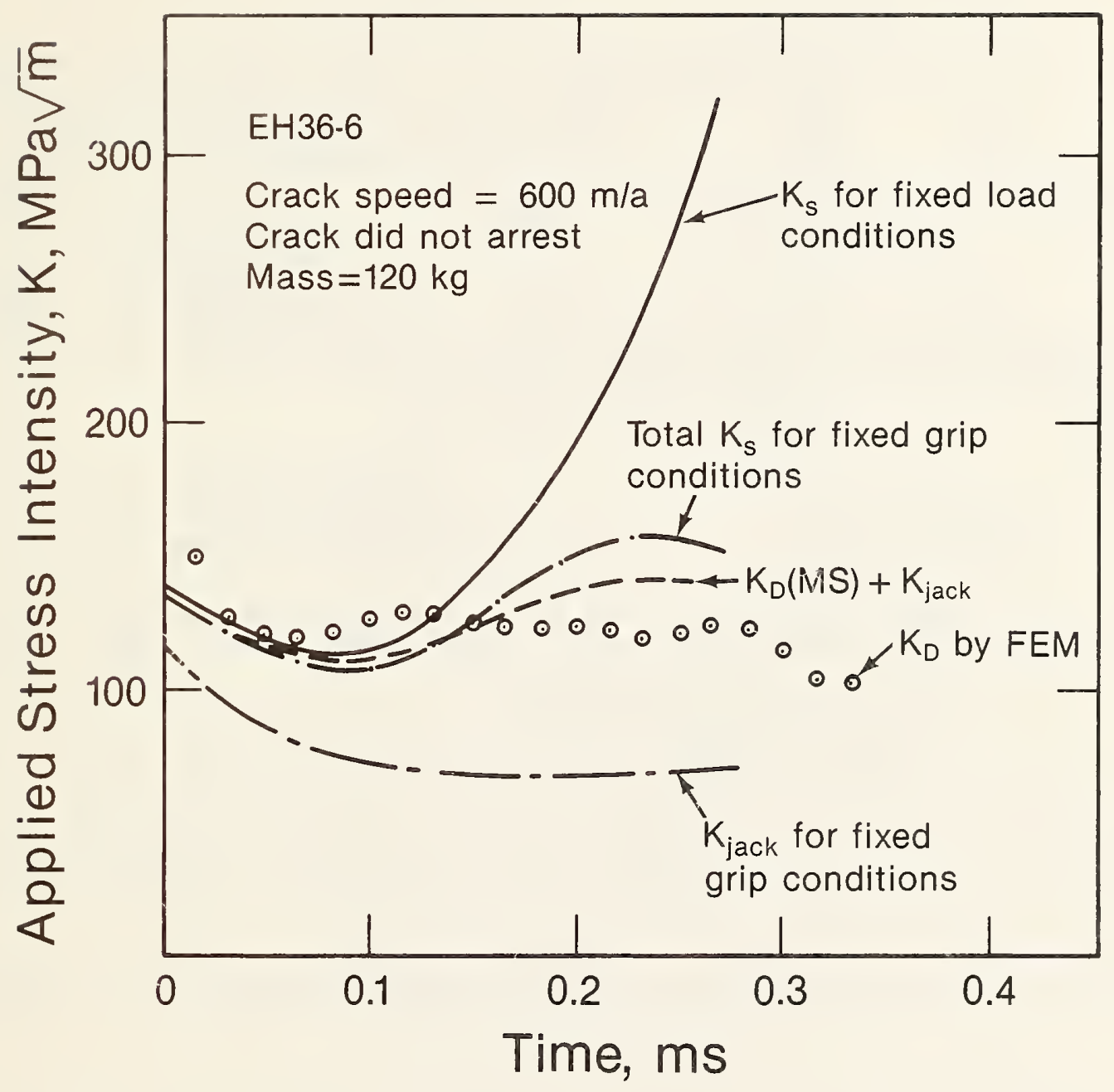

Figure 11c. Variation of stress intensity with time, specimen EH36-6. 


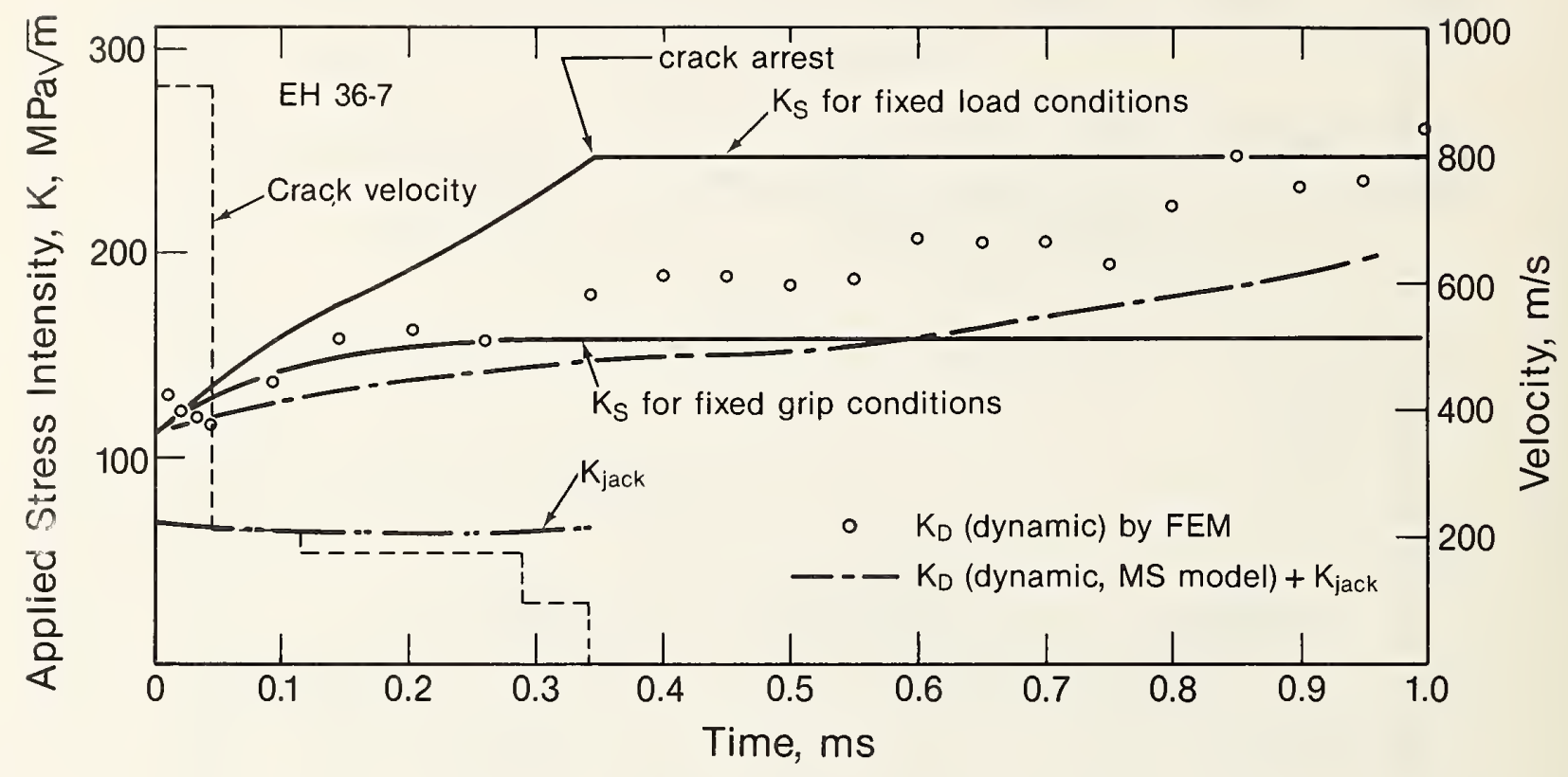

Figure 11d. Variation of stress intensity with time, specimen EH36-7. 


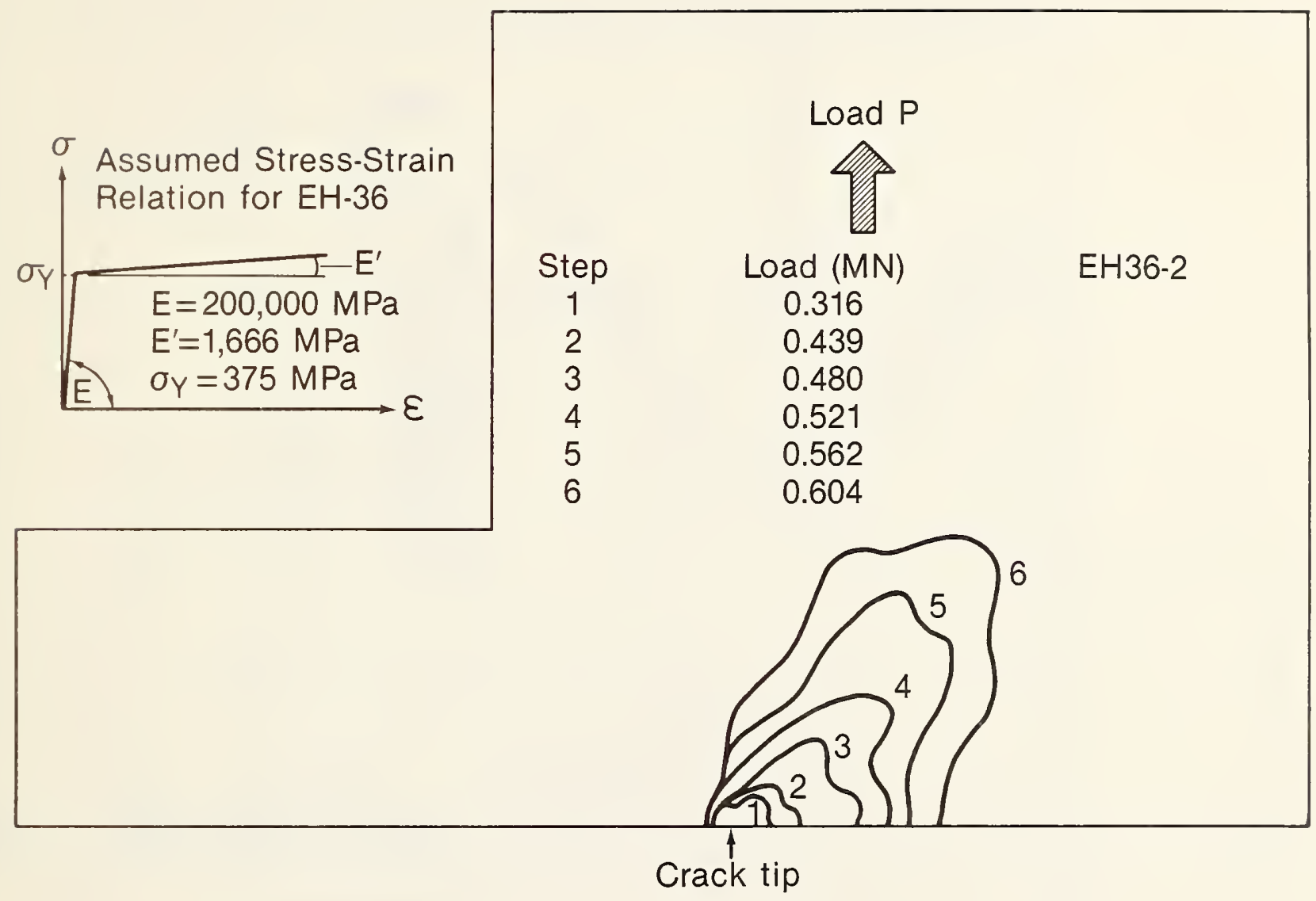

Figure 12a. Calculated size of plastic zone from main load for EH36-2. 


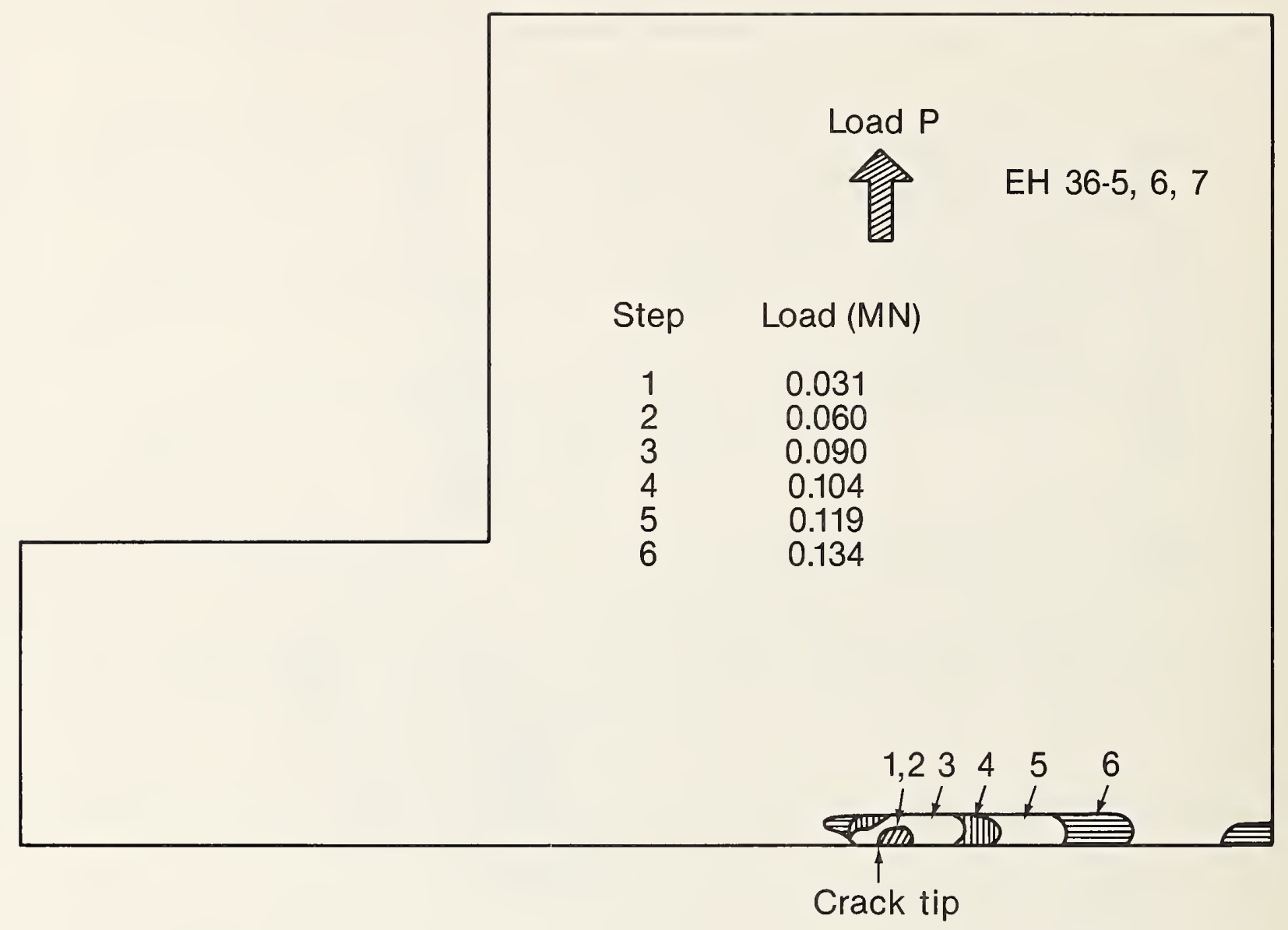

Figure 12b. Calculated size of plastic zone from main load for EH36-5, -6 , and -7 . 


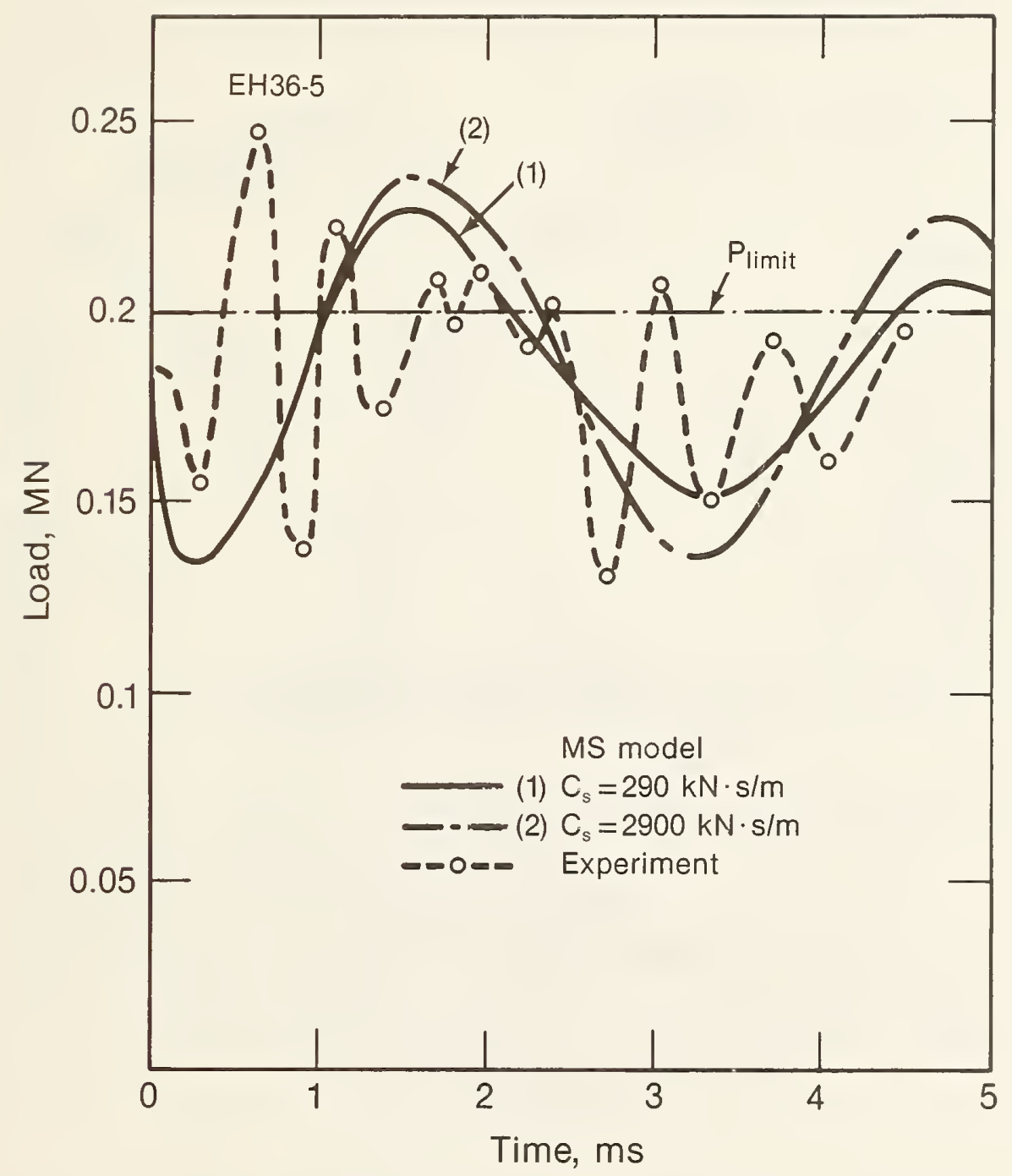

Figure 13. Variation of load with time for EH36-5, up to 5 ms after crack initiation. 


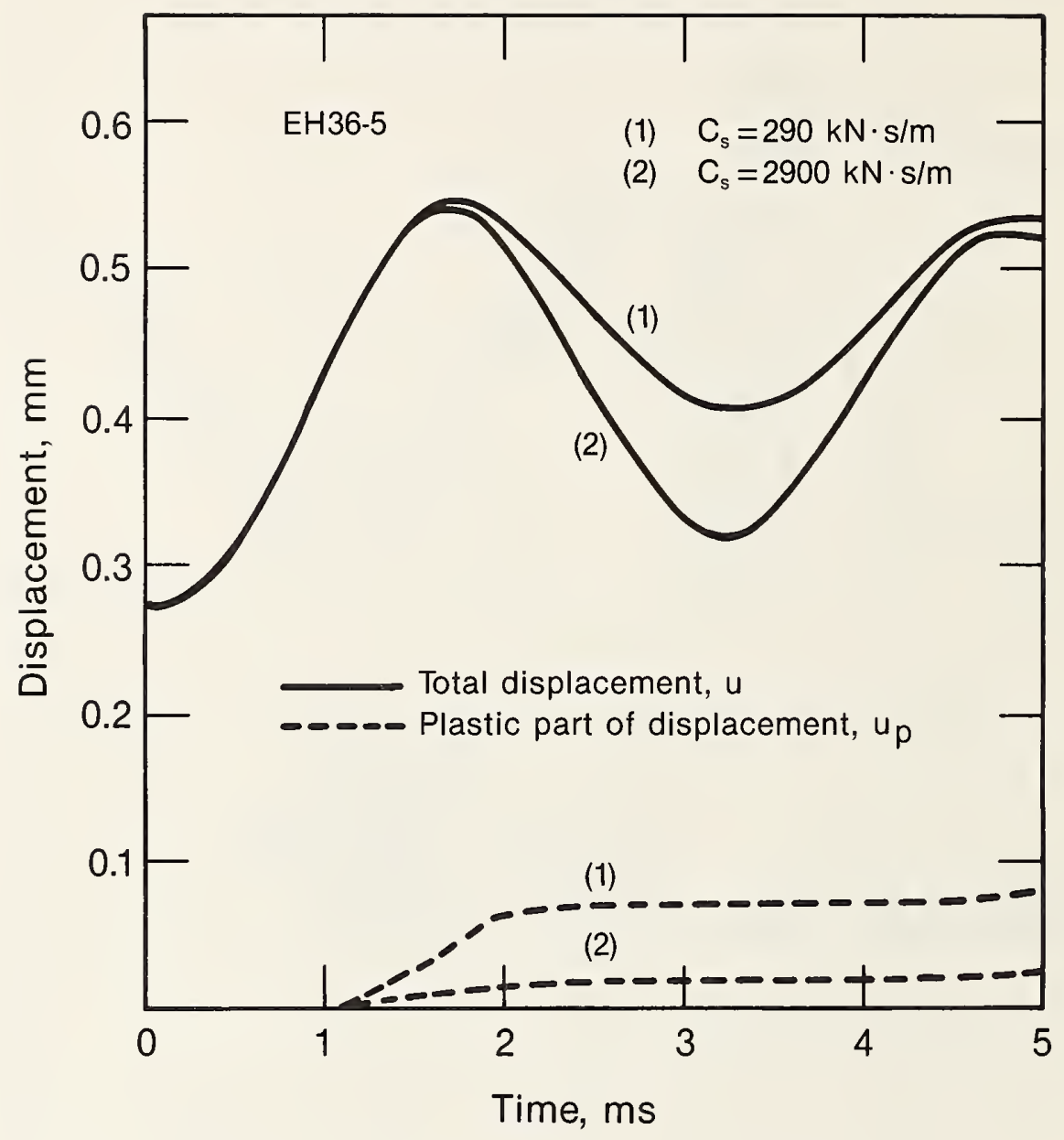

Figure 14. Variation of total and plastic displacement with time for EH36-5. 


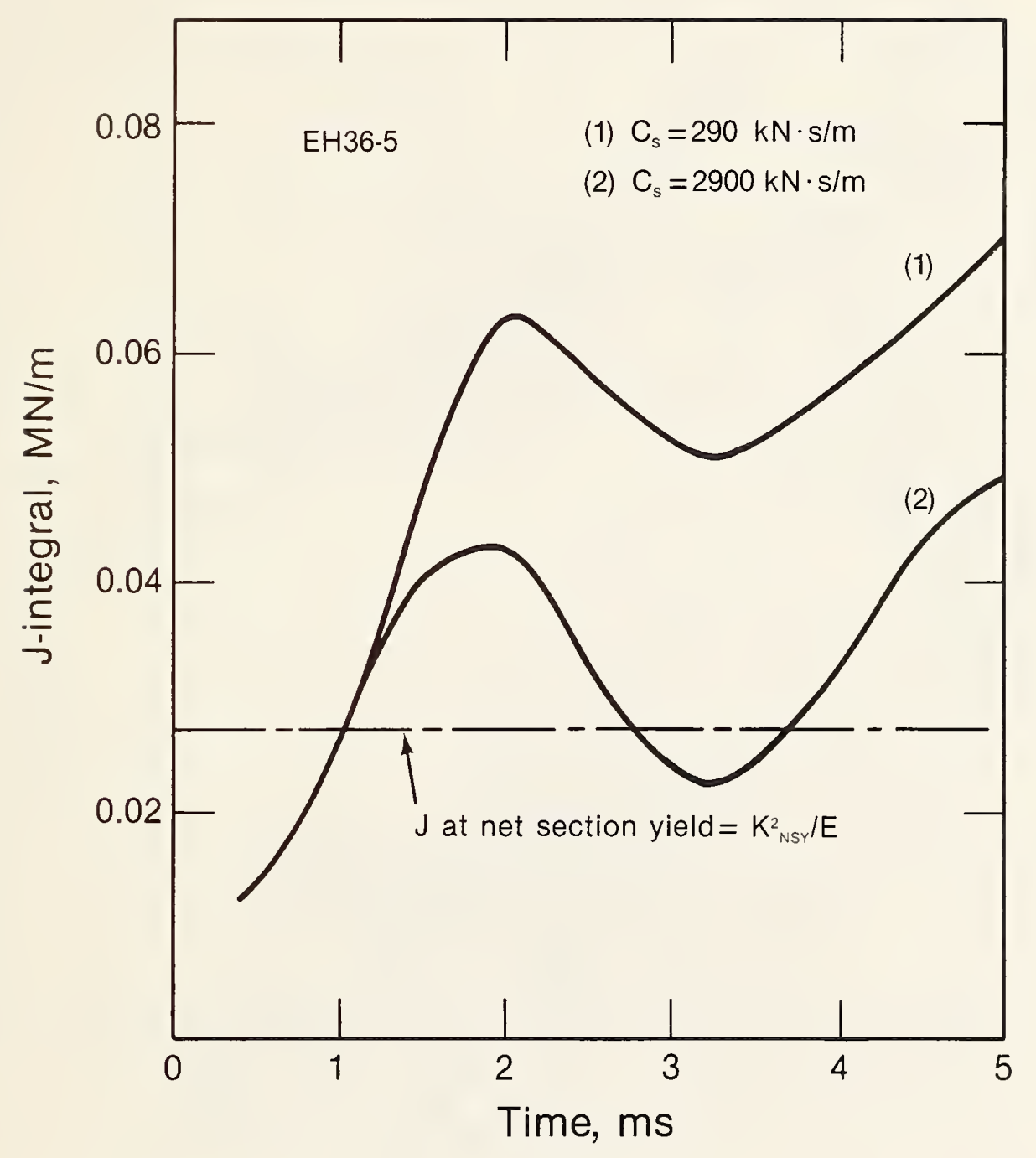

Figure 15. Variation of $J$ integral with time for EH36-5. 


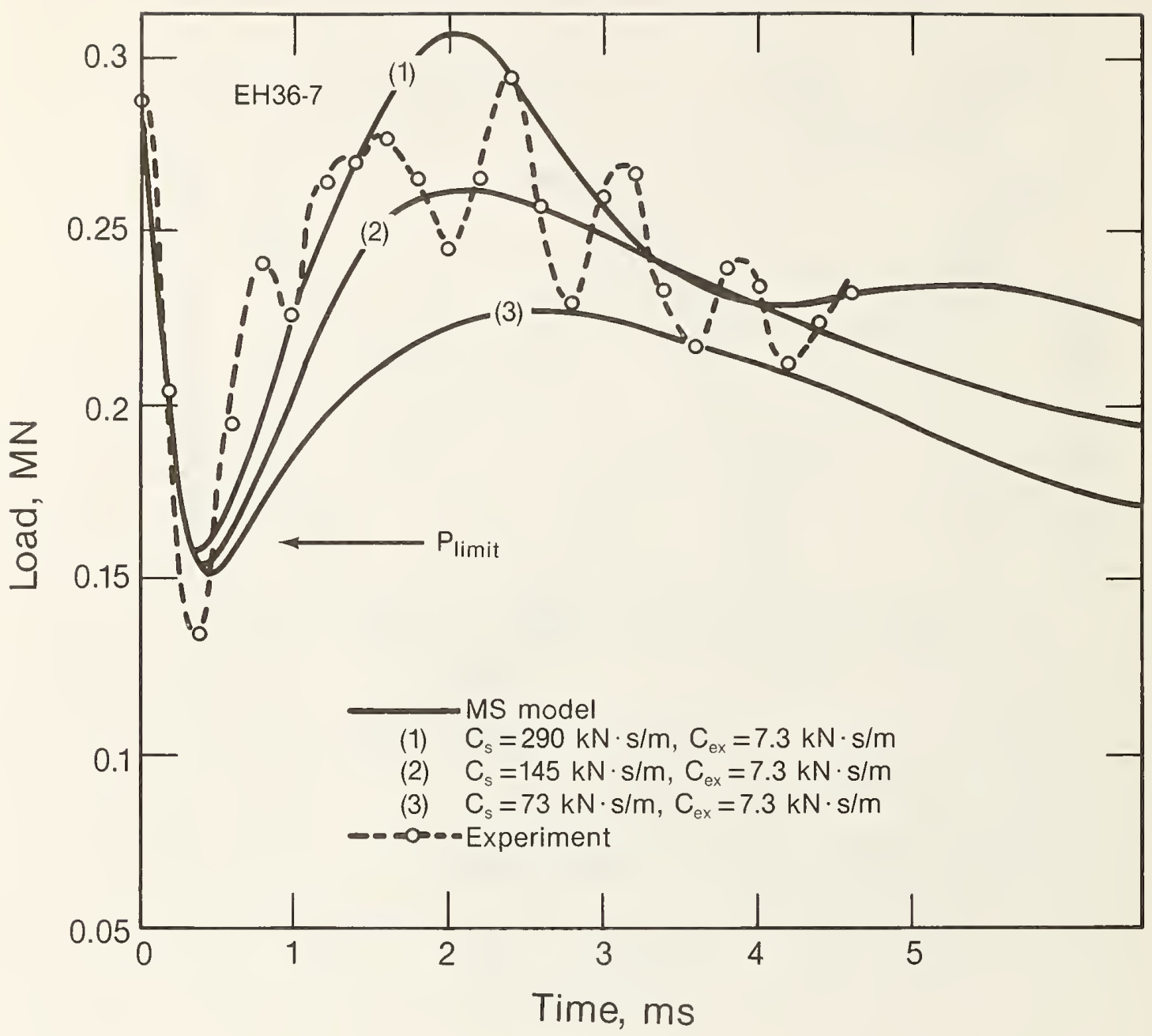

Figure 16. Variation of load with time for EH36-7, up to $5 \mathrm{~ms}$ after crack initiation. 


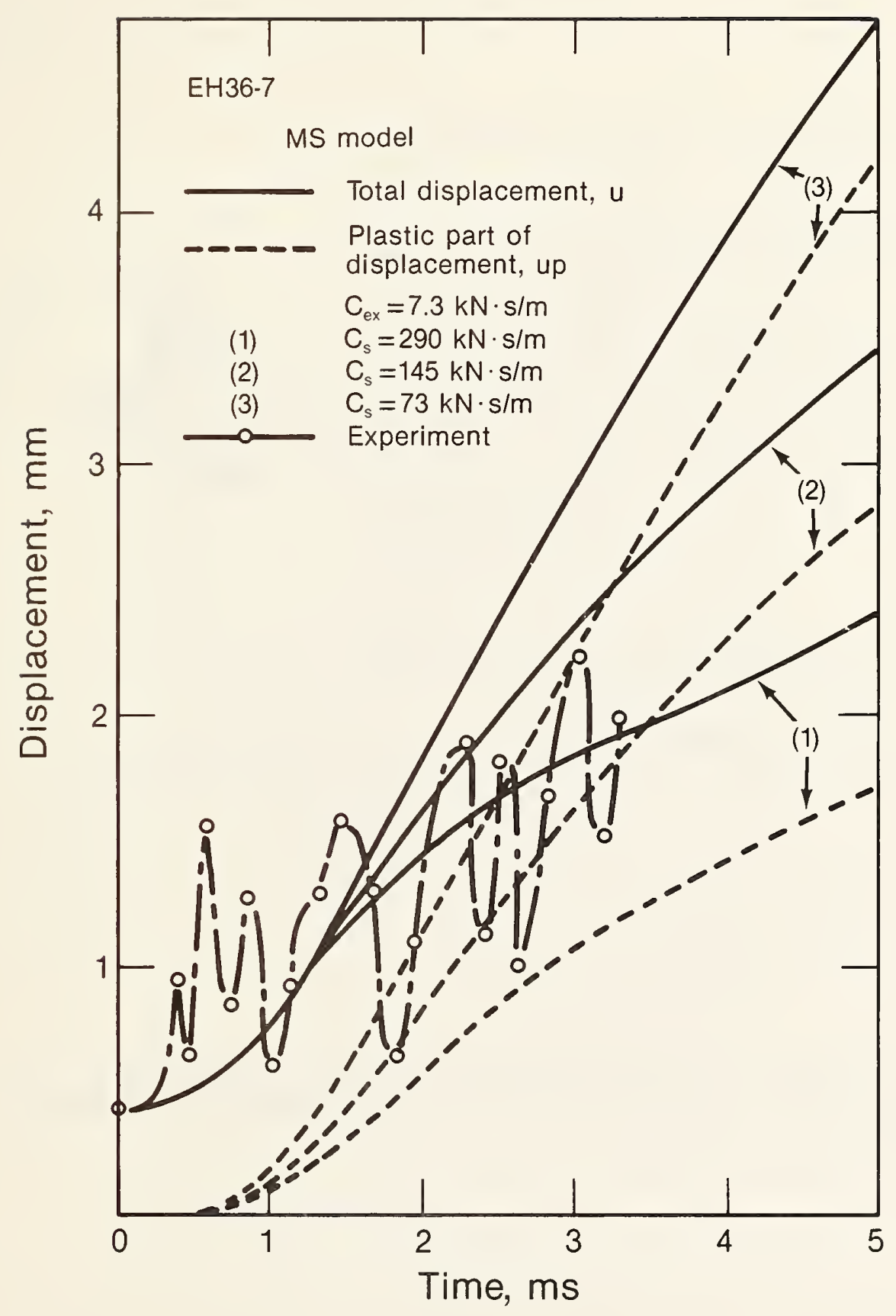

Figure 17. Variation of total and plastic displacement with time for EH36-7. 


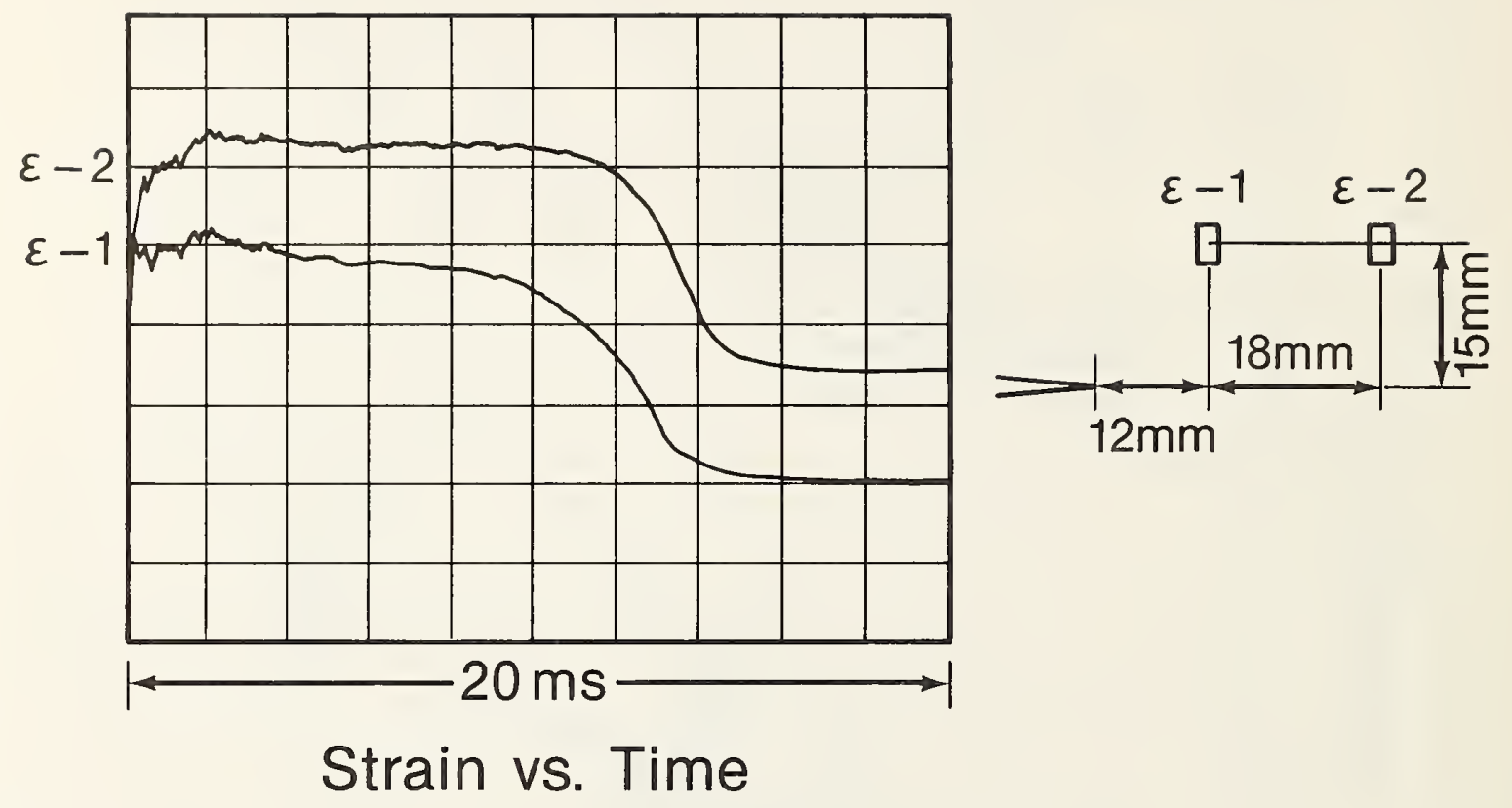

Figure 18. Oscilloscope trace of the strain gauge signal for specimen EH36-7. 


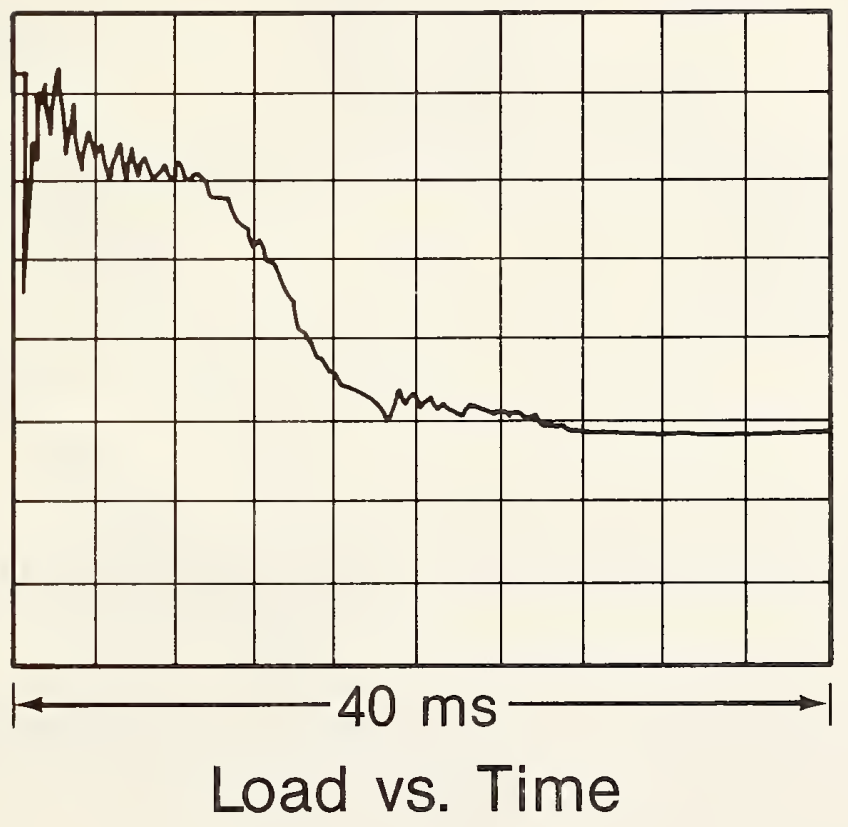

Figure 19. Oscilloscope trace of the load signal for speciment EH36-7. 


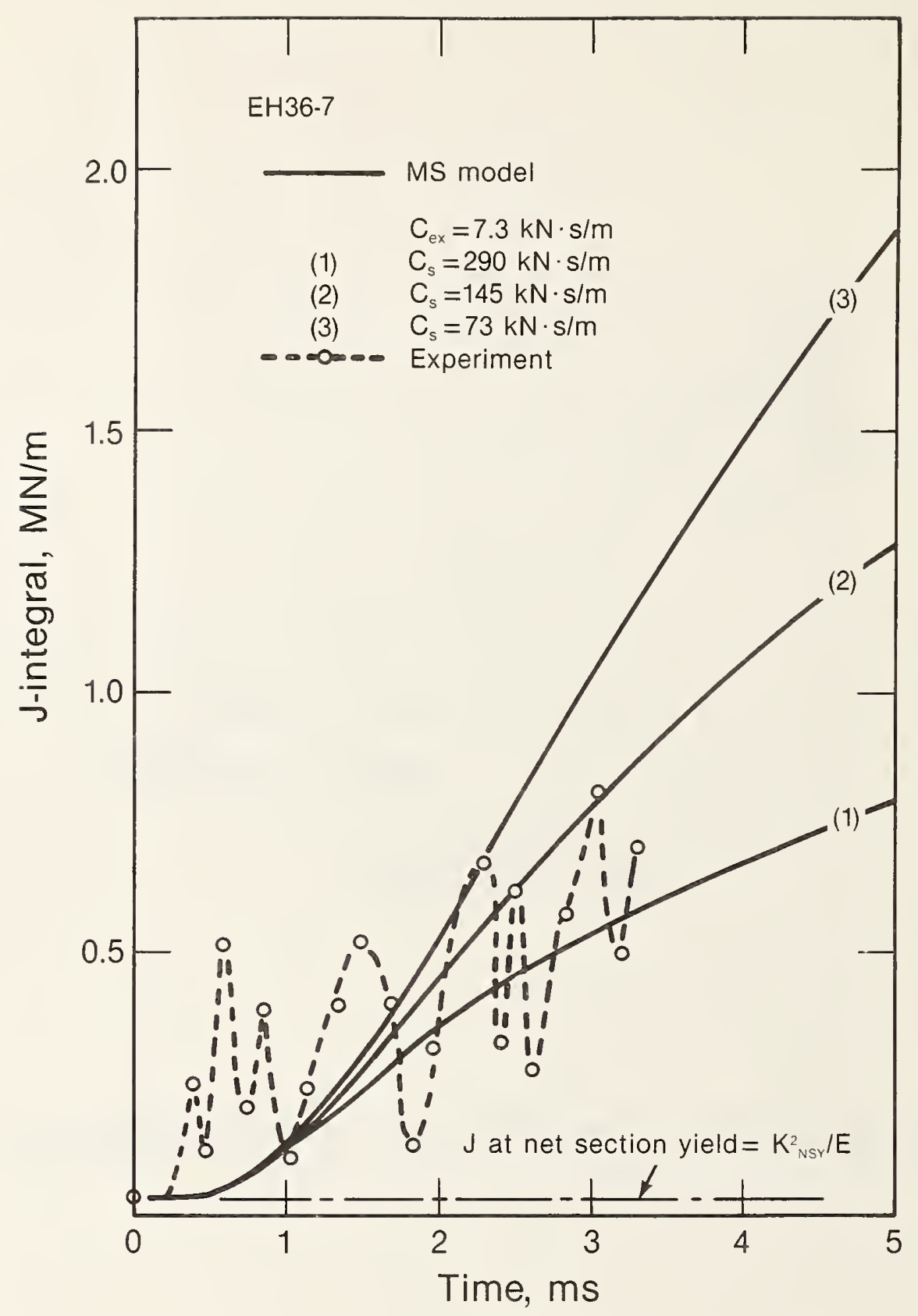

Figure 20. Variation of $\mathrm{J}$ integral with time for EH36-7. 


\begin{tabular}{|c|c|c|c|}
\hline $\begin{array}{c}\text { U.S. OEPT. OF COMM. } \\
\text { BIBLIOGRAPHIC DATA } \\
\text { SHEET (See instructions) }\end{array}$ & $\begin{array}{c}\text { 1. PUBLICATION OR } \\
\text { REPORT NO. } \\
\text { NBSIR 85-3034 }\end{array}$ & 2. Performing Organ. Report No. . Publication Date & $\begin{array}{c}\text { 3. PSO } \\
\text { June } 1986\end{array}$ \\
\hline
\end{tabular}

4. TITLE AND SUBTITLE

FRACTURE MECHANICS CHARACTERIZATION OF CRACK ARREST AND REINITIATION IN TWO UNCONVENTIONAL SPECIMENS

5. AUTHOR(S)

T. Teramoto, D.T. Read, and R.B. King

6. PERFORMING ORGANIZATION (If joint or other than NBS, see instructions)

NATIONAL BUREAU OF STANDARDS

DEPARTMENT OF COMMERCE

WASHINGTON, D.C. 20234

9. SPONSORING ORGANIZATION NAME AND COMPLETE ADDRESS (Street, City, State, ZIP)

Office of Naval Research

800 North Quincy Street

Arlington, Virginia 22217
David Taylor Naval Ship Research and Development Center

Annapolis, Maryland 21402

10. SUPPLEMENTARY NOTES

Document describes a computer program; SF-185, FIPS Software Summary, is attached.

11. ABSTRACT (A 200-word or less factual summary of most significant information. If document includes a significant bibliography or literature survey, mention it here)

The fracture mechanics parameters $K$ (the stress intensity factor) and $J$ (the value of the J-integral) are estimated for crack arrest (K) and reinitiation (J) in two unconventional specimen geometries: a short double-cantilever-beam or "compact" specimen; and a single-edge-cracked tensile specimen that provides a rising $K$ field as the crack advances. These specimens both have relatively large in-plane dimensions $(\sim 0.5 \mathrm{~m})$ and were loaded through a large mechanical spring that simulated structural compliance. Both of these specimens were shown to be capable of complete dynamic fracture with no arrest as well as of crack arrest, depending on the temperature. This indicates sensitivity to the crack arrest toughness of the specimen material.

A simple elastic-plastic-fracture-mechanics-based model of crack propagation, arrest, reinitiation, and propagation is described and used to estimate $K$ at crack arrest and $J$ during reinitiation. This model requires much less computing resources than dynamic, elastic-plastic finite element calculations and allows esimates of applied J-integral, load, and crack mouth opening displacement during initial rapid crack propagation, reinitiation, and repropagation. A comparison of this new model to other available models and to experimental results indicates that it can successfully reproduce the essential features of the behavior of specimens containing propagating cracks.

12. KEY WORDS ( $S$ ix to twelve entries; alphabetical order; capitalize only proper names; and separate key words by semicolons) dynamic crack arrest; dynamic crack propagation; elastic-plastic; fracture; J-integral; mass spring model; rising $K_{\text {; }}$ side groove; stress-intensity factor

13. AVAILABILITY

XX Unlimited

$\square$ For Official Distribution. Do Not Release to NTIS $\square$ Order From Superintendent of Documents, U.S. Government Printing Office, Washington, D.C.
20402 .

14. NO. OF PRINTED PAGES 120

XX Order From National Technical Information Service (NTIS), Springfield, VA. 22161 


